INSTITUTO DE PESQUISAS ENERGÉTICAS E NUCLEARES

Autarquia associada à Universidade de São Paulo

\title{
MEDIDA DO BUCKLING E DA PROBABILIDADE DE FUGA DE NÊUTRONS DO NÚCLEO DO REATOR IPEN/MB-01
}

\author{
RAFAEL TURRINI PURGATO
}

Dissertação apresentada como parte dos requisitos para a obtenção do título de Mestre em Ciências na Área de Tecnologia Nuclear - Reatores.

Orientador:

Prof. Dr. Ulysses d'Utra Bitelli

Versão Corrigida

Versão Original disponível no IPEN

SÃO PAULO 
Dedico a minha amada esposa Suéllen, pelo amor incondicional, companheirismo e apoio em todos os momentos de nossa vida.

Aos meus filhos Victor e Giovanna, pela alegria, pelo amor e por serem as maiores riquezas de minha vida.

Aos meus pais José e Rosangela, responsáveis por eu existir, pelo carinho e apoio em todas as decisões e desafios de minha vida.

Aos meus irmãos, avós, tios e tias, presentes e em memória, pelo carinho e admiração, propulsores de minhas conquistas.

Aos amigos e a todos que torcem por mim. 


\section{AGRADECIMENTOS}

Ao Dr. Ulysses d’Utra Bitelli, pelo companheirismo, ensinamentos, conselhos, paciência e, sobretudo por sua orientação competente e fundamental para o desenvolvimento e conclusão deste trabalho.

Aos meus colegas de mestrado, Vitor Ottoni Aredes, Alexandre F. Póvoa da Silva, Diogo Feliciano dos Santos, pela amizade, companheirismo, parceria e estimáveis contribuições ao trabalho.

Ao Sr. Rogério Jerez, pelo acompanhamento da operação do reator, montagem dos arranjos experimentais e obtenção das medidas.

Ao Sr. Cesar Luiz Veneziani, operador do reator, pelos desenhos representativos do núcleo do reator IPEN/MB-01.

Aos Drs. Tufic Madi Filho e Luis Antonio Albiac Terremoto pelas contribuições e aprimoramentos dados ao trabalho.

Ao Dr. Odair Lelis Gonçalez, do Instituto de Estudos Avançados pelas excelentes contribuições e correções ao trabalho.

A Dra. Ana Cecilia Lima pelas contribuições para o fechamento deste trabalho.

A Secretaria Estadual de Educação do Estado de São Paulo, por ter me concedido a Bolsa Mestrado e com isso facilitado minha manutenção e conclusão do trabalho.

A todos os professores das diferentes disciplinas por compartilharem seu conhecimento e permitir meu aprofundamento teórico e experimental.

Ao IPEN por ter me possibilitado realizar um curso de qualidade com profissionais de alto nível e em instalações tecnológicas imprescindíveis para o desenvolvimento da ciência em nosso país. 
Aos meus colegas professores da E. E. Diógenes Duarte Paes, pelo incentivo, motivação, companheirismo e apoio nos meus planos e minhas ações. 
"Ninguém ignora tudo. Ninguém sabe tudo.

Todos nós sabemos alguma coisa.

Todos nós ignoramos alguma coisa.

Por isso aprendemos sempre".

Paulo Freire 


\section{MEDIDA DO BUCKLING E DA PROBABILIDADE DE FUGA DE NÊUTRONS DO NÚCLEO DO REATOR IPEN/MB-01}

\section{Rafael Turrini Purgato}

Um dos parâmetros fundamentais da física de reatores é a curvatura do fluxo de nêutrons (Buckling) do núcleo do reator. Ele está relacionado com outros parâmetros importantes, tais como as taxas de reação, potencia de operação, queima de combustível, entre outros. Num reator crítico, o Buckling depende das características geométricas e de material do núcleo do reator.

Este trabalho apresenta os resultados do Buckling experimental para o reator nuclear IPEN/MB-01 em sua configuração cilíndrica com 28 barras de combustível ao longo de seu diâmetro. O IPEN/MB-01 é um reator de potência zero projetado para operar em uma potência máxima nominal de 100 watts. É uma instalação nuclear versátil que permite a simulação de todas as características de um grande reator nuclear e ideal para este tipo de medição.

Foi realizado um mapeamento do fluxo de nêutrons no interior do reator e, assim, determinado o Buckling total da configuração cilíndrica. O reator foi operado durante uma hora para cada experimento. Em seguida, a taxa de reação nuclear das varetas de combustível foram medidas por espectrometria gama em um detector de germânio hiper-puro (HPGe) que escaneou as varetas axial e radialmente. Foram analisados os fótons gama do ${ }^{239} \mathrm{~Np}$ ( 276,6 keV), gerado a partir da captura de nêutrons epitérmicos e rápidos, e do ${ }^{143} \mathrm{Ce}$ ( 293,3 keV ), gerado por fissão em ambos ${ }^{238} \mathrm{U}$ e ${ }^{235} \mathrm{U}$, respectivamente. Foram analisadas as direções axial e radial. Outras medições foram realizadas com fios e folhas de ouro nas direções radial e axial do núcleo do reator. O Buckling total obtido a partir da média ponderada dos três métodos medidos é de $96,55 \pm 7,47 \mathrm{~m}^{-2}$.

Os objetivo dos valores experimentais obtidos é obter um conjunto de dados experimentais que permitam uma comparação direta com valores calculados pelos códigos de Física de Reatores CITATION e MCNP. 


\title{
DETERMINATION OF BUCKLING AND PROBABILITY OF LEAKAGE OF NEUTRON IN THE IPEN/MB-01 REACTOR IN CYLINDRICAL CONFIGURATION
}

\author{
Rafael Turrini Purgato
}

\begin{abstract}
One of the key parameters in reactor physics is the Buckling of a reactor core. It is related to important parameters such as reaction rates, nuclear power operation, fuel burning, among others. In a critical reactor, the Buckling depends on the geometric and material characteristics of the reactor core.

This work presents the results of experimental Buckling in the reactor IPEN/MB-01 nuclear reactor in its cylindrical configuration with 28 fuel rods along its diameter. The IPEN/MB-01 is a zero power reactor designed to operate at a maximum power of 100 watts, it is a versatile nuclear facility which allows the simulation of all the characteristics of a large nuclear power reactor and ideal for this type of measurement.
\end{abstract}

We conducted a mapping of neutron flux inside the reactor and thereby determined the total Buckling of the cylindrical configuration. The reactor was operated for one hour. Then, the activity of the fuel rods was measured by gamma spectrometry on a rod scanner HPGe detector. We analyzed the gamma photons of the ${ }^{239} \mathrm{~Np}(276,6$ $\mathrm{keV})$ for neutron capture $(\mathrm{n}, \mathrm{\gamma})$ and the ${ }^{143} \mathrm{Ce}(293,3 \mathrm{keV})$ for fission $(\mathrm{n}, \mathrm{f})$ on both ${ }^{238} \mathrm{U}$ and ${ }^{235} \mathrm{U}$, respectively. We analyzed the axial and radial directions. Other measurements were performed using wires and gold foils in the radial and axial directions of the reactor core.

The Buckling Total obtained from the three methods by weighted mean is $96,55 \pm 7,47 \mathrm{~m}^{-2}$.

The goal is to obtain experimental values of a set of experimental data to allow one direct comparison with values calculated by the codes used in reactor physics CITATION and MCNP. 


\section{SUMÁRIO}

1 Introdução 09

$\begin{array}{lll}1.1 & \text { Objetivo } & 10\end{array}$

$\begin{array}{lll}1.2 & \text { Metodologia } & 10\end{array}$

1.3 Roteiro 11

2 Fundamentos Teóricos 12

2.1 Técnica de Analise por Ativação 12

2.2 Taxa de Reação Nuclear 12

2.3 Buckling de um Reator Nuclear 17

3 Materiais e Métodos 23

3.1 O reator nuclear IPEN/MB-01 23

3.2 Componentes irradiados para a obtenção de dados experimentais 28

3.2.1 Varetas combustível 28

3.2.2 Fios e folhas de ouro $\quad 30$

3.3 Tratamento de dados e sistema de detecção 31

3.4 Incerteza associada ao calculo do Buckling 34

$4 \quad$ Resultados e discussões $\quad 35$

4.1 Medidas obtidas para vareta combustível 35

4.1.1 Direção radial Leste - Oeste 35

4.1.2 Direção radial Norte - Sul 42

4.1.3 Direção axial 49

4.1.4 Buckling das varetas combustível 56

4.2 Medidas obtidas para os fios de ouro 57

4.2.1 Direção radial ao longo do núcleo do reator 59

4.2.2 Direção Axial ao longo do núcleo do reator 66

4.2.3 Buckling obtido para os fios de ouro irradiados 72

4.3 Medidas obtidas para as folhas de ouro 73

4.4 Buckling total do reator IPEN/MB-01 para a configuração cilíndrica de 28 varetas ao longo do diâmetro do núcleo. 74

4.5 Determinação da probabilidade de fuga de nêutrons 75

5 Conclusões do trabalho 77

APÊNDICE A - Dados obtidos na espectrometria das varetas combustível $\quad 79$ 
APÊNDICE B - Dados obtidos na espectrometria dos fios de ouro

APÊNDICE C - Dados obtidos na espectrometria das folhas de ouro

APÊNDICE D - Obtenção da função de bessel para o ajuste da curvatura do fluxo

de nêutrons

APÊNDICE E - O ensino do tema energia nuclear no ensino médio

ANEXO A - O Reator Nuclear IPEN/MB-01

ANEXO B - Propagação de erros

ANEXO C - Buckling para diversas configurações de núcleo

REFERÊNCIAS BIBLIOGRÁFICAS 


\section{Introdução}

A segurança de Reatores Nucleares tem despertado grande atenção na atualidade, sobretudo após o acidente ocorrido nas usinas de Fukushima no Japão, em março de 2011. Mesmo com as notícias adversas à utilização de reatores nucleares para geração de eletricidade, estudos indicam que até 2030, mesmo numa perspectiva de baixo crescimento, haverá um acréscimo mínimo mundial de 8\% na geração de energia elétrica a partir de usinas nucleares, podendo, entretanto, chegar ao dobro da capacidade atual em um cenário de alto crescimento, ou seja, 489 novos reatores ${ }^{1}$ no mundo. No Brasil, em 2010, foram iniciadas as obras de Angra 3 e a previsão é de inicio de operação em maio de $2018^{2}$.

Uma das justificativas para esse acréscimo mundial está na necessidade de maior geração de energia elétrica, na grande capacidade energética das fontes nucleares e, concomitante, na redução da emissão de gases geradores do efeito estufa na atmosfera ${ }^{3}$.

Nesse sentido, entendemos que estudar parâmetros nucleares que possam aperfeiçoar o entendimento e funcionamento de reatores, bem como compartilhar essas informações e trabalhar com essa temática na educação básica, são fundamentais para uma boa utilização dos reatores, para a formação de corpo técnico qualificado e para a formação da consciência crítica da sociedade.

Os primeiros experimentos na área de Física de Reatores, tinham o objetivo de obter dados empíricos, que pudessem ser inseridos em modelos teóricos que possibilitassem a obtenção de alguns parâmetros fundamentais para o projeto de um reator nuclear. Com o passar dos anos e o desenvolvimento de novas metodologias de cálculo, aliada a maior precisão de dados nucleares, as medidas experimentais passaram a ser de fundamental importância na validação dessas metodologias, bem como no teste de diversas bibliotecas de dados nucleares. No entanto, os experimentos têm que ser altamente precisos para poderem servir de padrões de comparação internacional ("benchmarks"). Neste contexto, as medidas têm que ser cuidadosamente planejadas a fim de se obter parâmetros nucleares de 
interesse à Física de Reatores cada vez mais precisos. A utilização da técnica de analise por ativação permite obter muitos parâmetros de interesse da Física de Reatores ${ }^{4}$, sendo umas das técnicas experimentais mais utilizadas na espectrometria e medida da distribuição espacial do fluxo de nêutrons num reator nuclear.

\subsection{Objetivo}

O presente trabalho visa obter valores experimentais da curvatura do fluxo de nêutrons nas direções axiais, radial norte-sul e radial Leste-Oeste, dentro da região assintótica do núcleo do reator, na sua configuração de núcleo cilíndrica, longe das perturbações causadas por refletor e barra de controle. Com isso, podese estimar experimentalmente a fuga de nêutrons térmicos e rápidos nestas três direções ortogonais e consequentemente o valor do "Buckling" do reator para uma dada configuração de núcleo e temperatura do moderador. Os valores de Buckling obtidos podem ser comparados aos valores obtidos por códigos computacionais tais como o CITATION e MCNP e suas bibliotecas de dados nucleares associados.

\subsection{Metodologia}

A técnica de analise por ativação permite a obtenção de muitos parâmetros da Física de Reatores a partir da irradiação de materiais alvo de composição química bem definida no interior do núcleo do reator ${ }^{5}$ e posterior realização de espectrometria gama nos alvos irradiados.

Em um reator de potência zero, como o Reator Nuclear IPEN/MB-01, é possível obter experimentalmente informações do fluxo absoluto de nêutrons em seu núcleo, uma vez que se trata de um reator flexível que permite a montagem de diversas configurações de varetas combustíveis no núcleo, bem como permite a inserção de folhas e fios de ativação no interior do núcleo dentro de sua região 
assintótica (livre de perturbação do campo neutrônico devido a barras de controle e refletor).

Conhecendo parâmetros experimentais, como tempos de irradiação, de espera e de contagem da atividade induzida num espectrômetro gama e, ainda, a constante de decaimento do radionuclídeo formado, é possível determinar a atividade induzida nos alvos irradiados em cada posição dos mesmos no interior do núcleo.

A partir dessas informações, sendo a atividade induzida no alvo proporcional ao fluxo de nêutrons é possível obter a distribuição espacial do fluxo de nêutrons no núcleo do reator e, a partir disso, determinar o Buckling do reator e a probabilidade da fuga de nêutrons do mesmo.

\subsection{Roteiro}

O capitulo 2 apresenta a fundamentação teórica sobre ativação por nêutrons e sobre o Buckling de um reator. No capitulo 3 são apresentados os materiais e métodos utilizados para obtenção dos dados e resultados. No capitulo 4 são apresentados os resultados experimentais obtidos. No capitulo 5 temos a conclusão deste trabalho. São apresentados os apêndices $A, B, C, D$ e E e anexos $A, B$ e $C$ que abordam respectivamente os dados obtidos na espectrometria das varetas combustíveis, fios de ouro, folhas de ouro, o ajuste da função de Bessel, analise sobre o ensino de energia nuclear no ensino médio, o reator nuclear IPEN MB-01, propagação de erros e a curvatura do fluxo de nêutrons até o seu valor atingir o seu valor zero, ou seja, desaparecer (Buckling) para diversas formas geométricas diferentes do núcleo. O trabalho é finalizado com as principais referências bibliográficas que serviram de consulta no desenvolver do trabalho. 


\section{Fundamentos Teóricos}

\subsection{Técnica de Analise por Ativação}

Para determinação absoluta do fluxo de nêutrons e do espectro neutrônico um método muito utilizado em Física de Reatores é o de análise por ativação neutrônica que consiste em irradiar materiais metálicos de alta pureza em um campo de nêutrons a ser investigado ${ }^{5}$. A radioatividade induzida nestes materiais, denominados detectores de ativação, é proporcional ao fluxo de nêutrons no local da irradiação ${ }^{6 .}$

Embora seja uma medida indireta pela impossibilidade de se obter medidas em tempo real, esta técnica experimental é amplamente utilizada na análise espectral devido a algumas vantagens ${ }^{7,8,9}$, tais como:

- Baixo custo quando comparados com detectores de indicação direta;

- Insensibilidade ao intenso campo gama gerado no interior do núcleo do reator;

- Pequena perturbação causada no campo neutrônico, devido às suas diminutas dimensões;

- Acessibilidade a regiões do núcleo e blindagens externas do reator onde os detectores de indicação direta não têm acesso;

- Altas seções de choques para nêutrons térmicos, epitérmicos e rápidos;

\subsection{Taxa de reação nuclear}

Ao ser submetido a um campo neutrônico estacionário, produzido por um reator nuclear, um detector de ativação produz átomos radioativos e a equação que 
rege tal fenômeno é dada por ${ }^{10,11}$,

$$
\frac{\mathrm{dn}}{\mathrm{dt}}=N \bar{\sigma}_{\mathrm{act}} \phi-n \bar{\sigma}_{a} \phi-n \lambda
$$

sendo $n$ o número de átomos produzidos ativação neutrônica, $N$ o número de átomos alvo contidos na amostra, $\sigma_{a t v}$ a seção de choque microscópica de ativação média, $\phi$ o fluxo de nêutrons ao qual este detector esta submetido, $\sigma_{a}$ a seção de choque microscópica média de absorção dos nuclídeos produzidos pela ativação neutrônica e $\lambda$ a constante de decaimento do radionuclídeo produzido.

Por sua vez, a taxa de consumo dos átomos contidos no detector de ativação pode ser expressa por,

$$
\frac{\mathrm{dN}}{\mathrm{dt}}=-N \bar{\sigma}_{t} \phi
$$

Sendo $\bar{\sigma}_{t}$ seção de choque total do nuclídeo alvo e esta taxa conhecida como taxa de consumo de núcleos alvo. A solução da equação (2) é então,

$$
N(t)=N_{0} \cdot e^{-\sigma_{T} \phi t}
$$

sendo $N_{0}$ o número de átomos alvos no inicio da irradiação. Substituindo esta equação em (1), encontra-se

$$
\frac{\mathrm{dn}}{\mathrm{dt}}=N_{0} e^{-\sigma_{T} \phi t} \sigma_{\mathrm{atv}} \phi-n\left(\sigma_{a} \phi+\lambda\right)
$$

A solução desta última equação é feita através de uma técnica matemática conhecida como técnica do fator integrante que consiste em multiplicar ambos os lados da igualdade pelo fator $e^{(\sigma a \cdot \phi+\lambda) t}$, resultando em

$$
\frac{d}{\mathrm{dt}}\left[n e^{\left(\lambda+\sigma_{a} \phi\right) t}\right]=N_{0} \sigma_{\mathrm{atv}} \phi e^{\left(\lambda+\sigma_{a} \phi-\sigma_{T} \phi\right) t}
$$


A solução da equação (5), considerando que $\sigma_{\mathrm{a}} \phi<<\lambda$ e $\sigma_{T} \phi \ll \lambda$ é

$$
n=\frac{\sigma_{\mathrm{atv}} \phi N_{0}}{\lambda}\left(1-e^{-\lambda t}\right)
$$

onde $N_{0}=N V$, sendo $N_{0}$ o número inicial de átomos alvo presentes na folha de ativação e $V$ o volume do detector de ativação. Assim, multiplicando ambos os lados da equação (6) pela constante de decaimento, obtêm-se:

$$
A_{0}=n \lambda=\sigma_{\text {atv }} N \phi V\left(1-e^{-\lambda t}\right)=\Sigma_{\text {atv }} \phi V\left(1-e^{-\lambda t}\right)
$$

A equação (7) fornece a atividade $\left(A_{0}\right)$ ao término do tempo $t_{i}$ de irradiação, sendo $\Sigma_{\text {atv }}$ conhecido como seção de choque macroscópica média de ativação.

Para um tempo de irradiação muito longo $(t \rightarrow \infty)$, o detector de ativação atingirá sua atividade máxima conhecida como atividade de saturação, dada por

$$
A^{\infty}=\sigma_{\text {atv }} N \phi V=\Sigma_{\text {atv }} V \phi
$$

Portanto, pode-se escrever $A_{0}$ em termos de $A^{\infty}$. Assim,

$$
A_{0}=A^{\infty}\left(1-e^{-\lambda t}\right)
$$

Ao analisar a equação (8), nota-se que a atividade de saturação é a taxa de reação nuclear $R$ de um detector de ativação de massa $m$, submetido a um fluxo de nêutrons $\phi$, desta forma pode-se reescrever a atividade de saturação, considerando $N=\frac{N_{a} \rho}{P_{a}}$, onde $N_{a}$ é o número de Avogadro, $\rho$ é a densidade do detector de ativação e $P_{a}$ o peso atômico do núcleo alvo. Sendo $V=\frac{m}{\rho}$ e $m$ a massa do detector de ativação, pode-se determinar a atividade de saturação como, 


$$
A^{\infty}=\frac{N_{a} m \phi \sigma_{\mathrm{atv}}}{P_{a}}
$$

Isolando o fluxo de nêutrons na equação (10), tem-se

$$
\phi=\frac{A^{\infty} P_{a}}{N_{a} m \sigma_{\mathrm{atv}}}
$$

Agora será analisado outro parâmetro que pode ser obtido através da ativação de um detector, que é a contagem integrada entre os instantes $t_{1}$ e $t_{2}$. A contagem integrada no sistema de detecção por espectrometria gama é dada por,

$$
C=\varepsilon I \int_{t_{1}}^{t_{2}} A_{0} e^{-\lambda t} \mathrm{dt}+\mathrm{BG}
$$

sendo $\varepsilon$ a eficiência global da contagem, I a abundância gama do fotopico medido, $B G$ a radiação de fundo ("background") entre os instantes de contagem $t_{1}$ e $t_{2}$ e os limites $t_{1}$ e $t_{2}$ são o tempo inicial da contagem e tempo final da contagem, respectivamente. Assim, tem- se que:

$$
C=\frac{\varepsilon I A_{0}}{\lambda} e^{-\lambda t_{1}}\left[1-e^{-\lambda\left(t_{2}-t_{1}\right)}\right]+\mathrm{BG}
$$

De acordo com a figura 2.1 pode-se definir $t_{1}$ e $t_{2}$ como sendo os tempos de contagem e $t_{2}-t_{1}$ como o tempo no qual o detector de ativação foi analisado no sistema de espectrometria gama, representado por $t_{c}$. 


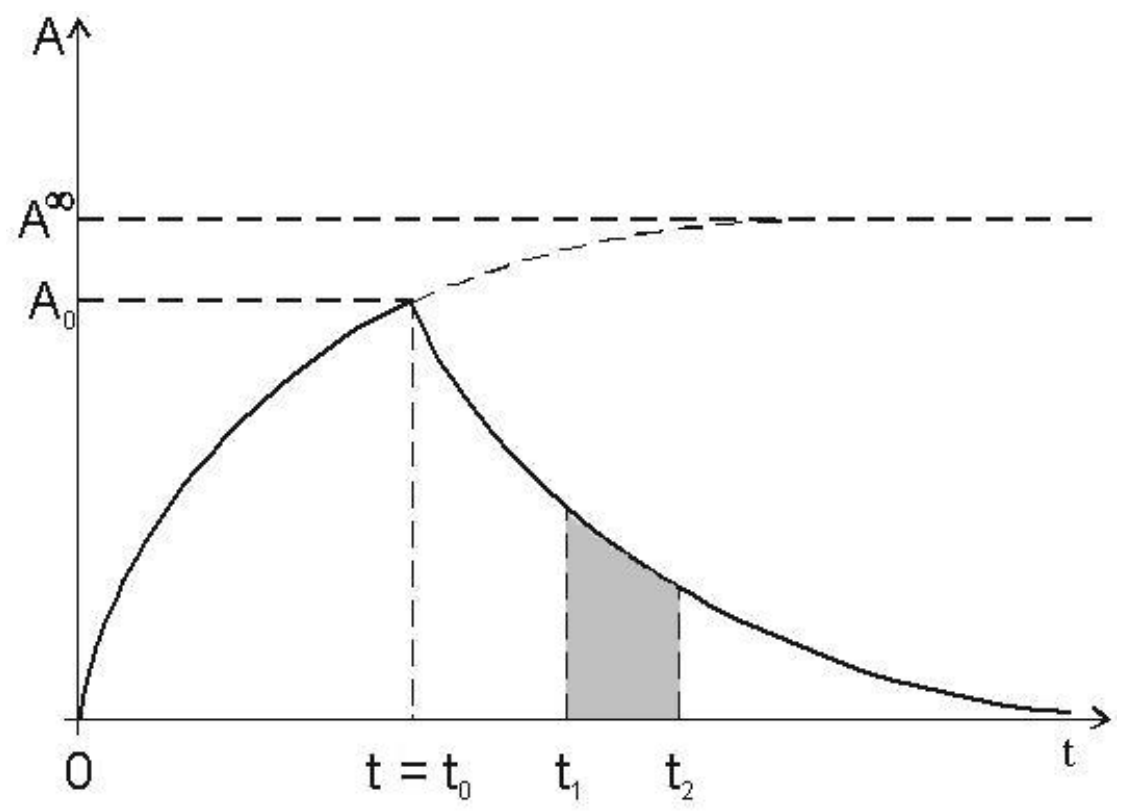

FIGURA 2.1: Atividade do radionuclídeo formado em função do tempo de irradiação (ti) e de contagem $(t 2-t 1)$.

Pode-se observar que $t$, representa o tempo de irradiação e $t+t_{e}=t_{1}$, portanto $e^{-\lambda . t 1}=e^{-\lambda t}$. $e^{-\lambda t e}$, sendo $e^{-\lambda t}=1$ (probabilidade do átomo não se desintegrar em $\mathrm{t}=\mathrm{t}_{0}$ é de $100 \%$ ), então reescrevendo (13), tem-se

$$
C=\frac{\varepsilon \cdot I \cdot A_{0}}{\lambda} e^{-\lambda t_{e}}\left(1-e^{-\lambda t_{c}}\right)+\mathrm{BG}
$$

Isolando $A_{0}$ da equação (14), sabendo que $A_{0}=A^{\infty}\left(1-e^{-\lambda t}\right)$ dado na equação (9), obtêm-se a atividade de saturação dada por,

$$
A^{\infty}=\frac{\lambda e^{\lambda t} e(C-\mathrm{BG})}{\varepsilon I\left(1-e^{-\lambda t_{i}}\right)\left(1-e^{-\lambda t_{c}}\right)}
$$

Substituindo a equação (15) em (11) tem-se a expressão para o fluxo de nêutrons obtido experimentalmente através da contagem de detectores de ativação, sendo importante, entretanto, salientar que nesta expressão não aparecem os fatores de correções que são necessários para corrigir o fluxo de 
nêutrons quanto aos efeitos de perturbação destes citados detectores. Por se tratar de uma analise do perfil do fluxo, este trabalho utiliza valores relativos. De qualquer forma, o fluxo de nêutrons corrigido pode ser obtido por ${ }^{12}$ :

$$
\phi=\frac{\lambda e^{\lambda t} e(C-\mathrm{BG}) P_{a}}{\varepsilon I\left(1-e^{-\lambda t_{i}}\right)\left(1-e^{-\lambda t_{c}}\right) N_{a} m \bar{\sigma}_{\mathrm{atv}}}
$$

A equação (16) pode ser utilizada para uma folha de ouro nua infinitamente diluídas, irradiadas num campo neutrônico do núcleo do reator, e assim forneceria uma estimativa de ordem de grandeza do fluxo total de nêutrons no local de irradiação da folha de ouro, responsável pela atividade induzida na mesma.

\subsection{Buckling de um Reator Nuclear}

O Buckling é um parâmetro importantíssimo da física de reatores que nos fornece a informação relativa ao perfil da curva do fluxo de nêutrons ao longo das direções ortogonais do núcleo do reator, ou seja, o perfil da fuga de nêutrons do sistema. Com este parâmetro é possível se projetar um reator nuclear em termos de composição dos materiais constituintes do seu núcleo, bem como a forma geométrica do mesmo. Da teoria advém que na região central do reator a fuga de nêutrons é menor que nas regiões periféricas. Em um reator uniforme e infinito não há fugas - o fluxo de nêutrons não depende da posição e sua variação no espaço é nula e, portanto, o Buckling é zero. A Figura 1 ilustra essa situação.

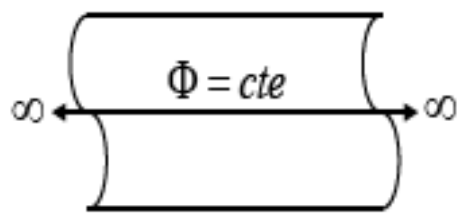

(a)

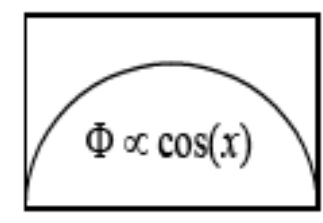

(b)

Figura 1 - Perfil da distribuição de nêutrons: (a) em reator infinito e (b) em reator finito 
Utilizando a equação da continuidade é possível derivar uma equação envolvendo apenas o fluxo de nêutrons e a solução desta equação mostra o comportamento do fluxo neutrônico em qualquer posição do reator em função do tempo, ou seja, $\phi(P, t)$. A equação (17) é conhecida como a equação de difusão de nêutrons e é de grande importância na física de reatores ${ }^{12,13,14}$,

$$
\mathrm{D} \nabla^{2} \phi-\sum_{\mathrm{a}} \phi+\mathrm{s}=\frac{\partial \mathrm{n}}{\partial \mathrm{t}}
$$

onde s é a taxa de emissões de nêutrons. Este termo leva em consideração a fonte externa de nêutrons e os nêutrons advindos das fissões no combustível, como as emissões no combustível em estado estacionário, $\partial \mathrm{n} / \partial \mathrm{t}=0$, é muito maior que as emissões da fonte de nêutrons, então, o termo referente a fonte externa de nêutrons pode ser desprezada restando apenas o termo referente as fissões no combustível, $v \Sigma f \quad \phi$. Sendo assim, a equação da difusão de nêutrons na criticalidade pode ser expressa de acordo com a equação (18).

$$
\nabla^{2} \phi+\left(\frac{v \Sigma_{\mathrm{f}}-\Sigma_{\mathrm{a}}}{D}\right) \phi=0
$$

A equação (2) pode ser reescrita de conforme a equação (19),

$$
\nabla^{2} \phi+B_{g}^{2} \phi=0
$$

onde $\mathrm{B}_{\mathrm{g}}{ }^{2}$ é o Buckling geométrico que depende do fluxo de nêutrons que por sua vez depende da geometria do núcleo do reator. Com este parâmetro se pode 
projetar um reator, mensurando suas medidas e determinando seu volume crítico mínimo ${ }^{10}$. O Buckling é um parâmetro que fornece a medida da curvatura do fluxo de nêutrons até se reduzir o seu valor a zero e independe da potência do reator, pois se aumentando a potência se tem mais nêutrons, mas a distribuição neutrônica continua a mesma ${ }^{15}$. No caso do reator IPEN/MB-01 no formato cilíndrico o Laplaciano é desenvolvido em coordenadas cilíndricas e a equação (19) toma a forma da equação (20).

$$
\frac{1}{r} \frac{\partial}{\partial r}\left(r \frac{\partial \phi}{\partial r}\right)+\frac{\partial^{2} \phi}{\partial z^{2}}+B_{g}^{2} \phi=0
$$

Para o reator no formato cilíndrico a parte angular é zero, pois o fluxo de nêutrons é constante, ou seja, o Buckling é simétrico com relação a parte angular. A equação (4) pode ser resolvida pelo método de separação de variáveis e tem uma solução do tipo $\phi(r, z)=X(r)$. Z (z). Utilizando esta solução na equação anterior e dividindo-a por $\phi$, obtém-se a equação (21).

$$
\frac{1}{X r} \frac{d}{d r}\left(r \frac{d X}{d r}\right)+\frac{1}{Z} \frac{\partial^{2} Z}{\partial z^{2}}+B_{g}^{2}=0
$$

O primeiro e segundo termos dependem apenas de $r$ e $z$, respectivamente, $e$ podem ser expressos como constantes. A solução para o fluxo de nêutrons e o Buckling com o reator no formato cilíndrico na criticalidade estão, respectivamente, expressos nas equações (22) e (23),

$$
\phi(r, z)=X(r) \cdot Z(z)
$$




$$
\begin{gathered}
\phi(r, z)=A J_{0}\left(\frac{2,405 r}{R_{e x}}\right) \cos \left(\frac{\pi z}{H_{e x}}\right) \\
B_{g}^{2}=\left(\frac{2,405}{R_{e x}}\right)^{2}+\left(\frac{\pi}{H_{e x}}\right)^{2}
\end{gathered}
$$

onde A é a amplitude que depende diretamente da potência, Rex e Hex são o raio extrapolado e a altura extrapolada, respectivamente, que são obtidos extrapolando as curvas dos ajustes das funções até que o valor do fluxo de nêutrons se anule (zero).

A curvatura do fluxo de nêutrons é devido a fuga de nêutrons do sistema que é expresso na fórmula dos seis fatores, equação (24), por $P_{F}$ (probabilidade de não-fuga epitérmica) e $\mathrm{P}_{\mathrm{T}}$ (probabilidade de não-fuga térmica) que estão de acordo com as equações (25) e (26), respectivamente.

$$
\begin{array}{r}
k_{e f}=\varepsilon p f \eta P_{F} P_{T}=k_{\infty} P_{F} P_{T} \\
P_{F}=\frac{1}{1+B^{2} \tau} \\
P_{T}=\frac{1}{1+B^{2} L^{2}}
\end{array}
$$

Sendo $\tau$ a idade de Fermi e $\mathrm{L}^{2}$ a área de difusão de nêutrons térmicos, em que a idade de Fermi corresponde a um sexto da menor distância ao quadrado 
$\left(\tau=\frac{r_{F}^{2}}{6}\right)$ percorrida por um nêutron do ponto onde este nasce rápido até o ponto onde é completamente moderado e a área de difusão igual a um sexto da menor distância ao quadrado $\left(L^{2}=\frac{r_{T}^{2}}{6}\right)$ percorrida por um nêutron do ponto onde este se torna térmico até desaparecer do sistema (ser absorvido ou escapar). De acordo com a equação (23) quanto menor forem as dimensões do núcleo do reator, maior será o Buckling e, consequentemente, uma maior fuga de nêutrons ${ }^{13,14}$.

Com o reator crítico, kef $=1$, e utilizando as equações (24), (25) e (26), obtém-se a equação (27),

$$
\frac{k_{\infty}}{1+B^{2}\left(L^{2}+\tau\right)}=1
$$

a quantidade $L^{2}+\tau$ é conhecida como área de migração térmica, $\mathrm{M}^{2}$, e com esta definição o Buckling pode ser reescrito como a equação (28).

$$
B_{M}^{2}=\frac{k_{\infty}-1}{M^{2}}
$$

Neste caso, o Buckling dependerá apenas dos materiais que compõem o núcleo do reator por isso é conhecido como "Buckling material"16.

$\mathrm{Na}$ condição de criticalidade o Buckling material é igual ao Buckling geométrico, $\mathrm{B}_{\mathrm{g}}{ }^{2}=\mathrm{B}_{\mathrm{m}}{ }^{2}$, e isto tem aplicação prática. Neste caso como mostrado na equação (29) para um reator cilíndrico, pode-se obter a quantidade de combustível necessária para tornar o sistema crítico ou se obter as dimensões necessárias para 
se atingir a criticalidade do sistema ${ }^{17,20}$. O sistema é dito crítico quando a população de nêutrons é constante ao longo do tempo.

$$
\frac{k_{\infty}-1}{M^{2}}=\frac{\eta \varepsilon p f-1}{L^{2}+\tau}=\left(\frac{2,405}{R_{e x}}\right)^{2}+\left(\frac{\pi}{H_{e x}}\right)^{2}
$$

Quando o $\mathrm{B}_{\mathrm{g}}{ }^{2}$ supera $\circ \mathrm{B}_{\mathrm{m}}{ }^{2}$, ou seja, $\mathrm{B}_{\mathrm{g}}{ }^{2}>\mathrm{B}_{\mathrm{m}}{ }^{2}$ temos a condição em que o reator se encontrara na condição subcrítica, ou seja, a população de nêutrons é decrescente ao longo do tempo. Ao contrário quando o $\mathrm{B}_{\mathrm{m}}{ }^{2}$ supera $\circ \mathrm{B}_{\mathrm{g}}{ }^{2}$, ou seja, $\mathrm{B}_{\mathrm{g}}{ }^{2}<\mathrm{B}_{\mathrm{m}}{ }^{2}$ temos a condição em que o reator se encontra na condição de Supercriticalidade, ou seja, a população de nêutrons é crescente ao longo do tempo. 


\section{Materiais e Métodos}

\subsection{O Reator Nuclear IPEN/MB-01}

O reator IPEN/MB-01, Figura 3.1, é um reator nuclear de potência zero concebido para funcionar a uma potência máxima de 100 watts para a configuração padrão retangular de 28x26 varetas combustíveis (680 varetas) . É uma instalação nuclear, que permite a simulação de todas as características de um reator nuclear de grande escala, sem a necessidade de construir um sistema de remoção de calor complexo. Este tipo de reator representa uma ferramenta básica, que permite que os pesquisadores possam estudar não só através de cálculos teóricos, mas também com as medições experimentais, o desempenho e as características do núcleo de um reator de energia, simulando as condições do projeto ${ }^{24}$.

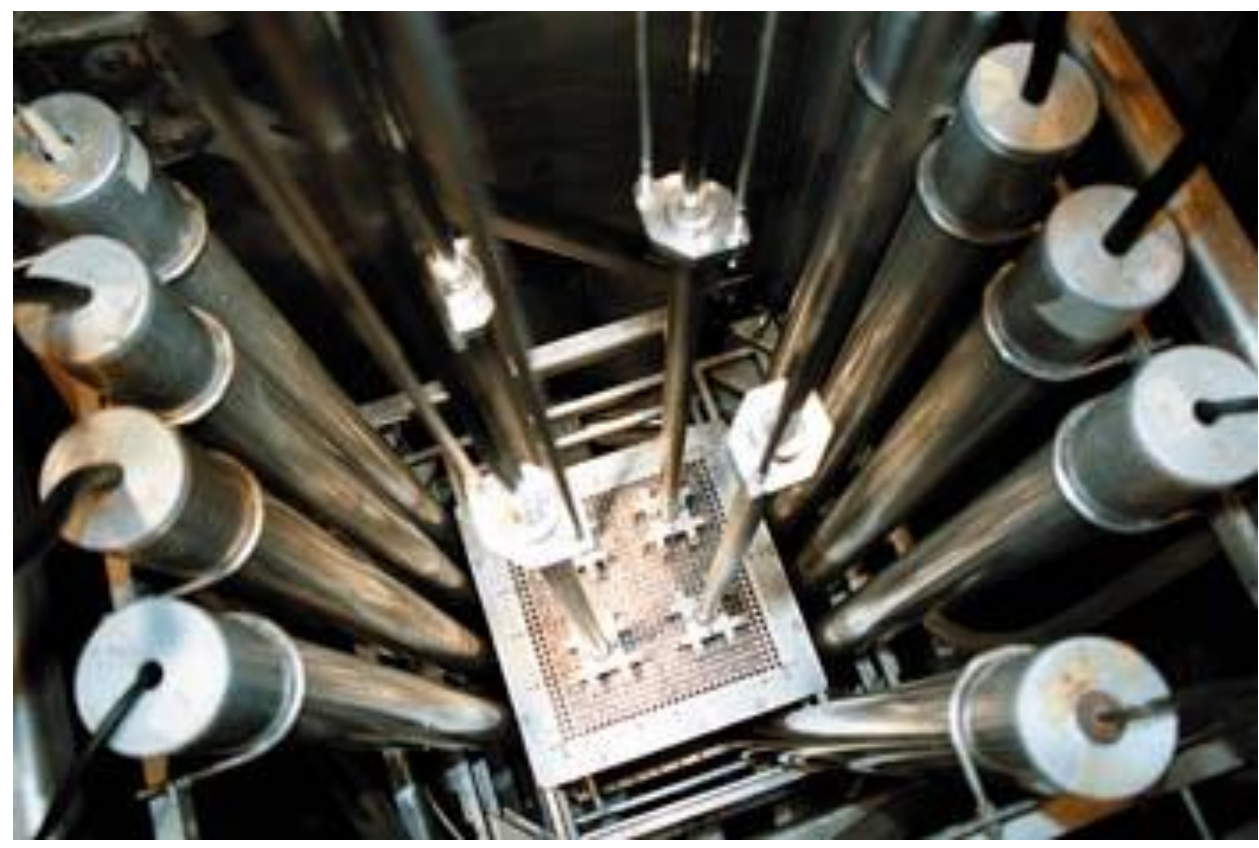

Figura 3.1: vista superior do reator nuclear - IPEN/MB-01 
Dada a flexibilidade do reator IPEN/MB-01, uma das configurações possíveis do núcleo é a cilíndrica, utilizada neste trabalho, com 28 varetas de combustível ao longo de seu diâmetro e 48 barras absorvedoras de neutrons (controle e segurança), ver a Figura 3.2. Esta configuração foi escolhida porque, entre as configurações cilíndricas críticas, a de 28 varetas combustíveis ao longo de seu diâmetro têm o menor excesso de reatividade, a apenas 278,92 pcm (partes por cem mil) ${ }^{18}$. Isto assegura que a operação seja realizada com as barras de controle bem retiradas do núcleo do reator minimizando assim, perturbações no fluxo de neutrons no interior do núcleo, aumentando assim o comprimento da região assintótica de fluxo de neutrons. O Reator atingiu a criticalidade para esta configuração, à temperatura média entre todas as operações de $24,32 \pm 0,32{ }^{\circ} \mathrm{C}$ com as barras de controle $\mathrm{BC} 1$ e $\mathrm{BC} 2$ igualmente retiradas em aproximadamente $88 \%$ do comprimento ativo axial do combustível do reator, cujo valor nominal é de $54,6 \mathrm{~cm}^{18,25}$.

A Figura 3.3 apresenta uma representação de corte lateral do núcleo do reator nuclear IPEN/MB-01, bem como os locais de irradiação dos fios de ouro e as respectivas posições nas quais foram feitas as medidas de ativação. A Figura 3.4 apresenta as posições de irradiação das folhas de ouro na configuração cilindrica estudada. 


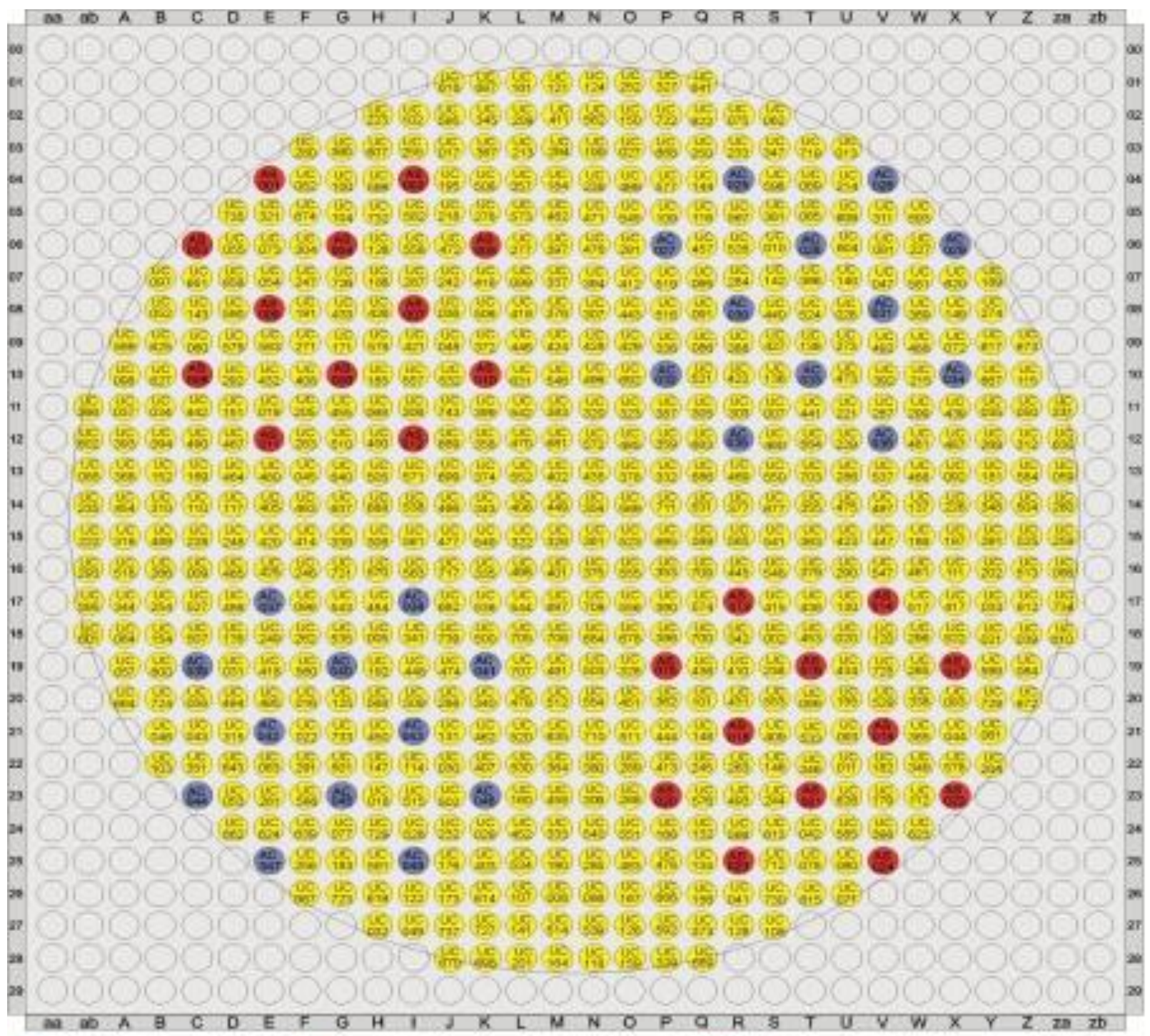

(t6) Vareta Combustivel 0 Vareta Absorvedora de Controle Vareta Absorvedora de Segurança

Figura 3.2: representação da configuração cilindrica do reator IPEN/MB-01 


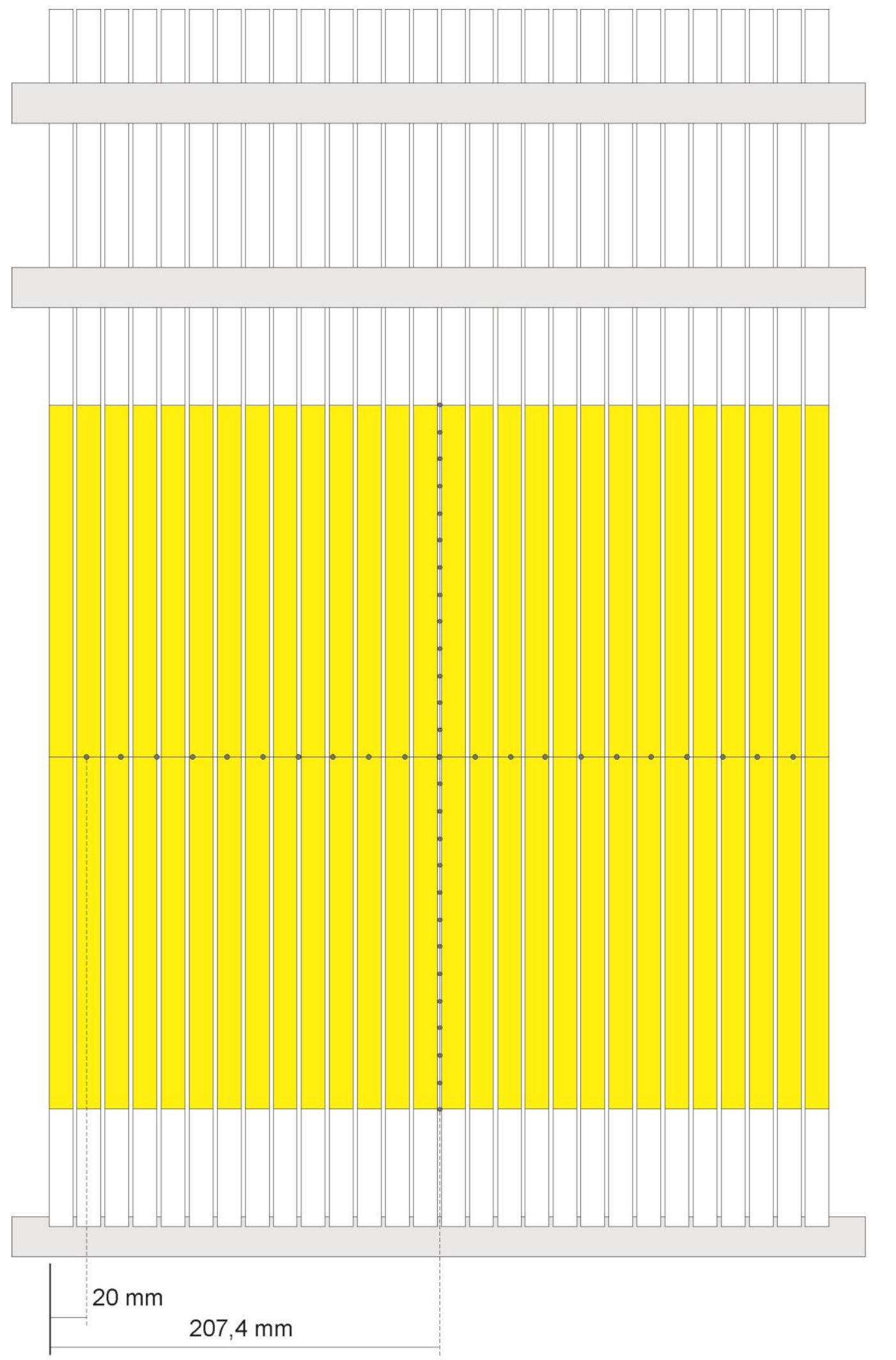

$637 \mathrm{~mm}$

$546 \mathrm{~mm}$

$455 \mathrm{~mm}$

$364 \mathrm{~mm}$

$273 \mathrm{~mm}$

$182 \mathrm{~mm}$

$91 \mathrm{~mm}$

Figura 3.3 - Posicionamento dos Fios de Ouro Irradiados no Núcleo do Reator IPEN/MB-01 - Configuração Cilindrica de 28x28 varetas combustíveis. 


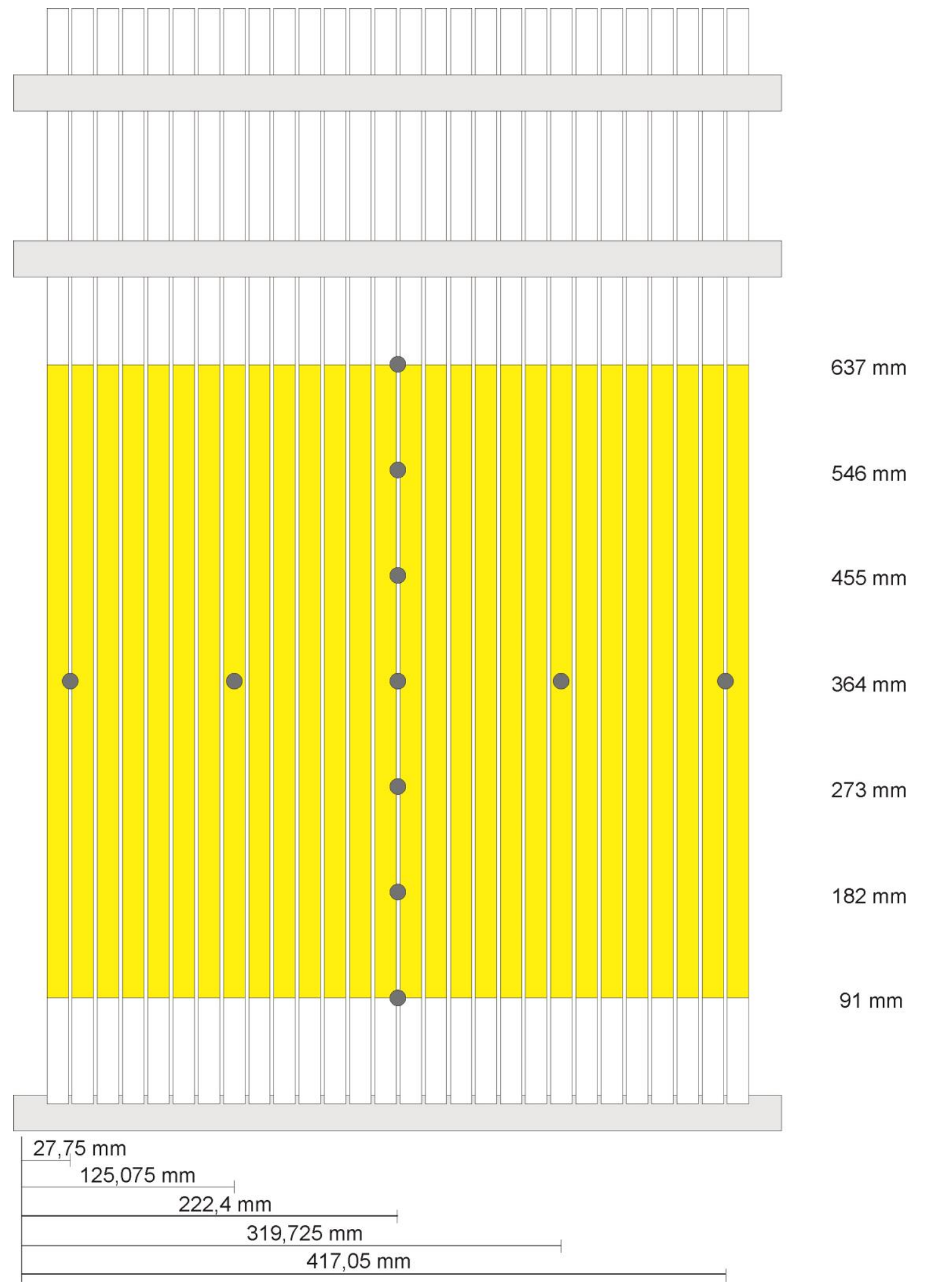

Figura 3.4 - Posicionamento das Folhas de Ouro Irradiadas no Núcleo do Reator IPEN/MB-01 - Configuração Cilindrica de 28x28 varetas combustíveis. 


\subsection{Componentes irradiados para obtenção de dados experimentais}

Para a obtenção dos dados experimentais de ativação neutrônica foram irradiados varetas de combustível, fios de ouro e folhas de ouro.

\subsection{1 - Varetas de combustivel}

Para a irradiação das varetas de combustível, o reator foi críticalizado a 30 watts, dado pelo canal nuclear do reator № 6 , e operado durante 1 hora. Uma vareta nova de combustível foi usada para adquirir os dados de mapeamento de fluxo axial, na região central do núcleo do reator.

Foram realizadas medidas em 31 varetas combustivel, sendo 30 utilizadas para as direções radiais Norte-Sul (N-S) e Leste-Oeste (L-O) e uma (01) para a direção axial central do núcleo do reator.

Foi realizada espectrometria gama nas varetas de combustível irradiadas usando um detector de germânio hiperpuro (HPGe). Para medir o perfil do fluxo de nêutrons predominantemente epitérmicos foi analisado o fóton gama de $276,6 \mathrm{keV}$ do ${ }^{239} \mathrm{~Np}$ com probabilidade de emissão de $14,28 \%$.

Para medir o perfil relativo de fluxo de nêutrons predominantemente térmicos foi analisado o fóton gama de ${ }^{143} \mathrm{Ce}$ de $293,3 \mathrm{keV}$ com a probabilidade de emissão de $42,8 \%$. O ${ }^{143} \mathrm{Ce}$ é um produto da fissão do ${ }^{235} \mathrm{U}$ por neutrons térmicos ${ }^{23}$ e tem a vantagem de ter um rendimento razoável de fissão $(\sim 6 \%)$ e uma meia-vida suficientemente longa ( 33 horas ) para viabilizar uma análise espectral de raios gama com boa estatistica de contagem.

O fluxo de neutrons na direção radial foi obtido para as direções norte-sul e leste-oeste, sendo medidas 15 varetas em cada direção. As varetas eram retiradas do núcleo e inseridas no detector, foi realizada uma medida para cada vareta e essa medida foi obtida a partir da contagem (Cnet) obtida com o detector na posição de 364 milímetros da vareta na dimensão axial que 
corresponde a metade do comprimento do núcleo ativo. O Tempo real utilizado foi 1800 segundos.

$\mathrm{Na}$ contagem axial (Cnet) foram feitas medidas dos fotópicos gama para as energias de emissão do ${ }^{239} \mathrm{~Np}$ e ${ }^{143} \mathrm{Ce}$ em 29 regiões axiais com separação de 20 milímetros uma da outra, com duração de 30 minutos em cada região. A vareta utilizada foi retirada da posição central M14 do núcleo do reator.

As taxas de contagens foram corrigidas $\left(\mathrm{C}_{\text {corrigido }}\right)$ devido ao decaimento, de acordo com a equação (30) e os desvios nas taxas de contagens corrigidas foram considerados, de acordo com a equação (31), utilizando as constantes de decaimento $(\lambda) \mathrm{de}^{239} \mathrm{~Np}\left(\lambda=3,41 \times 10^{-6} \mathrm{~s}^{-1}\right) \mathrm{e}^{143} \mathrm{Ce}\left(\lambda=5,83 \times 10^{-6} \mathrm{~s}^{-1}\right)$.

$$
\begin{aligned}
& C_{\text {corrigido }}=\frac{C_{N e t}}{L T} e^{\lambda T E} \\
& \sigma_{C_{c o r}}^{2}=\left(\frac{C_{c o r}}{C_{N e t}}\right)^{2} \sigma_{C_{N e t}}^{2}
\end{aligned}
$$

Na equação (30), temos que:

$\mathrm{C}_{\mathrm{Net}}$ é a contagem líquida fornecida pelo detector;

LT é o tempo real de contagem descontado o tempo morto;

TE é o tempo de espera desde de o fim da irradiação até o momento da medida;

$\mathrm{Na}$ equação (31), temos as incertezas associadas as medidas e resultados obtidos com a equação (30).

Assim, para se obter as contagens corrigidas, foi essencial registrar o tempo de espera entre o fim da irradiação e o tempo de medição ( TE ) .

No apêndice A, são apresentados os dados obtidos para as medidas das varetas. 


\subsubsection{Fios e folhas de ouro}

Para os fios de ouro foram realizadas 02 irradiações uma na direção axial e outra na radial, em canais de irradiação centrais do núcleo do reator, apresentados na representação da Figura 3.5. A irradiação foi realizada na potência máxima de operação do reator IPEN/MB-01, isto é, a $100 \mathrm{~W}$. Para os experimentos os tempos de irradiação foram de 2 horas, na direção axial e 01 hora na radial. Foram utilizados dois fios de ouro. Os mesmos parametros e as equações (30) e (31) utilizados para as varetas foram usadas para os fios. No entanto, os resultados foram registrados a cada $20 \mathrm{~mm}$ ao longo do fio, sendo de uma hora o tempo em cada uma dessas posições. A constante de decaimento do ouro é $\lambda=2,97 \times 10^{-6} \mathrm{~s}^{-1}$. Os dados obtidos para os fios são apresentados no apêndice $B$.

Para irradiar e posicionar no centro do núcleo do reator as folhas de ouro foram colocadas numa placa de lucite, Figura 3.5, e o sistema foi irradiado com 100 watts por 1 hora. As folhas de ouro infinitamente diluidas, 1\% Au-90\% Al, tinham massa de $0,02394 \mathrm{~g}$ e espessura de $0,02 \mathrm{~cm}$. Foram utilizadas 11 folhas dispostas de acordo com a representação da Figura 3.4. Os dados obtidos para as folhas de ouro são apresentados no apêndice C. 


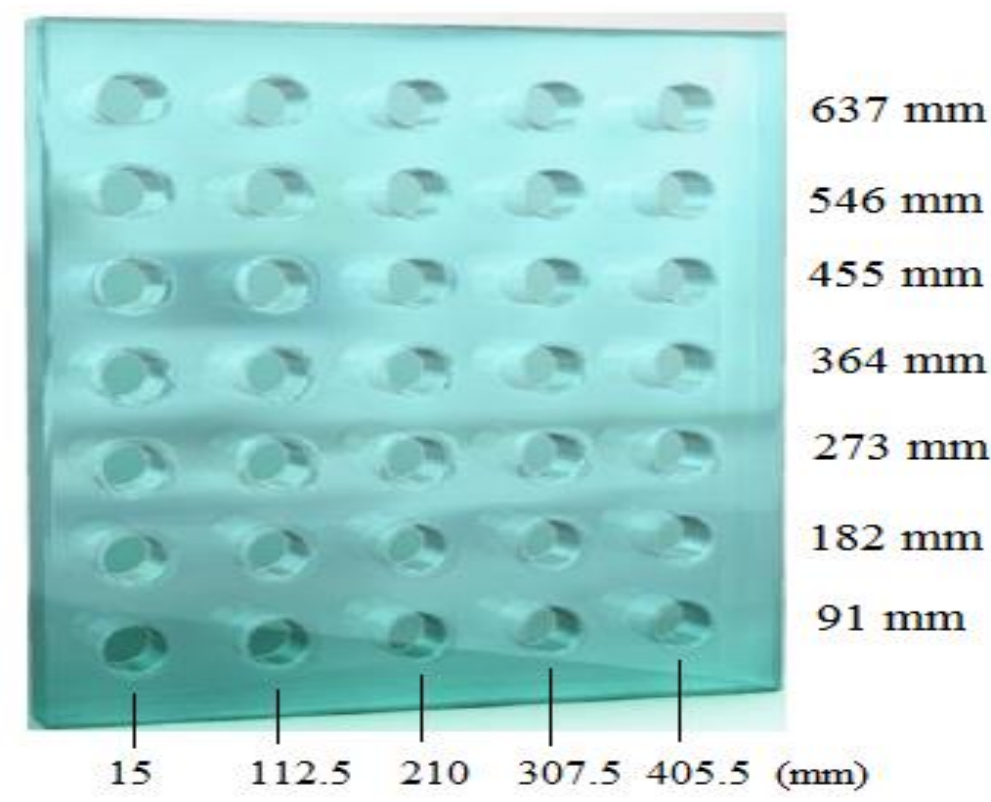

Figura 3.5: Imagem da placa de lucite e das posições das folhas de ativação e as suas respectivas cotas radiais e axiais.

\subsection{Tratamento de Dados e Sistemas de Detecção}

Os dados obtidos com as contagens e as respectivas posições de irradiação foram inseridos no software Origin e os valores de raio e altura efetivos, nas direções radial e axial, respectivamente, foram determinados com ajustes para as funções cosseno e de Bessel. $O$ apêndice $D$ traz a descrição da função de Bessel obtida para o ajuste.

Os detectores de gêrmanio hiperpuro (HPGe) são assim denominados devido a concentrações extremamente baixas de impurezas. Uma de suas características importantes é que ao ser resfriado com nitrogênio líquido se torna um excelente semicondutor e por esse motivo sua banda de valência esta bem próxima da banda de condução o que facilita sua ionização. A grande vantagem desse detector é sua resolução para raios gama creditada a três fatores: espalhamento estatístico inerente pelo número de coletores de carga, variações na eficiência de coleção de cargas e baixas contribuições de ruído eletrônico. $\mathrm{Na}$ 
Figura 3.6, é apresentada uma imagem do sistema de detecção utilizado para as varetas combustíveis e para os fios de ouro.

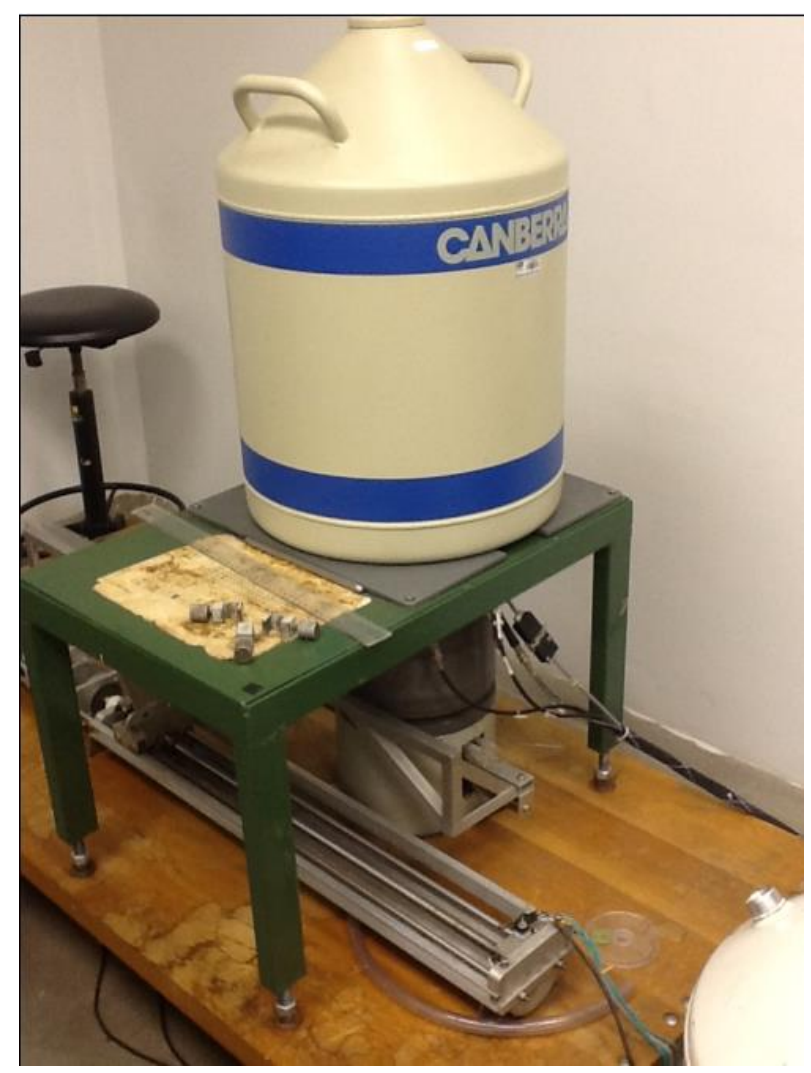

Figura 3.6: Sistema de Varredura utilizando detetor de germânio hiperpuro para espectrometria gama das varetas combustíveis e fios de ouro irradiados.

Esse detector apresenta alta resolução para os raios gama e quando associado a um multicanal de alta precisão é possível obter boa discriminação entre os pulsos gerados no interior do detector. A Figura 3.7 apresenta a imagem do sistema de detecção utilizado para as folhas de ouro. 


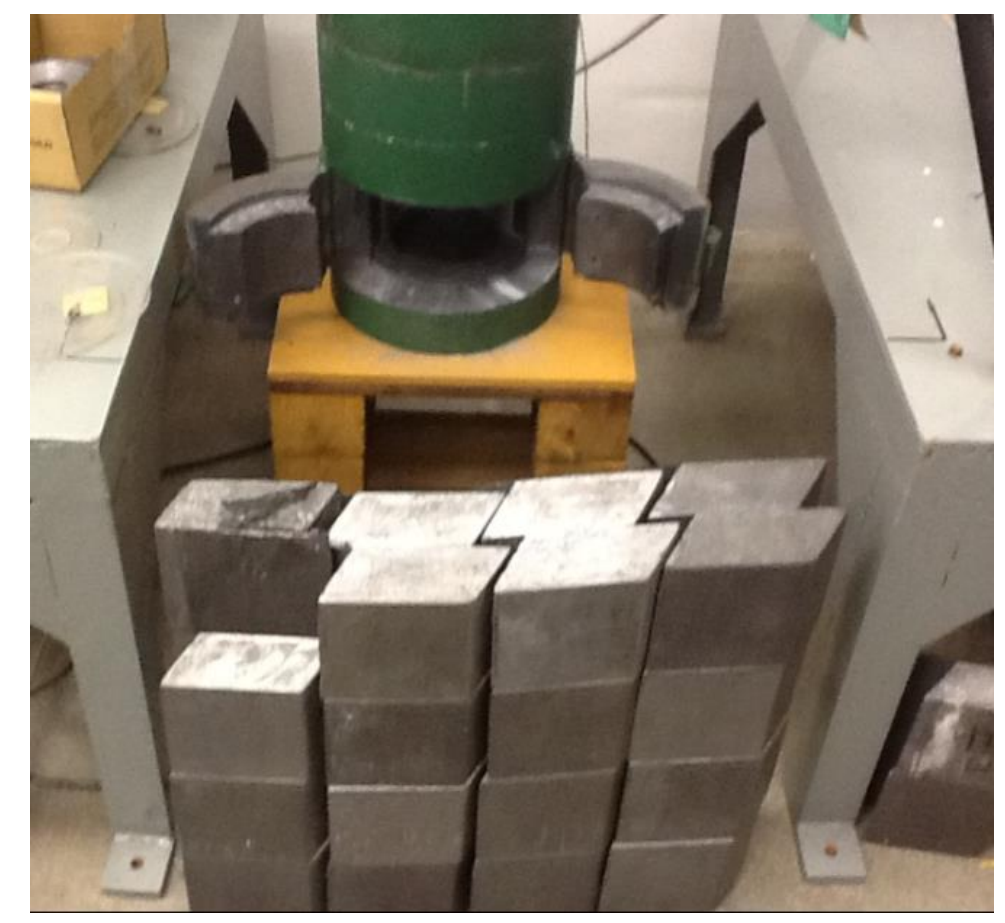

Figura 3.7: Detector de HPGe utilizado para as folhas de ouro

A eletrônica associada ao detector é constituída por um pré-amplificador (acoplado ao detector) que amplifica o sinal advindo das ionizações induzidas pela radiação dentro da região ativa do cristal de germânio. Esse sinal é enviado para um amplificador que o reconfigura e reduz o ruído associado. Então o sinal amplificado é enviado para uma placa de aquisição multicanal que discrimina as diferentes alturas de pulsos, associando-os a um dos 8200 canais do sistema. Cada canal foi ajustado para $0,25 \mathrm{keV}$ de precisão com $2 \%$ de resolução. $\mathrm{O}$ espectro de amplitude de pulsos armazenados ao longo da aquisição multicanal é processado e foi analisado utilizando o software MAESTRO que apresenta os espectros e determina automaticamente os fotopicos dos gamas gerados pela fonte radioativa ${ }^{24}$. A Figura 3.8 apresenta o diagrama esquemático com as características da eletrônica da bancada experimental associada ao detector HPGe. 


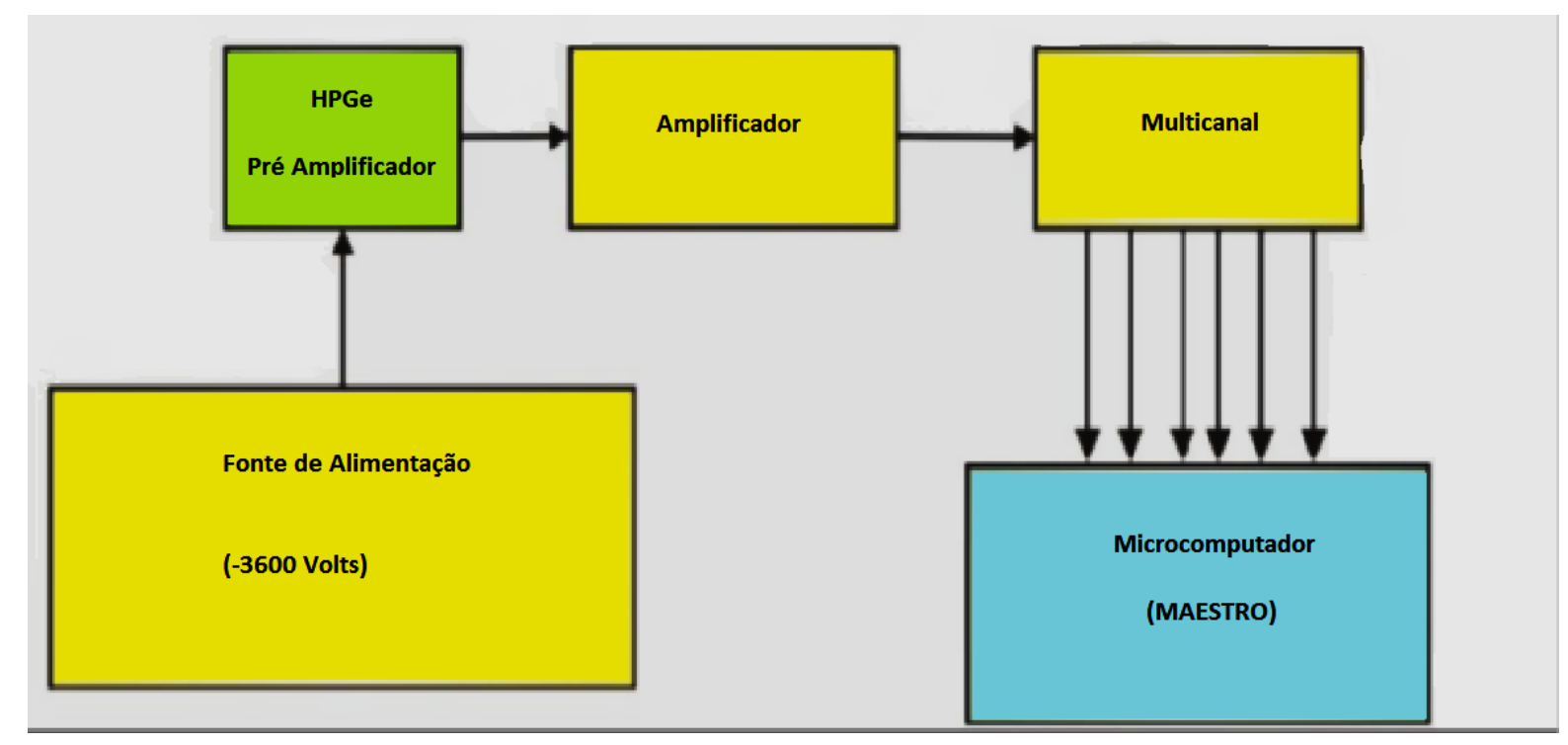

Figura 3.8: Características da eletrônica da bancada experimental associada ao detector HPGe.

\subsection{Incerteza associada ao calculo do Buckling}

Com o perfil da distribuição dos fluxos de nêutrons em cada uma das situações analisadas e com o Buckling geométrico obtido a partir da equação (23), utilizando técnicas de propagação de erros, Anexo B, é possível calcular a incerteza associada a partir da equação (32) para os nêutrons epitérmicos e térmicos.

$$
\sigma_{B_{g}^{2}}=2\left(\frac{2,405^{4}}{R_{e x}^{6}} \sigma_{R_{e x}}^{2}+\frac{\pi^{4}}{H_{e x}^{6}} \sigma_{H_{e x}}^{2}\right)^{1 / 2}
$$




\section{Resultados e Discussões}

\subsection{Medidas obtidas para varetas combustível}

Os perfis das distribuições das contagens corrigidas em função da posição das varetas de combustível são mostrados a seguir.

\subsubsection{Direção Radial Leste - Oeste}

Na Figura 4.1 é mostrado o perfil de distribuição do fluxo de neutrons térmicos e epitérmicos na direção radial leste-oeste e também o ajuste efetuado para determinar o raio efetivo, a partir das taxas de contagem corrigidas do fotopico de $276,6 \mathrm{keV}$ do ${ }^{239} \mathrm{~Np}$.

Na Figura 4.2 é mostrado o perfil da distribuição do fluxo de neutrons térmicos e epitérmicos na direção radial leste-oeste e o ajuste feito para determinar o raio efetivo, a partir das taxas de contagem corrigidas do fotopico gama de 293,3 keV do ${ }^{143} \mathrm{Ce}$.

Na Figura 4.3 é mostrado o perfil de distribuição do fluxo de neutrons térmicos na direção radial leste-oeste e também o ajuste efetuado para determinar o raio efetivo, a partir das taxas de contagem corrigidas do fotopico de $276,6 \mathrm{keV}$ do ${ }^{239} \mathrm{~Np}$.

$\mathrm{Na}$ Figura 4.4 é mostrado o perfil de distribuição do fluxo de neutrons epitérmicos na direção radial leste-oeste e também o ajuste efetuado para determinar o raio efetivo, a partir das taxas de contagem corrigidas do fotopico de $276,6 \mathrm{keV}$ do ${ }^{239} \mathrm{~Np}$.

Na Figura 4.5 é mostrado o perfil da distribuição do fluxo de neutrons térmicos na direção radial leste-oeste e o ajuste feito para determinar o raio efetivo, a partir das taxas de contagem corrigidas do fotopico gama de $293,3 \mathrm{keV}$ do ${ }^{143} \mathrm{Ce}$. 
$\mathrm{Na}$ Figura 4.6 é mostrado o perfil da distribuição do fluxo de neutrons epitérmicos na direção radial leste-oeste e 0 ajuste feito para determinar o raio efetivo, a partir das taxas de contagem corrigidas do fotopico gama de $293,3 \mathrm{keV}$ do ${ }^{143} \mathrm{Ce}$.

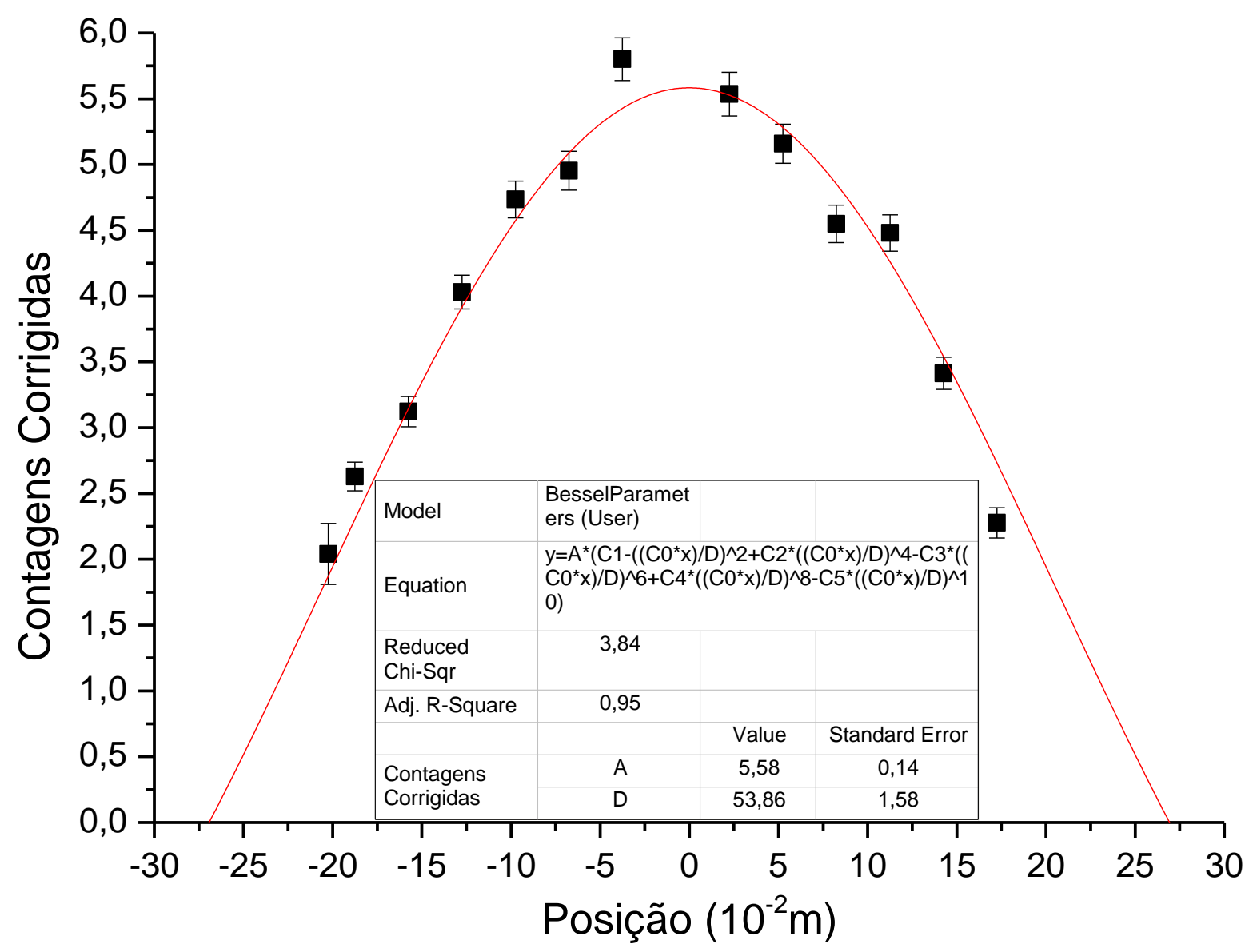

Figura 4.1: Gráfico do Perfil de Contagens por Posição na direção Leste-Oeste para $\mathrm{Np}$-239 correspondente ao perfil do fluxo de neutrons térmicos e epitérmicos. 


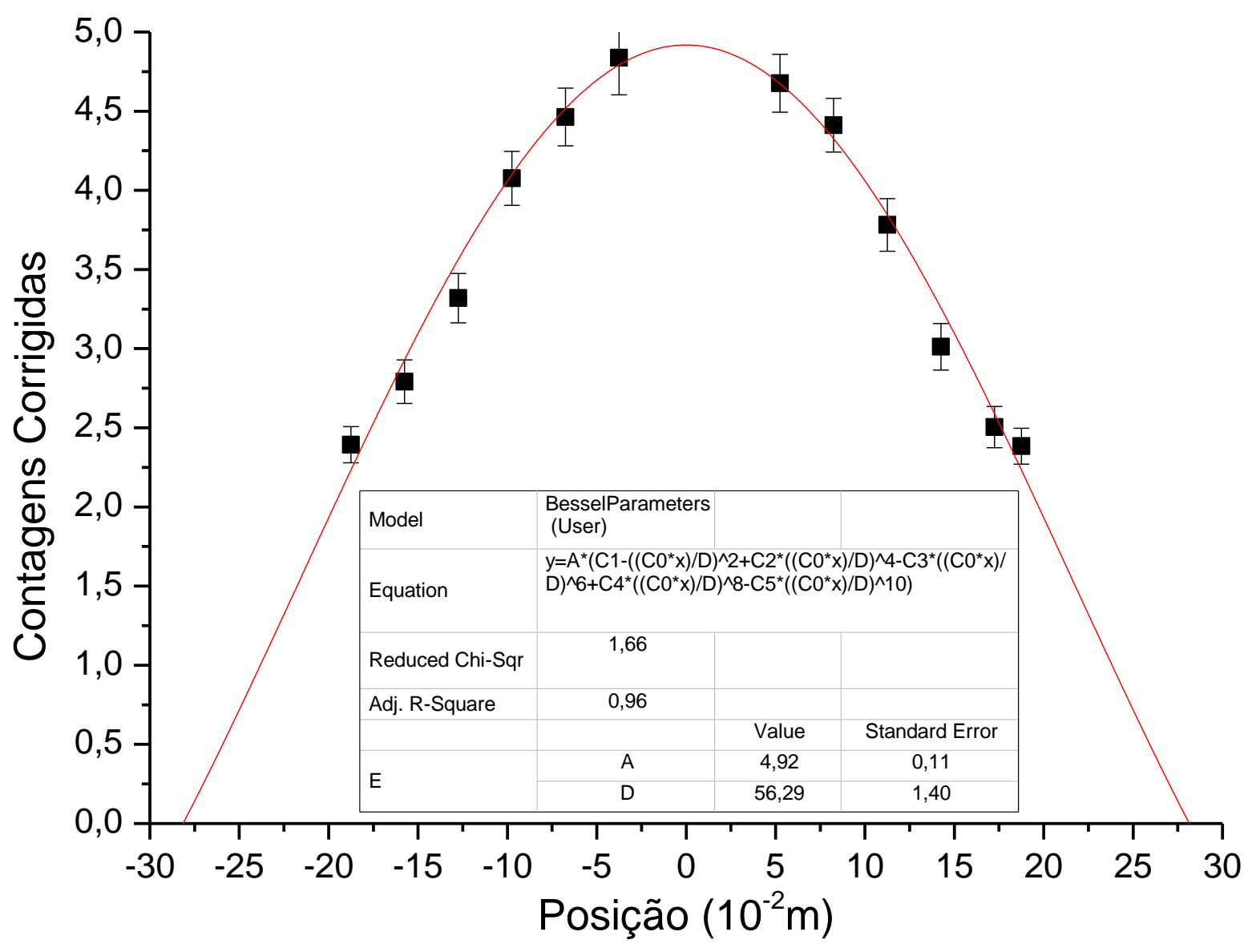

Figura 4.2: Gráfico do Perfil de Contagens por Posição na direção Leste-Oeste para Ce143 correspondente ao perfil do fluxo de neutrons térmicos e epitérmicos. 


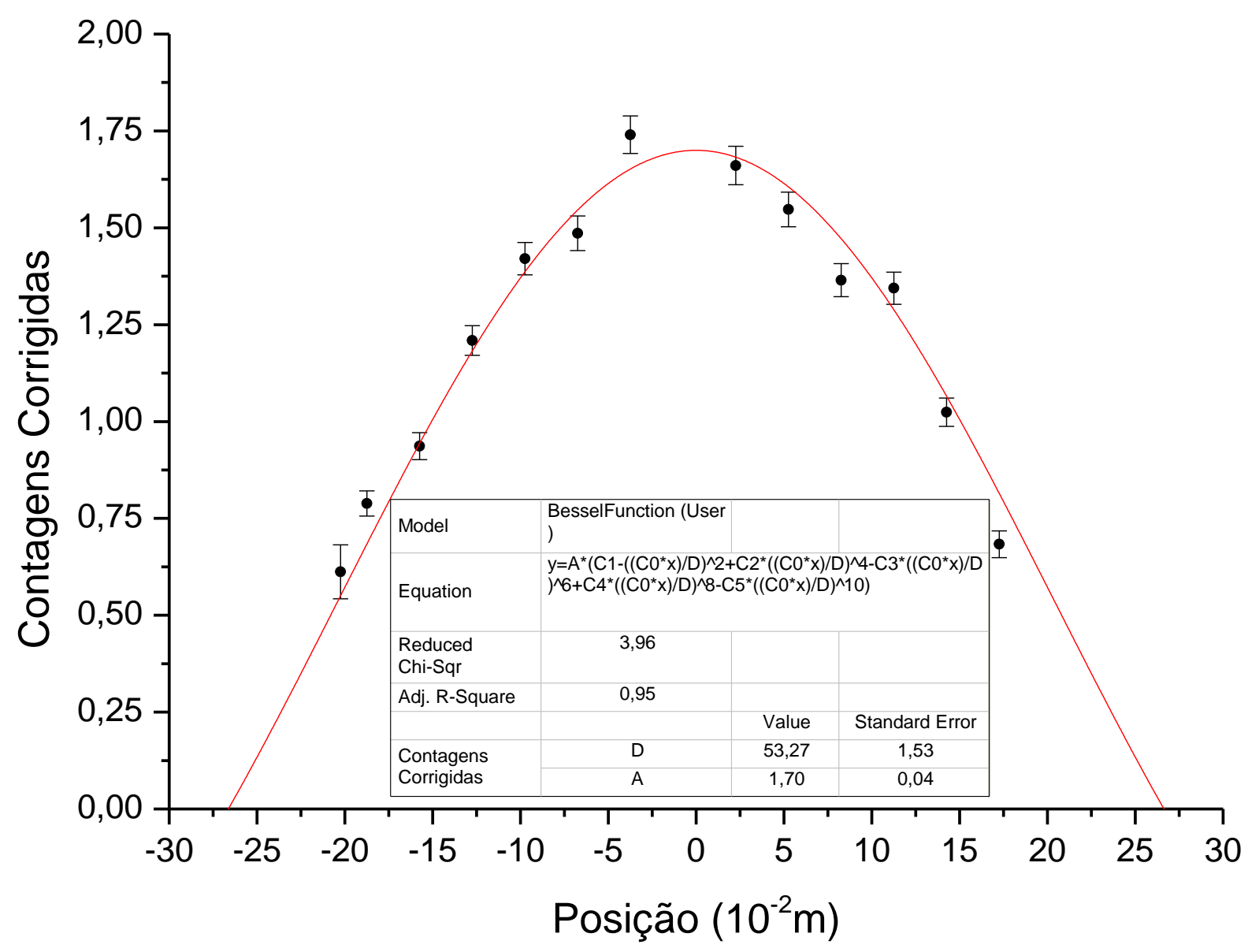

Figura 4.3: Gráfico do Perfil de Contagens por Posição na direção Leste-Oeste para ${ }^{239} \mathrm{~Np}$ correspondente ao perfil do fluxo de neutrons térmicos. 


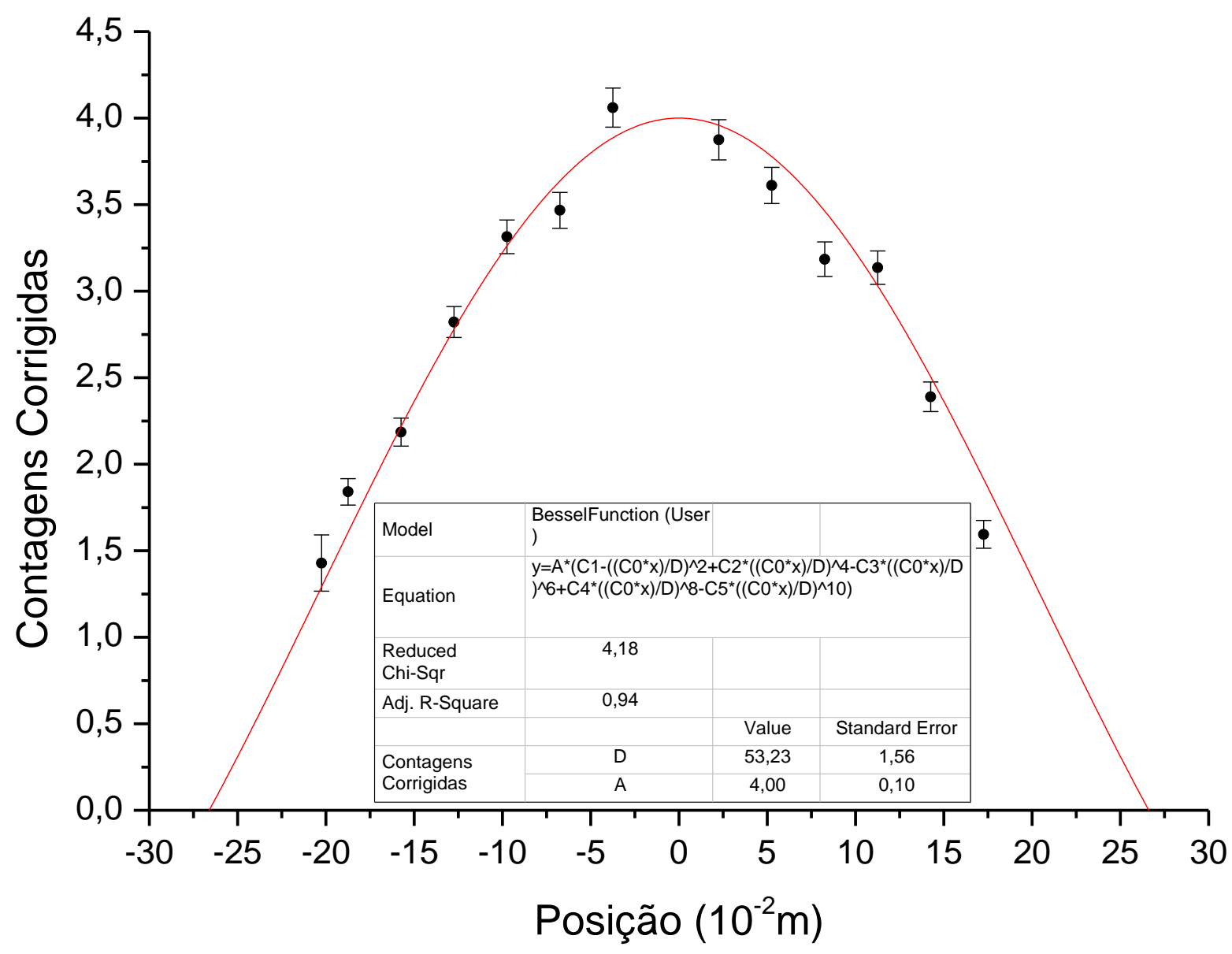

Figura 4.4: Gráfico do Perfil de Contagens por Posição na direção Leste-Oeste para ${ }^{239} \mathrm{~Np}$ correspondente ao perfil do fluxo de neutrons epitérmicos. 


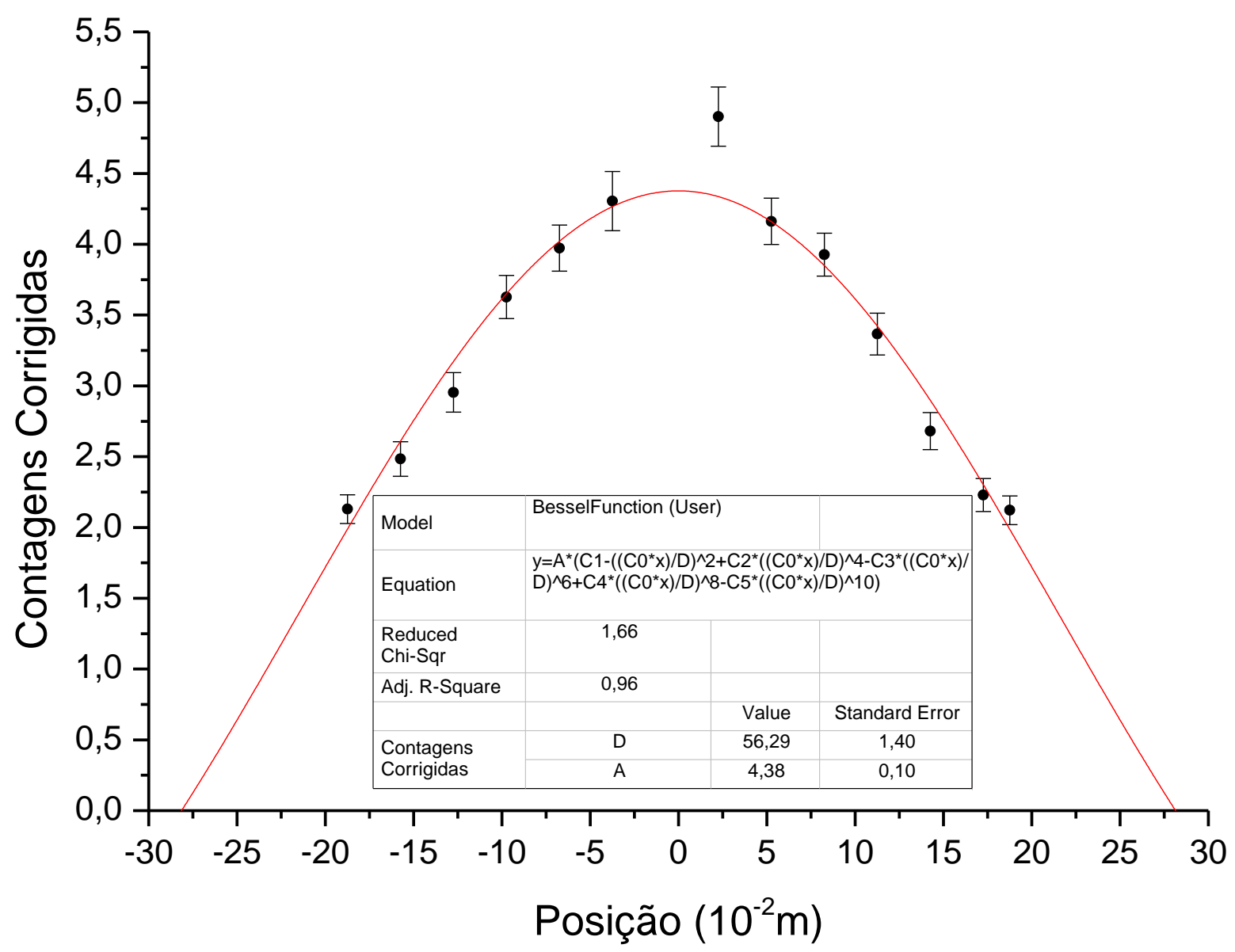

Figura 4.5: Gráfico do Perfil de Contagens por Posição na direção Leste-Oeste para ${ }^{143} \mathrm{Ce}$ correspondente ao perfil do fluxo de neutrons térmicos. 


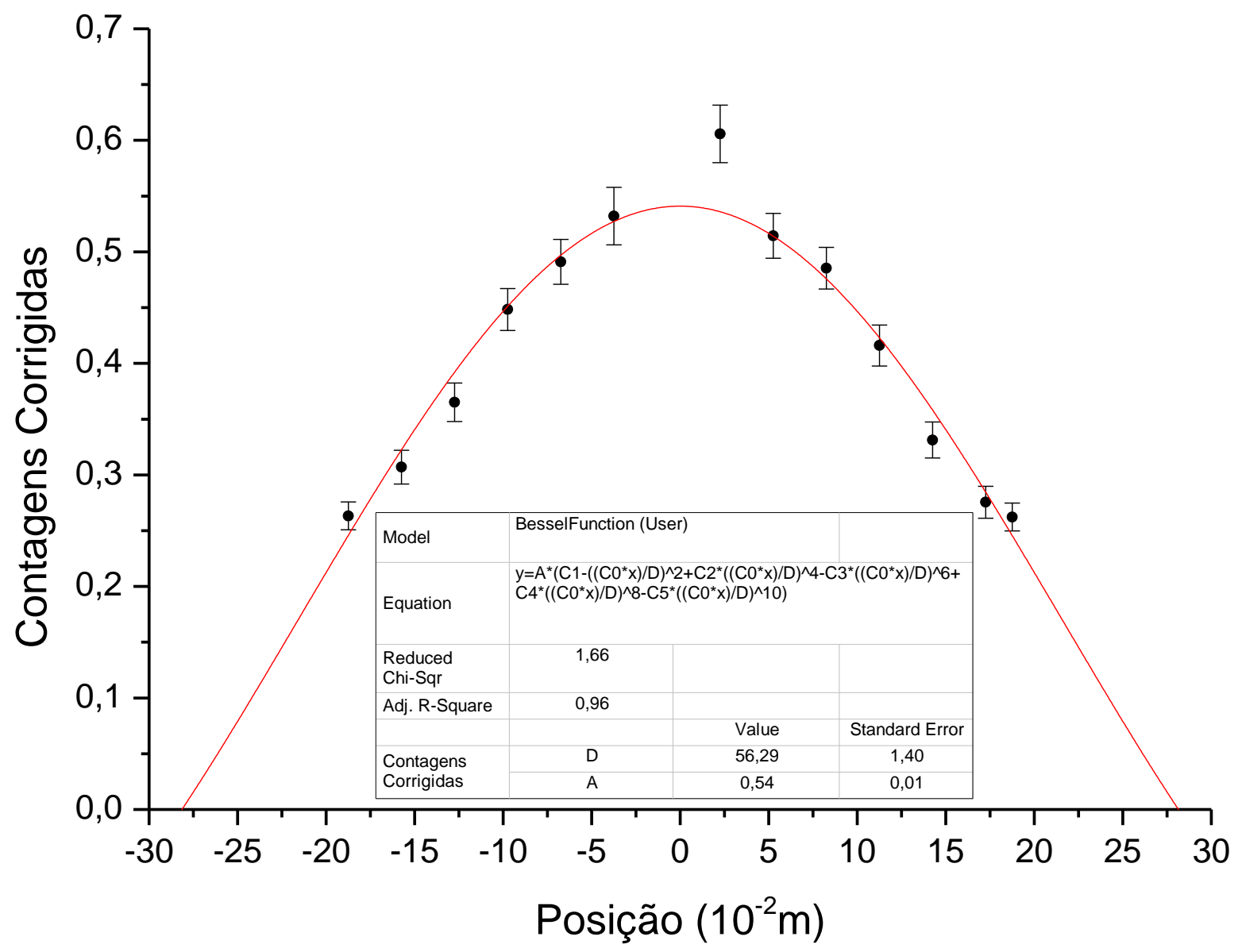

Figura 4.6: Gráfico do Perfil de Contagens por Posição na direção Leste-Oeste para ${ }^{143} \mathrm{Ce}$ correspondente ao perfil do fluxo de neutrons epitérmicos. 


\subsubsection{Direção Radial Norte - Sul à Vareta Combustível}

Na Figura 4.7 é mostrado o perfil de distribuição do fluxo de neutrons térmicos e epitérmicos na direção radial norte - sul e também o ajuste efetuado para determinar o raio efetivo, a partir das taxas de contagem corrigidas do fotopico de 276,6 keV do ${ }^{239} \mathrm{~Np}$.

Na Figura 4.8 é mostrado o perfil da distribuição do fluxo de neutrons térmicos e epitérmicos na direção radial norte - sul e o ajuste feito para determinar o raio efetivo, a partir das taxas de contagem corrigidas do fotopico gama de 293,3 keV do ${ }^{143} \mathrm{Ce}$.

Na Figura 4.9 é mostrado o perfil de distribuição do fluxo de neutrons térmicos na direção radial norte - sul e também o ajuste efetuado para determinar o raio efetivo, a partir das taxas de contagem corrigidas do fotopico de $276,6 \mathrm{keV}$ do ${ }^{239} \mathrm{~Np}$.

Na Figura 4.10 é mostrado o perfil de distribuição do fluxo de neutrons epitérmicos na direção radial norte - sul e também o ajuste efetuado para determinar o raio efetivo, a partir das taxas de contagem corrigidas do fotopico de 276,6 keV do ${ }^{239} \mathrm{~Np}$.

Na Figura 4.11 é mostrado o perfil da distribuição do fluxo de neutrons térmicos na direção radial norte - sul e o ajuste feito para determinar o raio efetivo, a partir das taxas de contagem corrigidas do fotopico gama de $293,3 \mathrm{keV}$ do ${ }^{143} \mathrm{Ce}$.

$\mathrm{Na}$ Figura 4.12 é mostrado o perfil da distribuição do fluxo de neutrons epitérmicos na direção radial norte - sul e o ajuste feito para determinar o raio efetivo, a partir das taxas de contagem corrigidas do fotopico gama de 293,3 keV do ${ }^{143} \mathrm{Ce}$. 


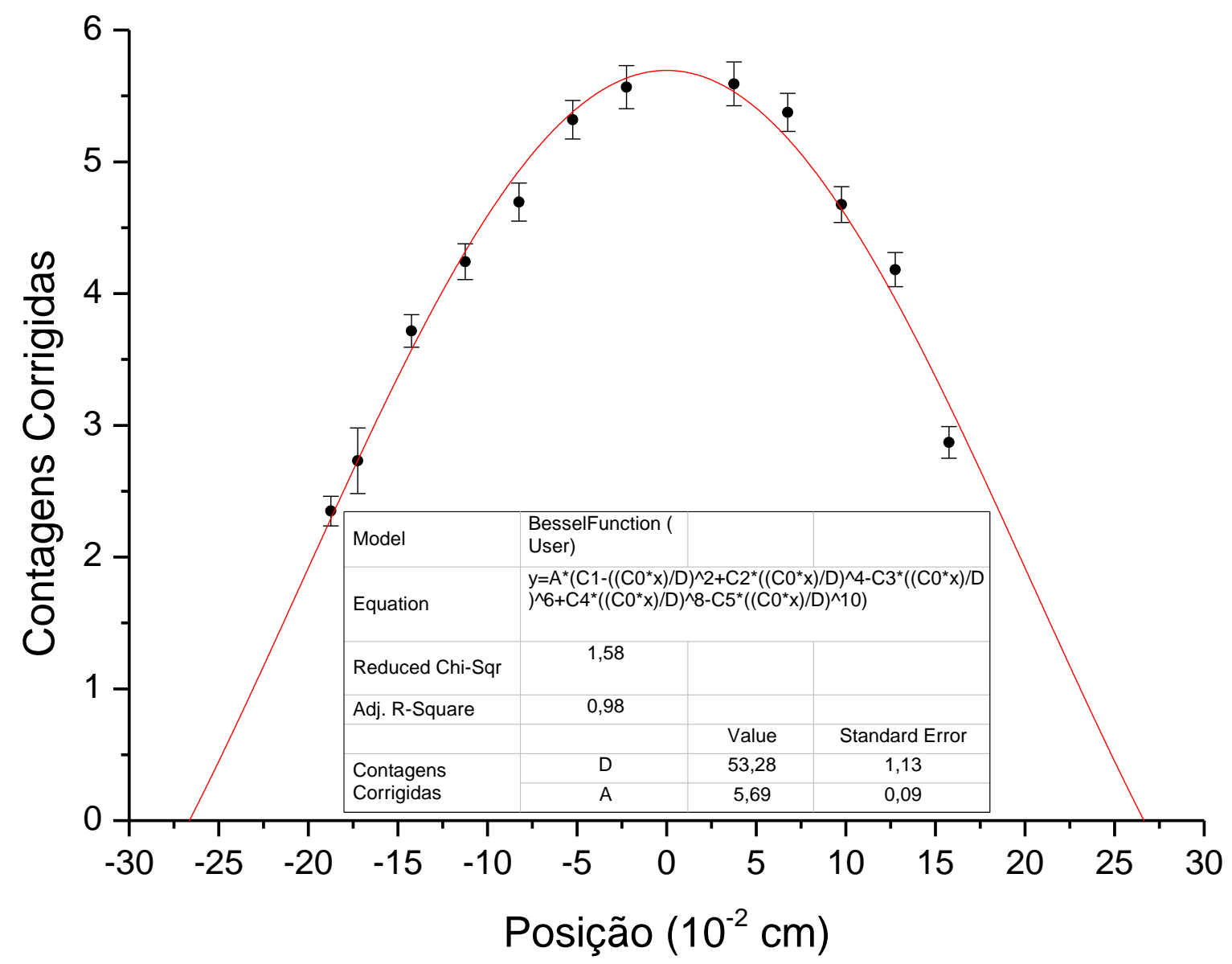

Figura 4.7: Gráfico do Perfil de Contagens por Posição na direção norte - sul para ${ }^{239} \mathrm{~Np}$ correspondente ao perfil do fluxo de neutrons térmicos e epitérmicos. 


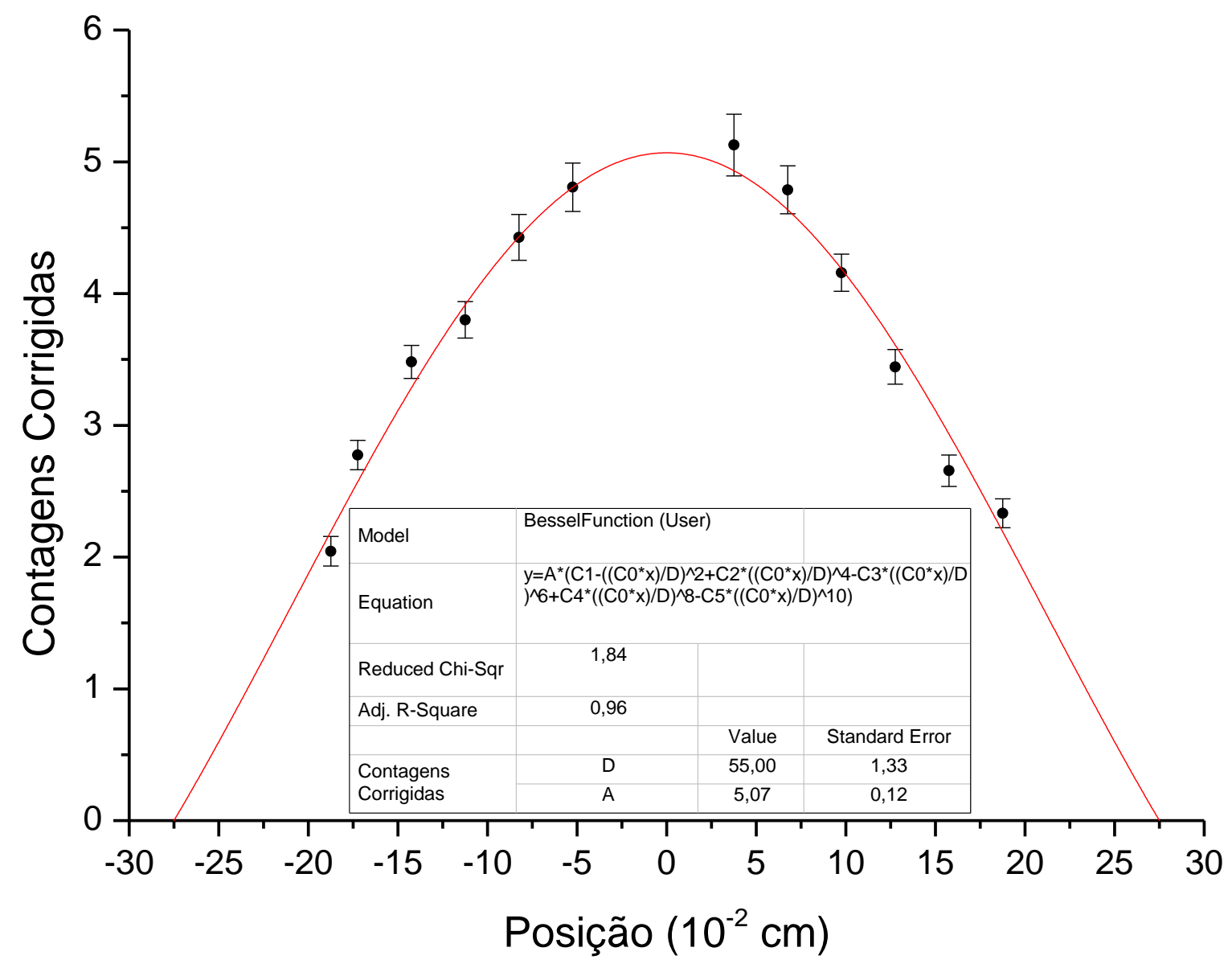

Figura 4.8: Gráfico do Perfil de Contagens por Posição na direção norte - sul para ${ }^{143} \mathrm{Ce}$ correspondente ao perfil do fluxo de neutrons térmicos e epitérmicos. 


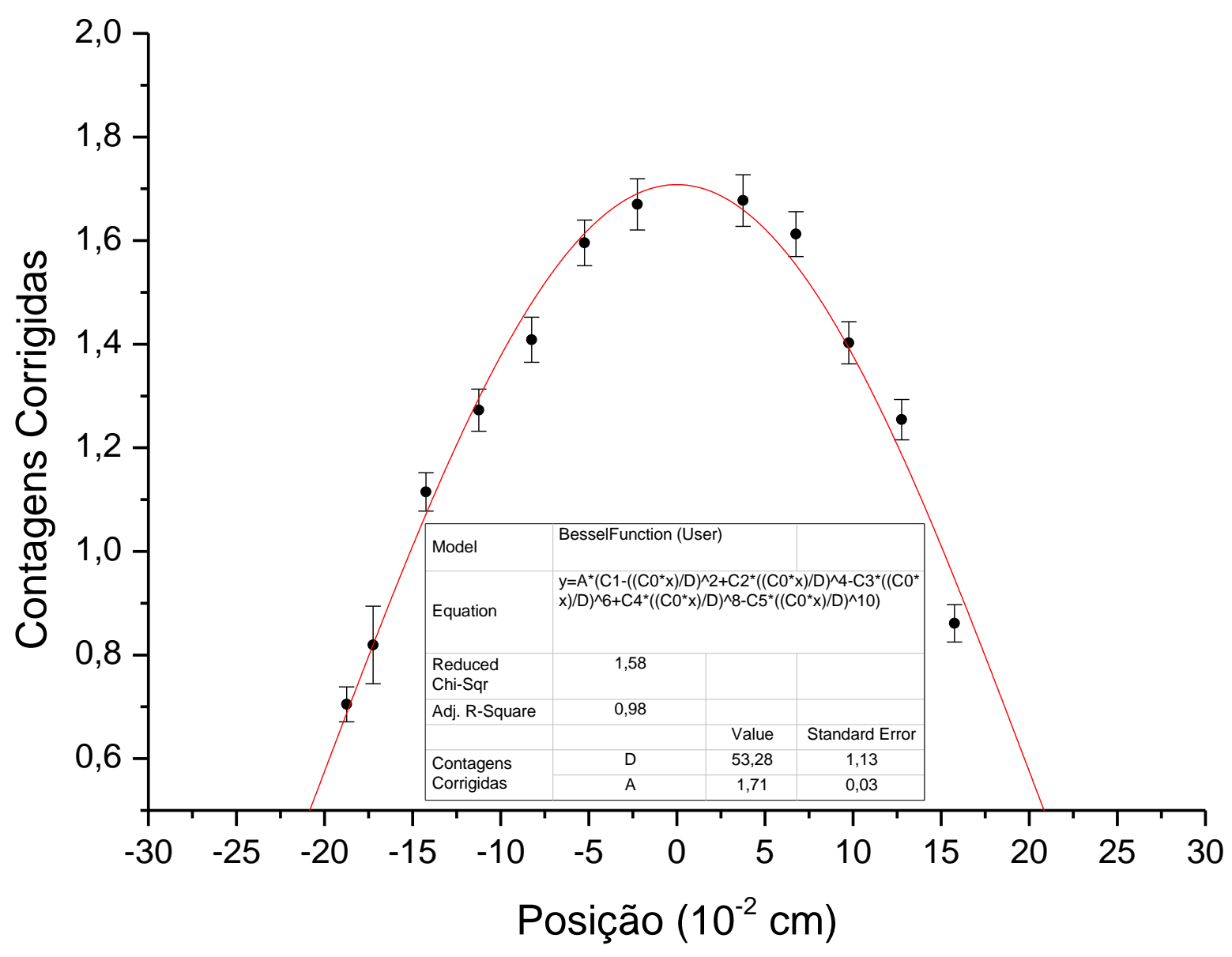

Figura 4.9: Gráfico do Perfil de Contagens por Posição na direção norte - sul para ${ }^{239} \mathrm{~Np}$ correspondente ao perfil do fluxo de neutrons térmicos. 


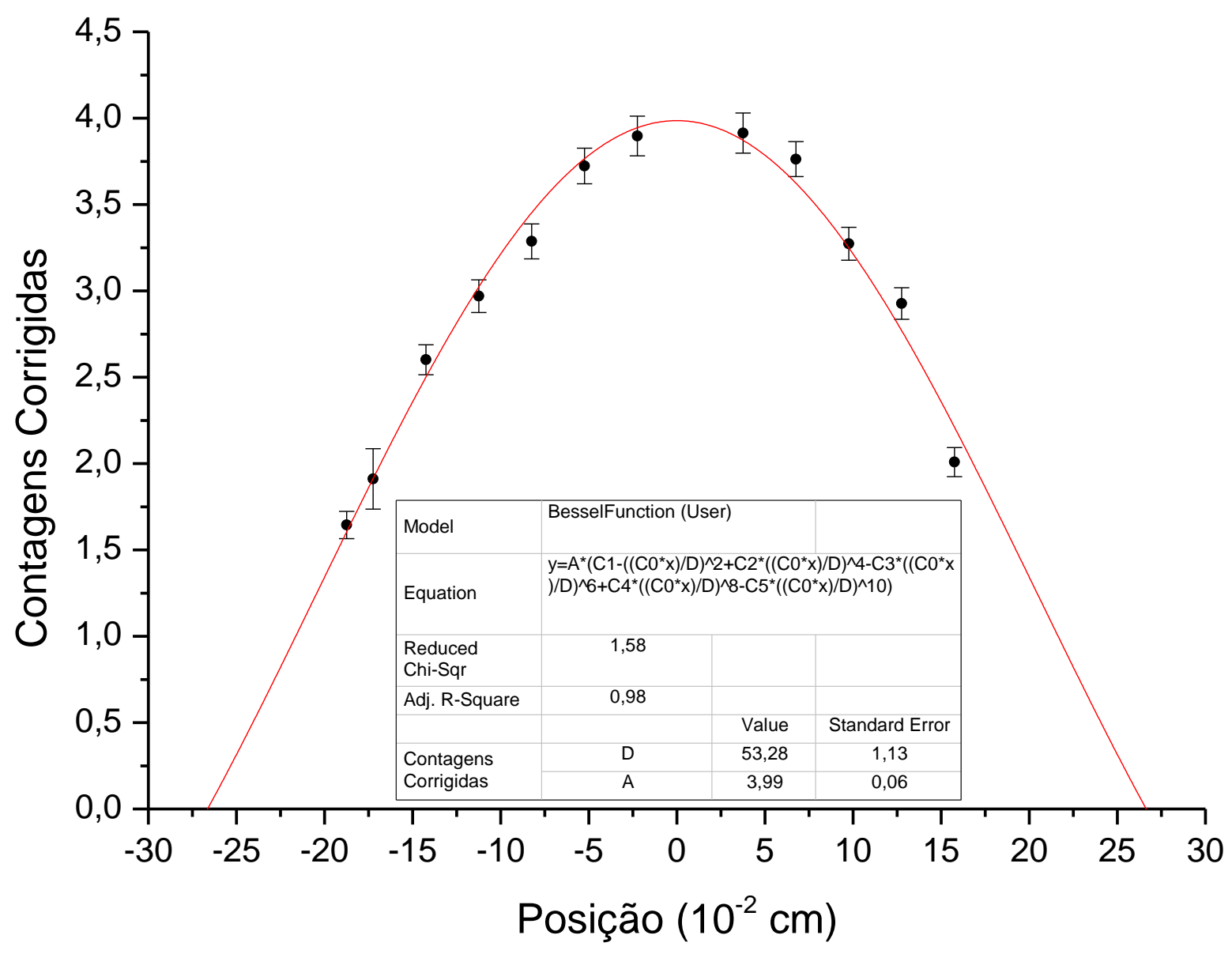

Figura 4.10: Gráfico do Perfil de Contagens por Posição na direção norte - sul para ${ }^{239} \mathrm{~Np}$ correspondente ao perfil do fluxo de neutrons epitérmicos. 


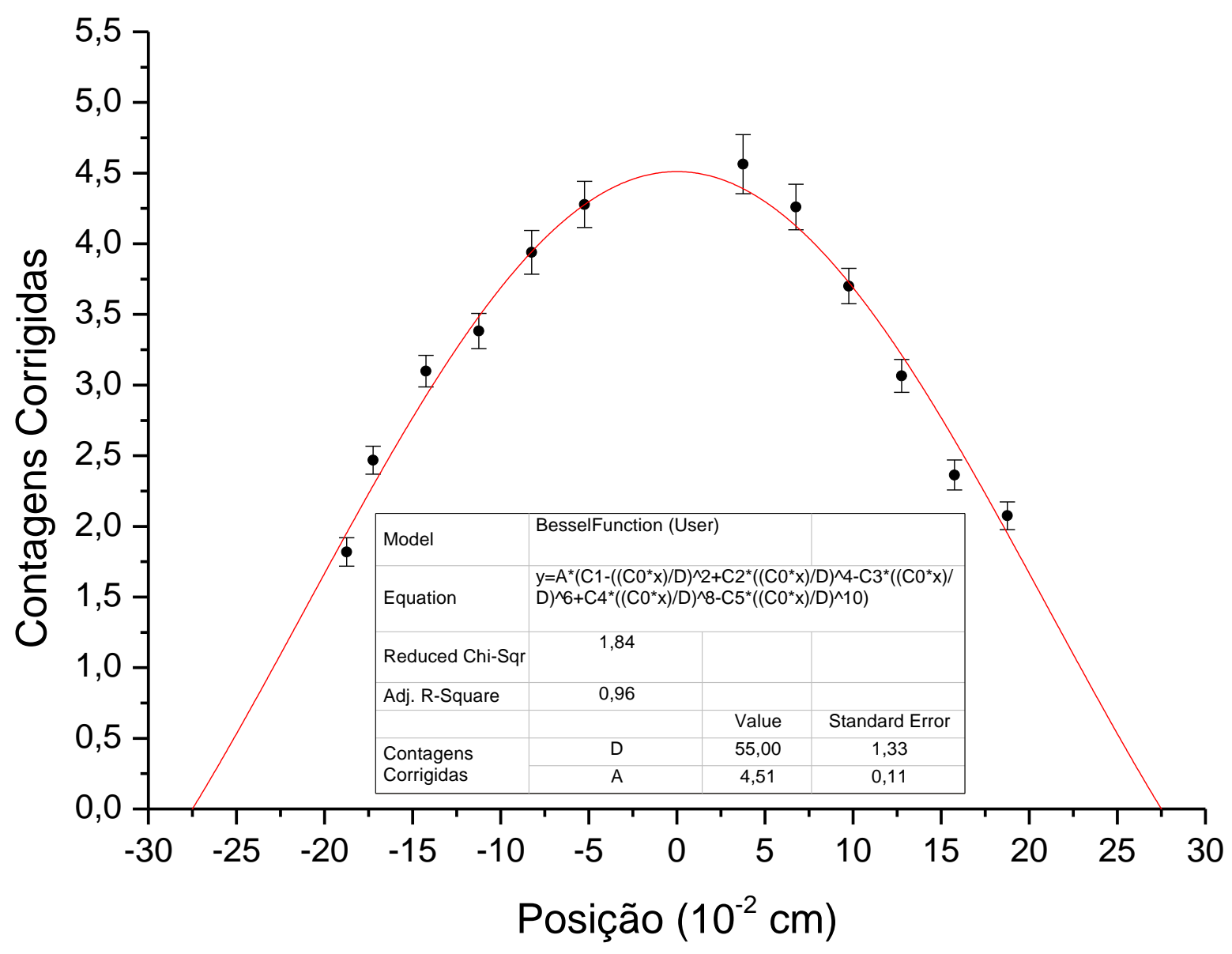

Figura 4.11: Gráfico do Perfil de Contagens por Posição na direção norte - sul para ${ }^{143} \mathrm{Ce}$ correspondente ao perfil do fluxo de neutrons térmicos. 


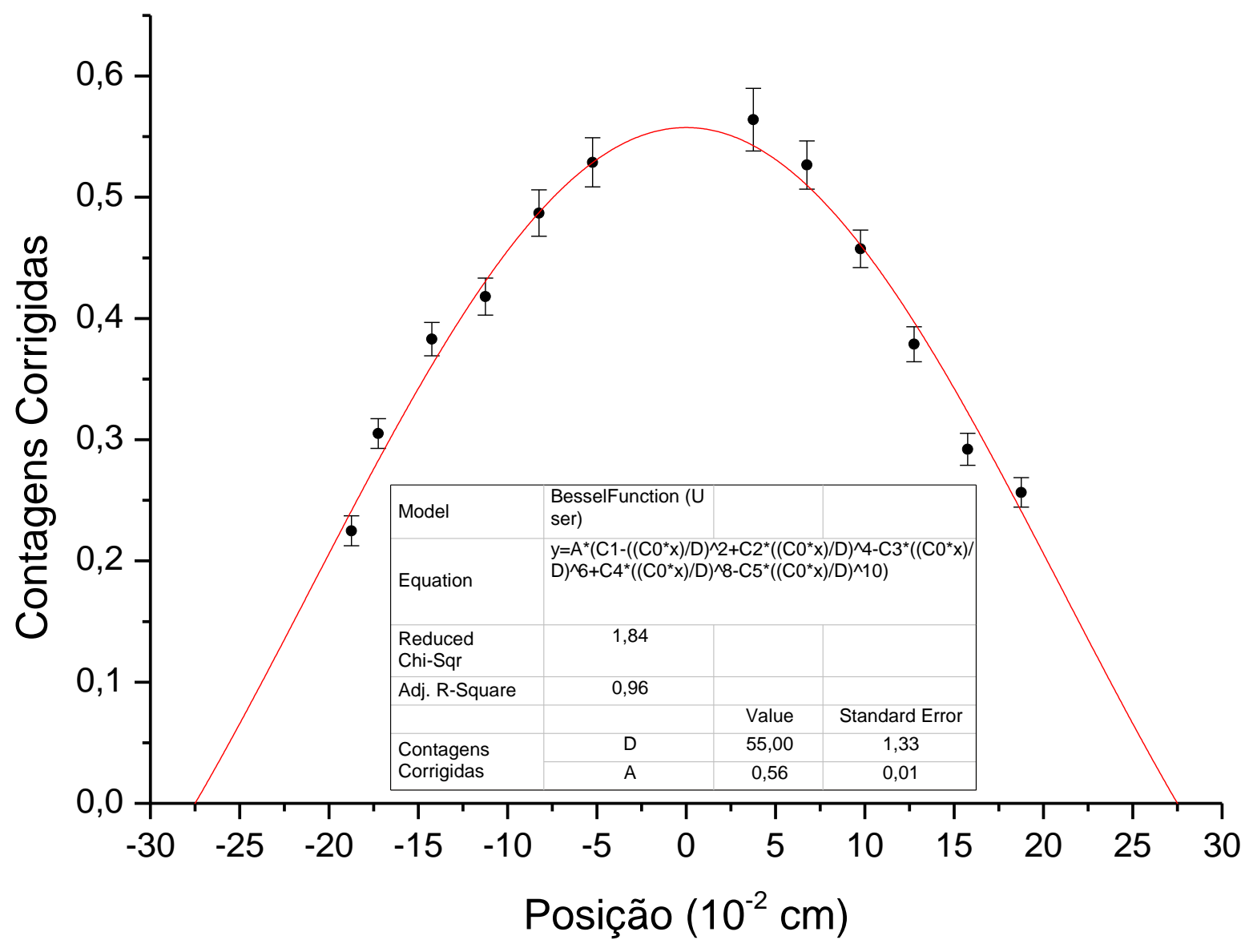

Figura 4.12: Gráfico do Perfil de Contagens por Posição na direção norte - sul para ${ }^{143} \mathrm{Ce}$ correspondente ao perfil do fluxo de neutrons epitérmicos. 


\subsubsection{Direção Axial à Vareta Combustível}

Na Figura 4.13 é mostrado o perfil de distribuição do fluxo de neutrons térmicos e epitérmicos na direção axial e também o ajuste efetuado para determinar a altura efetiva, a partir das taxas de contagem corrigidas do fotopico de 276,6 keV do ${ }^{239} \mathrm{~Np}$.

Na Figura 4.14 é mostrado o perfil da distribuição do fluxo de neutrons térmicos e epitérmicos na direção axial e o ajuste feito para determinar a altura efetiva, a partir das taxas de contagem corrigidas do fotopico gama de $293,3 \mathrm{keV}$ do ${ }^{143} \mathrm{Ce}$.

Na Figura 4.15 é mostrado o perfil de distribuição do fluxo de neutrons térmicos na direção axial e também o ajuste efetuado para determinar a altura efetiva, a partir das taxas de contagem corrigidas do fotopico de $276,6 \mathrm{keV}$ do ${ }^{239} \mathrm{~Np}$.

$\mathrm{Na}$ Figura 4.16 é mostrado o perfil de distribuição do fluxo de neutrons epitérmicos na direção axial e também o ajuste efetuado para determinar a altura efetiva, a partir das taxas de contagem corrigidas do fotopico de 276,6 keV do ${ }^{239} \mathrm{~Np}$.

Na Figura 4.17 é mostrado o perfil da distribuição do fluxo de neutrons térmicos na direção axial e o ajuste feito para determinar a altura efetiva, a partir das taxas de contagem corrigidas do fotopico gama de $293,3 \mathrm{keV}$ do ${ }^{143} \mathrm{Ce}$.

$\mathrm{Na}$ Figura 4.18 é mostrado o perfil da distribuição do fluxo de neutrons epitérmicos na direção axial e o ajuste feito para determinar a altura efetiva, a partir das taxas de contagem corrigidas do fotopico gama de $293,3 \mathrm{keV}$ do ${ }^{143} \mathrm{Ce}$. 


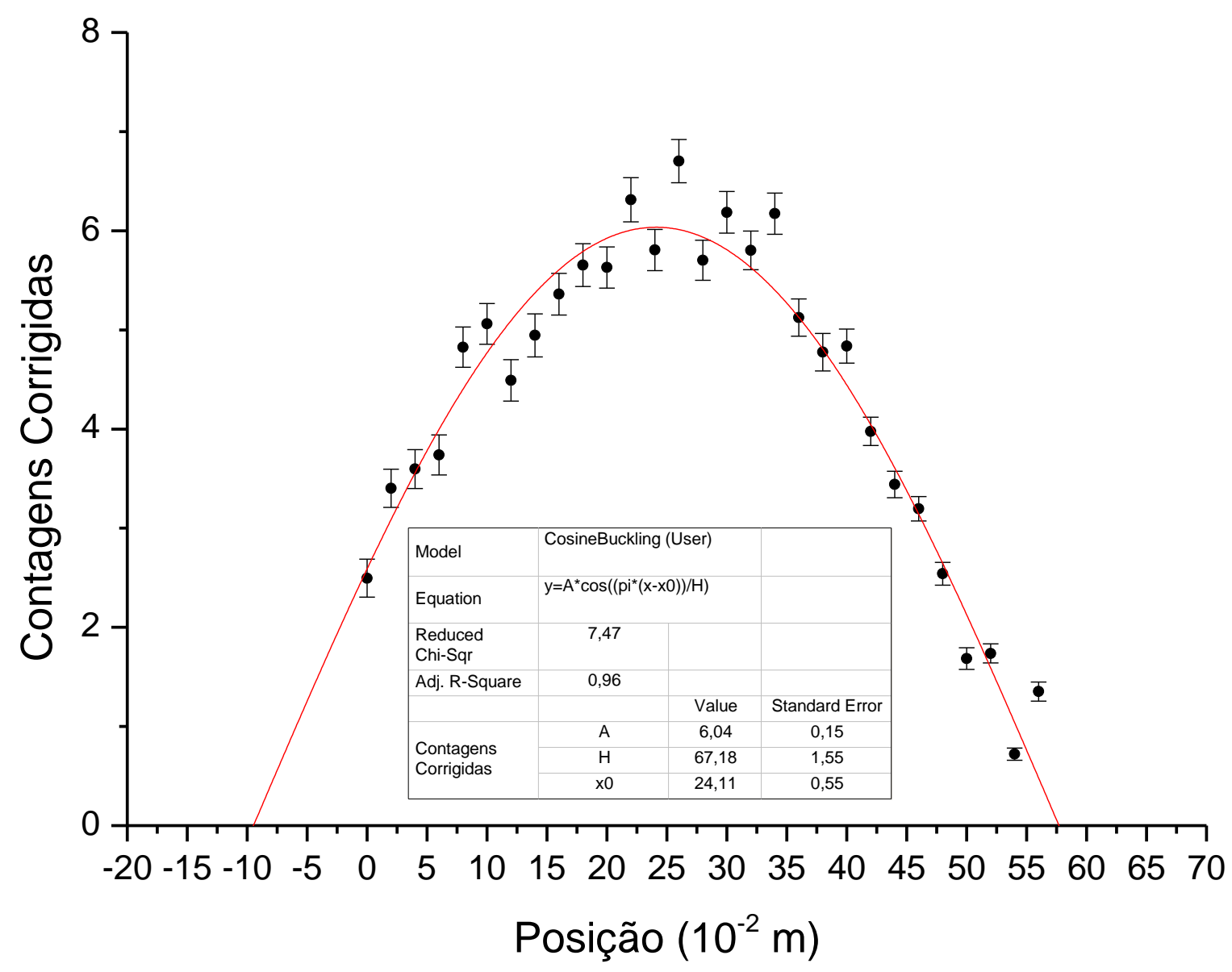

Figura 4.13: Gráfico do Perfil de Contagens por Posição na direção axial para ${ }^{239} \mathrm{~Np}$ correspondente ao perfil do fluxo de neutrons térmicos e epitérmicos. 


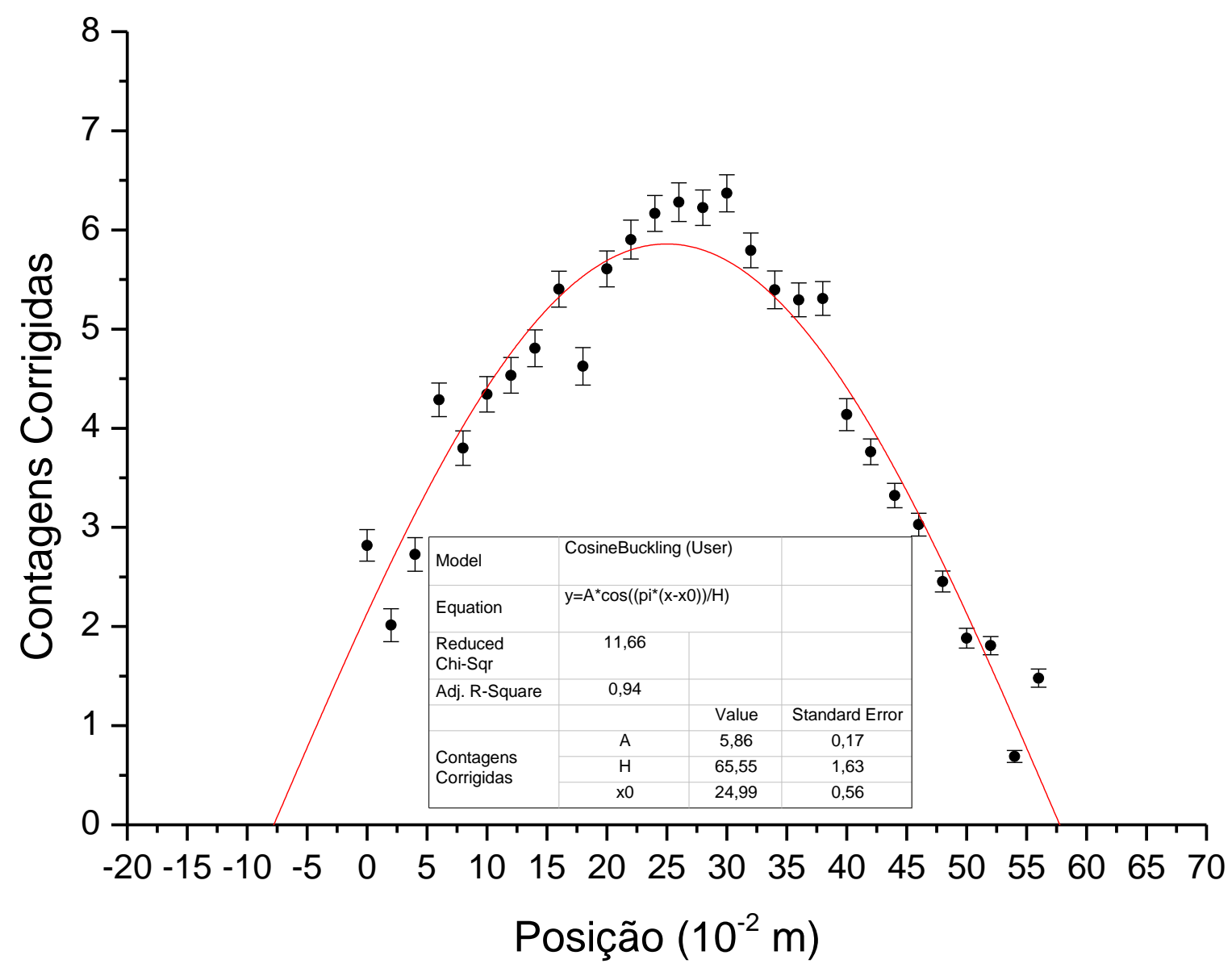

Figura 4.14: Gráfico do Perfil de Contagens por Posição na direção axial para ${ }^{143} \mathrm{Ce}$ correspondente ao perfil do fluxo de neutrons térmicos e epitérmicos. 


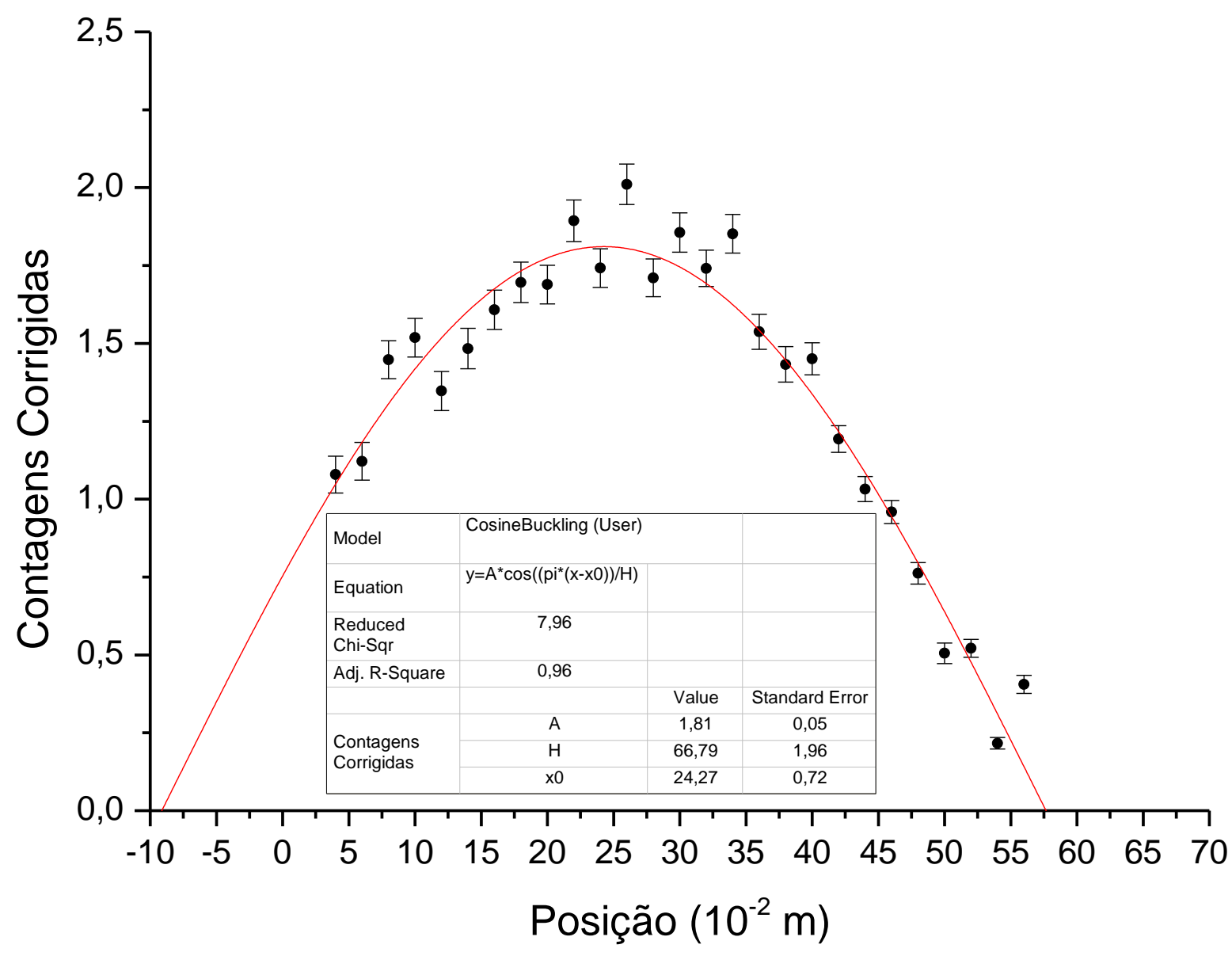

Figura 4.15: Gráfico do Perfil de Contagens por Posição na direção axial para ${ }^{239} \mathrm{~Np}$ correspondente ao perfil do fluxo de neutrons térmicos. 


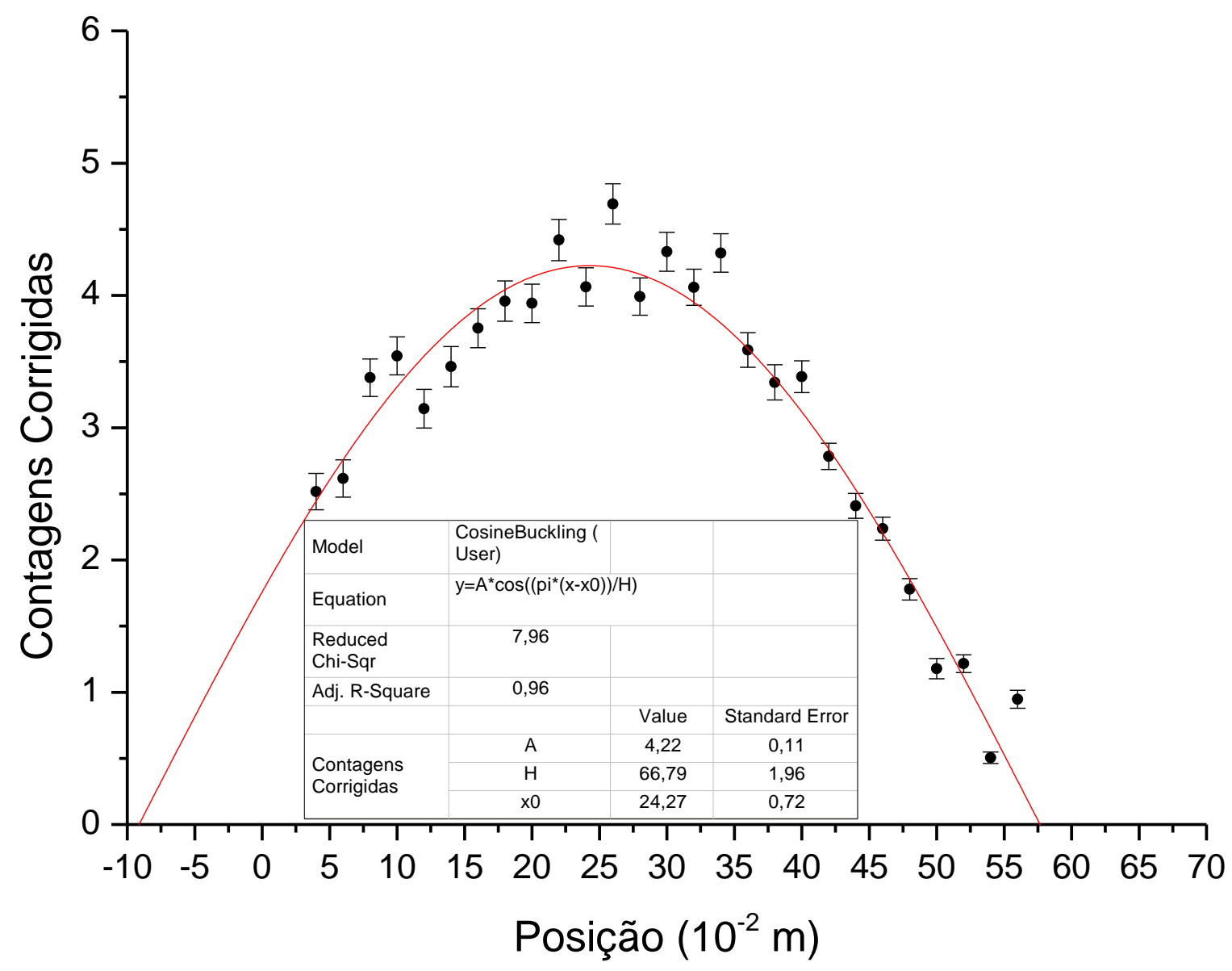

Figura 4.16: Gráfico do Perfil de Contagens por Posição na direção axial para ${ }^{239} \mathrm{~Np}$ correspondente ao perfil do fluxo de neutrons epitérmicos. 


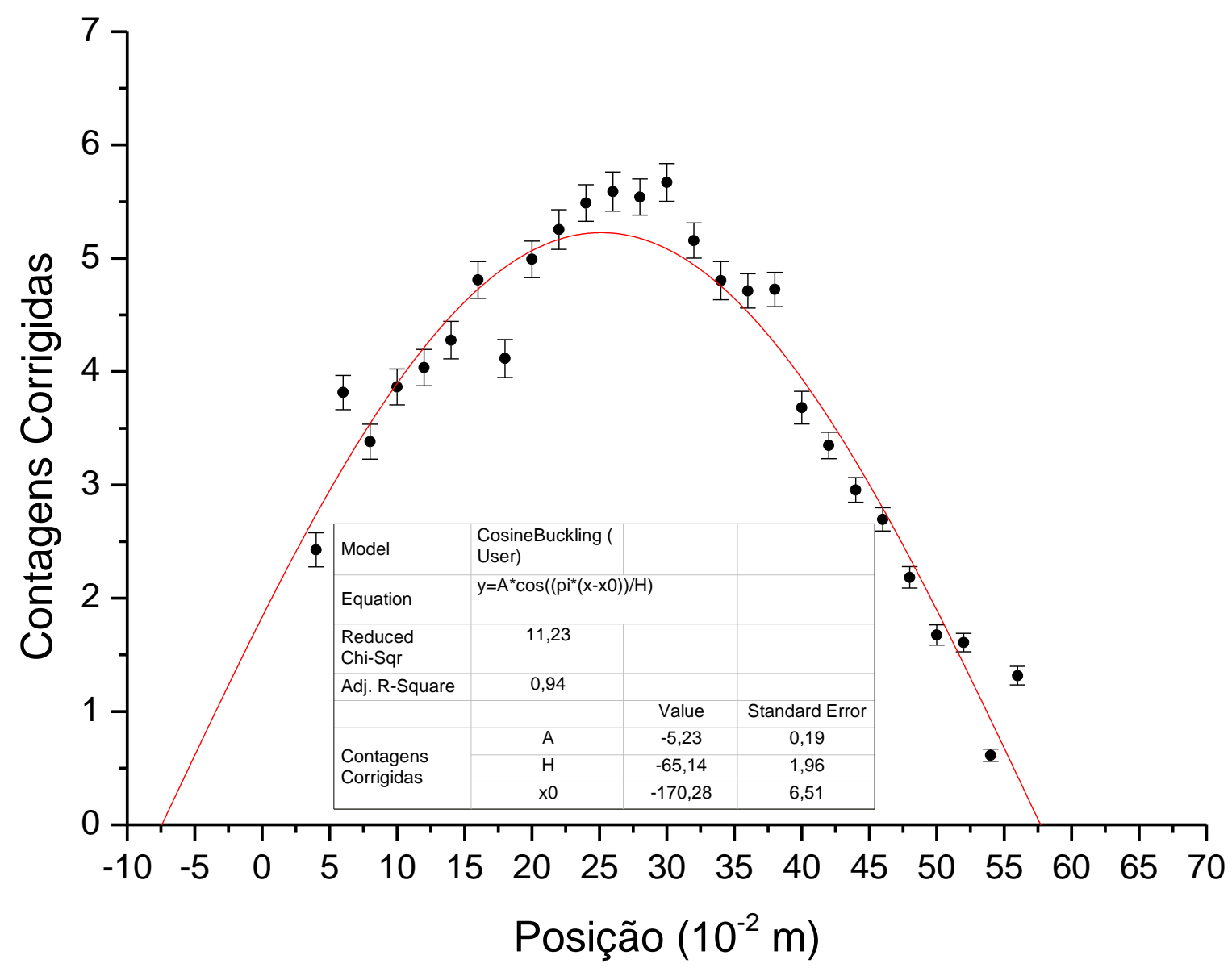

Figura 4.17: Gráfico do Perfil de Contagens por Posição na direção axial para ${ }^{143} \mathrm{Ce}$ correspondente ao perfil do fluxo de neutrons térmicos. 


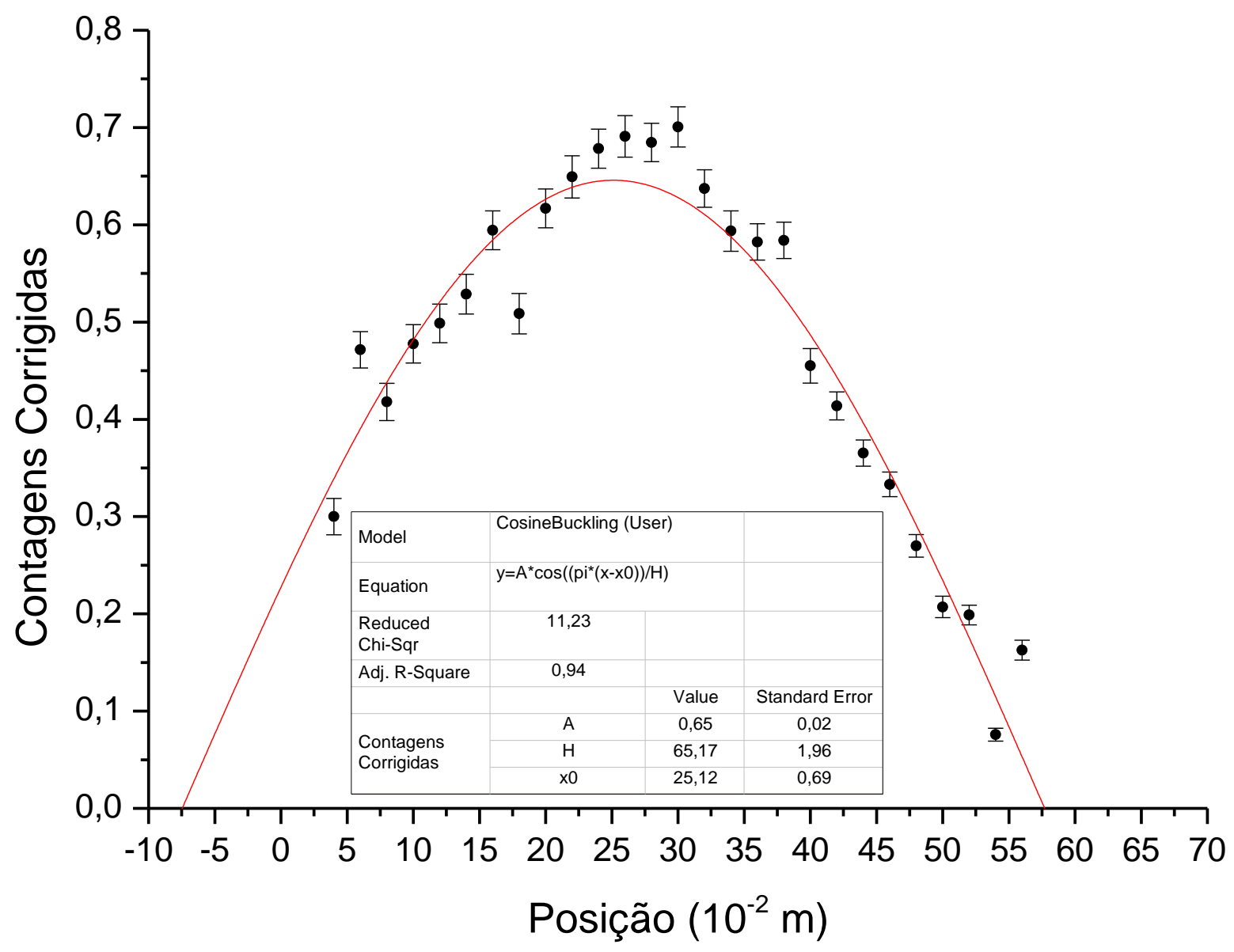

Figura 4.18: Gráfico do Perfil de Contagens por Posição na direção axial para ${ }^{143} \mathrm{Ce}$ correspondente ao perfil do fluxo de neutrons epitérmicos. 


\subsubsection{Buckling das Varetas Combustível}

A partir dos gráficos e ajustes das Figuras de 4.1 a 4.18 foram obtidos os raios e altura efetivos e o Buckling total das varetas de combustível do reator para os neutrons térmicos e epitérmicos.

A Tabela 4.1 apresenta os dados gerais obtidos para as varetas combustiveis, ou seja, sem separação dos neutrons térmicos e epitérmicos. Os dados são apresentados para as medidas com os fotopicos do ${ }^{239} \mathrm{~Np} \mathrm{e}{ }^{143} \mathrm{Ce}$.

Tabela 4.1: Dados obtidos e calculo do Buckling para neutrons térmicos e epitérmicos para as varetas combustiveis.

\begin{tabular}{|l|c|r|r|}
\hline Geral & Raio $\left(\mathbf{1 0}^{-\mathbf{2}} \mathbf{m}\right)$ & Altura $\left(\mathbf{1 0}^{-\mathbf{2}} \mathbf{~} \mathbf{)}\right.$ & $\mathbf{B}^{\mathbf{2}}$ Geral $\left.\mathbf{( m}^{-\mathbf{2}}\right)$ \\
\hline${ }^{239} \mathrm{~Np}$ & $26,64 \pm 0,56$ & $67,18 \pm 1,55$ & $\mathbf{1 0 3 , 3 7 \pm \mathbf { 3 , 5 7 }}$ \\
\hline${ }^{143} \mathrm{Ce}$ & $27,50 \pm 0,66$ & $65,55 \pm 1,63$ & $\mathbf{9 9 , 4 5} \pm \mathbf{3 , 8 4}$ \\
\hline
\end{tabular}

A Tabela 4.2 apresenta os dados obtidos para as varetas combustiveis a partir dos neutrons térmicos. Para obtenção dos dados foram utilizadas as informações dos indices espectrais ${ }^{28} \rho$ e ${ }^{25} \delta$ obtidos por Bitelli, $2001^{29}$. Esses indices ${ }^{33}$ estão associados à razão da taxa de reação nuclear de captura epitérmica no ${ }^{238} \mathrm{U}$ pela taxa de reação nuclear de captura radioativa no ${ }^{238} \mathrm{U}$ para o indice ${ }^{28} \rho$ e a razão da taxa de reação nuclear de fissão epitérmica no ${ }^{235} \mathrm{U}$ pela taxa de reação nuclear de fissão térmica no ${ }^{235} \mathrm{U}$ para o indice ${ }^{25} \delta$. Esses índices espectrais são necessários para discriminar as taxas de reação nuclear térmicas e epitérmicas no ${ }^{235} \mathrm{U}$ e ${ }^{238} \mathrm{U}$ obtidas da varredura gama (gamma scanning) das varetas combustíveis sem a necessidade de se usar um filtro neutrônico como o cádmio que sempre introduz uma perturbação significativa no sistema ${ }^{29,33}$. 
Tabela 4.2: Dados obtidos e calculo do Buckling para neutrons térmicos para as varetas combustiveis.

\begin{tabular}{|l|r|r|r|}
\hline Térmico & Raio $\left(\mathbf{1 0}^{-\mathbf{2}} \mathbf{m}\right)$ & Altura $\left(\mathbf{1 0}^{-\mathbf{2}} \mathbf{~}\right)$ & $\mathbf{B}^{2}$ Térmico $\left.\mathbf{( m}^{-\mathbf{2}}\right)$ \\
\hline${ }^{239} \mathrm{~Np}$ & $26,64 \pm 0,56$ & $66,79 \pm 1,96$ & $\mathbf{1 0 3 , 6 3} \mathbf{3 , 6 6}$ \\
\hline${ }^{143} \mathrm{Ce}$ & $27,50 \pm 0,66$ & $65,17 \pm 1,96$ & $\mathbf{9 9 , 7 2} \pm \mathbf{3 , 9 3}$ \\
\hline
\end{tabular}

A Tabela 4.3 apresenta os dados obtidos para as varetas combustiveis a partir dos neutrons epitérmicos. Os dados são apresentados para as medidas com os fotopicos do ${ }^{239} \mathrm{~Np} \mathrm{e}{ }^{143} \mathrm{Ce}$.

Tabela 4.3: Dados obtidos e calculo do Buckling para neutrons epitérmicos para as varetas combustiveis.

\begin{tabular}{|l|r|r|r|}
\hline Epitérmico & Raio $\left.\mathbf{( 1 0 ^ { - 2 }} \mathbf{m}\right)$ & Altura $\left(\mathbf{1 0}^{-\mathbf{2}} \mathbf{m}\right)$ & $\left.\mathbf{B}^{2}{ }_{\text {Epitérmico }} \mathbf{( m}^{-\mathbf{2}}\right)$ \\
\hline${ }^{239} \mathrm{~Np}$ & $26,64 \pm 0,56$ & $66,79 \pm 1,96$ & $\mathbf{1 0 3 , 6 3} \pm \mathbf{3 , 6 6}$ \\
\hline${ }^{143} \mathrm{Ce}$ & $27,50 \pm 0,66$ & $65,17 \pm 1,96$ & $\mathbf{9 9 , 7 2} \pm \mathbf{3 , 9 3}$ \\
\hline
\end{tabular}

Observa-se, a partir dos resultados obtidos para as varetas combustiveis e apresentados nas tabelas 4.1, 4.2 e 4.3, que os valores de Buckling para as varetas combustiveis apresentam diferenças dentro da margem de erro calculada e nos casos de térmico e epitérmico separados, o resultado foi idêntico.

\subsection{Medidas obtidas para os fios de ouro}

A seguir, são apresentados os gráficos com os perfis de fluxo de nêutrons obtidos para os fios de ouro nas direções radial e axial. As medidas para a direção radial foram realizadas apenas na direção leste - oeste, uma vez que o dispositivo móvel articulado, no qual o fio é ajustado e inserido no núcleo, não entra nos canais de irradiação da direção norte - sul, pois nesta direção estão 
colocados os tubulões dos canais nucleares do reator. Tal fato, não interfere nos resultados uma vez que existe simetria do núcleo, já identificada pelos resultados das varetas combustíveis.

As medidas foram efetuadas com os fios nus, ou seja, o fluxo de neutrons obtido inclue neutrons térmicos e epitérmicos. Porém, é possivel obter a razão de cádmio para o fio de ouro $\left(R_{C d}=2,1\right)$ e o fator de cadmio $\left(F_{C d}=1,325\right)$ da literatura exatamente para as dimensões e composição do fio de ${ }^{197} \mathrm{Au}$ utilizado ${ }^{34}$ e com isso separar a parcela de fluxo de neutrons térmica da epitérmica, através da equação $(33)^{11}$ :

$$
C_{n u a}=C_{t h}+C_{e p i t}
$$

Onde:

$\mathrm{C}_{\text {nua }}$ é a contagem associada ao fluxo de neutrons térmicos e epitérmicos obtida com os fios irradiados sem cobertura de cadmio;

$\mathrm{C}_{\text {th }}$ é a contagem para o fluxo de neutrons térmicos;

$\mathrm{C}_{\text {epit }}$ é a contagem para fluxo de neutrons epitérmicos.

A contagem para neutrons epitérmicos $\left(\mathrm{C}_{\text {epit }}\right)$ é obtida através da equação (34):

$$
C_{\text {epit }}=F_{C d} \frac{C_{n u a}}{R_{C d}}
$$

Com as equações (33) e (34) e conhecidos à razão de cadmio para o fio de ouro, bem como o fator de cadmio, pode-se determinar o perfil dos fluxos térmicos e epitérmicos nas direções radial e axial e consequentemente 0 Buckling obtido a partir da espectroscopia gama dos fios de ouro. 


\subsubsection{Direção radial ao Longo do Núcleo do Reator}

Na Figura 4.19 é mostrado o perfil de distribuição do fluxo de neutrons térmicos e epitérmicos na direção radial leste - oeste para o fio um (01) e também o ajuste efetuado para determinar o raio efetivo, a partir das taxas de contagem corrigidas do fotopico gama de $411,80 \mathrm{keV}$ do ${ }^{198} \mathrm{Au}$.

Na Figura 4.20 é mostrado o perfil de distribuição do fluxo de neutrons térmicos e epitérmicos na direção radial leste - oeste para o fio 02 e também o ajuste efetuado para determinar o raio efetivo, a partir das taxas de contagem corrigidas do fotopico gama de $411,80 \mathrm{keV}$ do ${ }^{198} \mathrm{Au}$.

Nas Figuras 4.21 e 4.22 são mostrados os perfis de distribuição do fluxo de neutrons térmicos na direção radial leste - oeste para os fios 01 e 02 , respectivamente, e também o ajuste efetuado para determinar o raio efetivo, a partir das taxas de contagem corrigidas do fotopico gama de $411,80 \mathrm{keV}$ do ${ }^{198} \mathrm{Au}$.

Nas Figuras 4.23 e 4.24 são mostrados os perfis de distribuição do fluxo de neutrons térmicos e epitérmicos na direção radial leste - oeste para os fios 01 e 02 , respectivamente, e também o ajuste efetuado para determinar o raio efetivo, a partir das taxas de contagem corrigidas do fotopico gama de $411,80 \mathrm{keV}$ do ${ }^{198} \mathrm{Au}$. 


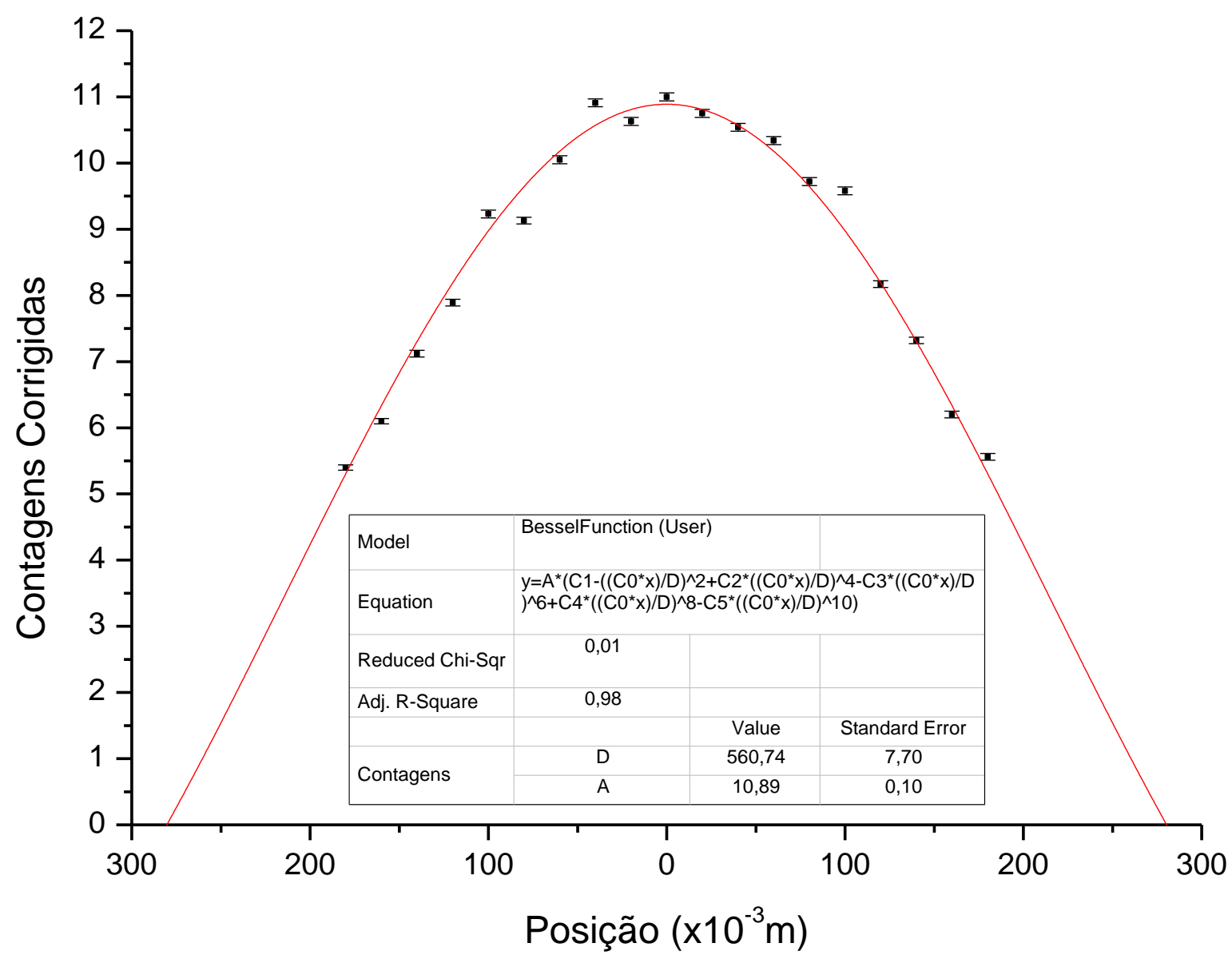

Figura 4.19: Perfil de distribuição do fluxo de neutrons térmicos e epitérmicos na direção radial leste - oeste para o fio de ouro um (01). 


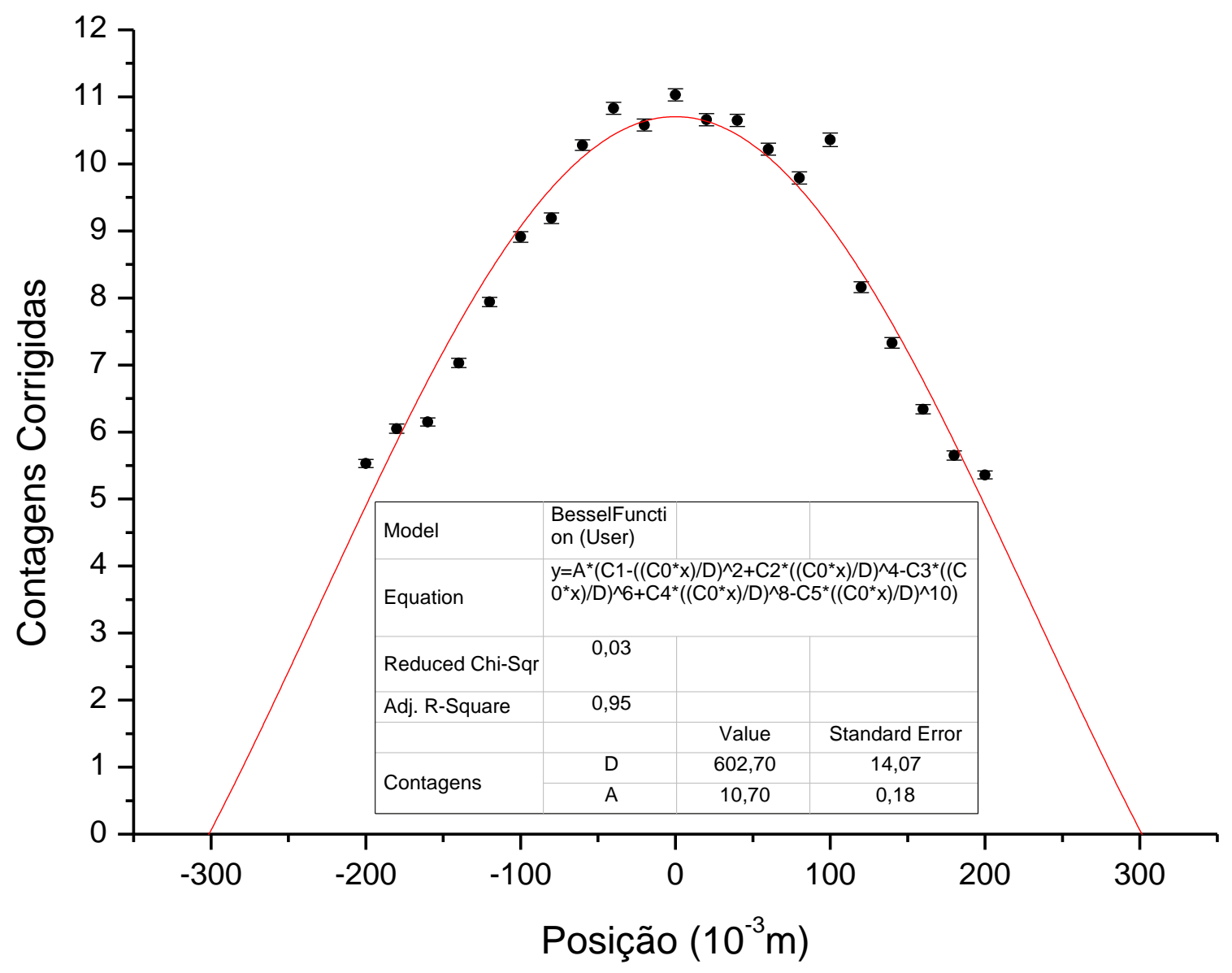

Figura 4.20: Perfil de distribuição do fluxo de neutrons térmicos e epitérmicos na direção radial leste - oeste para o fio de ouro 02. 


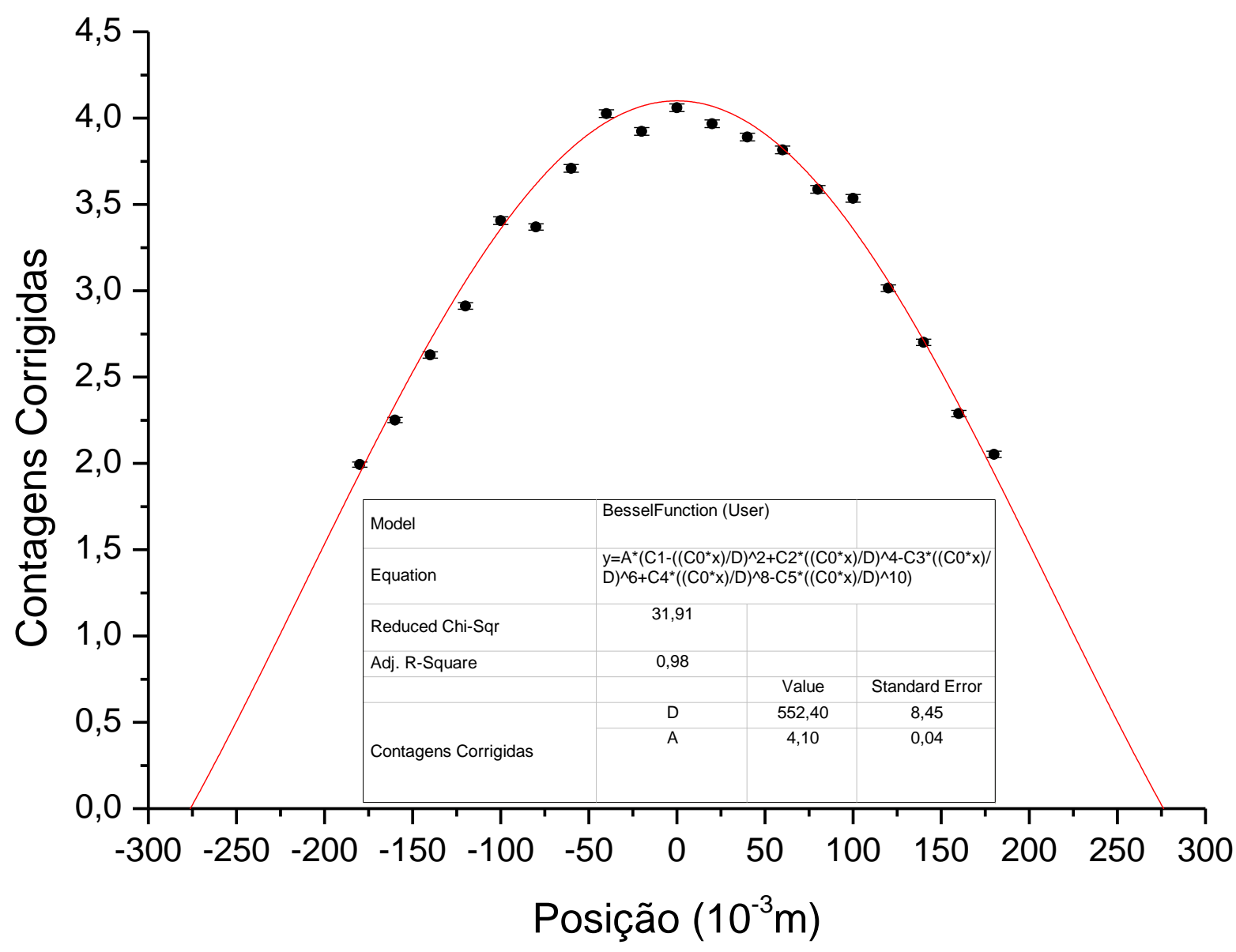

Figura 4.21: Perfil de distribuição do fluxo de neutrons térmicos na direção radial leste - oeste para o fio de ouro um (01). 


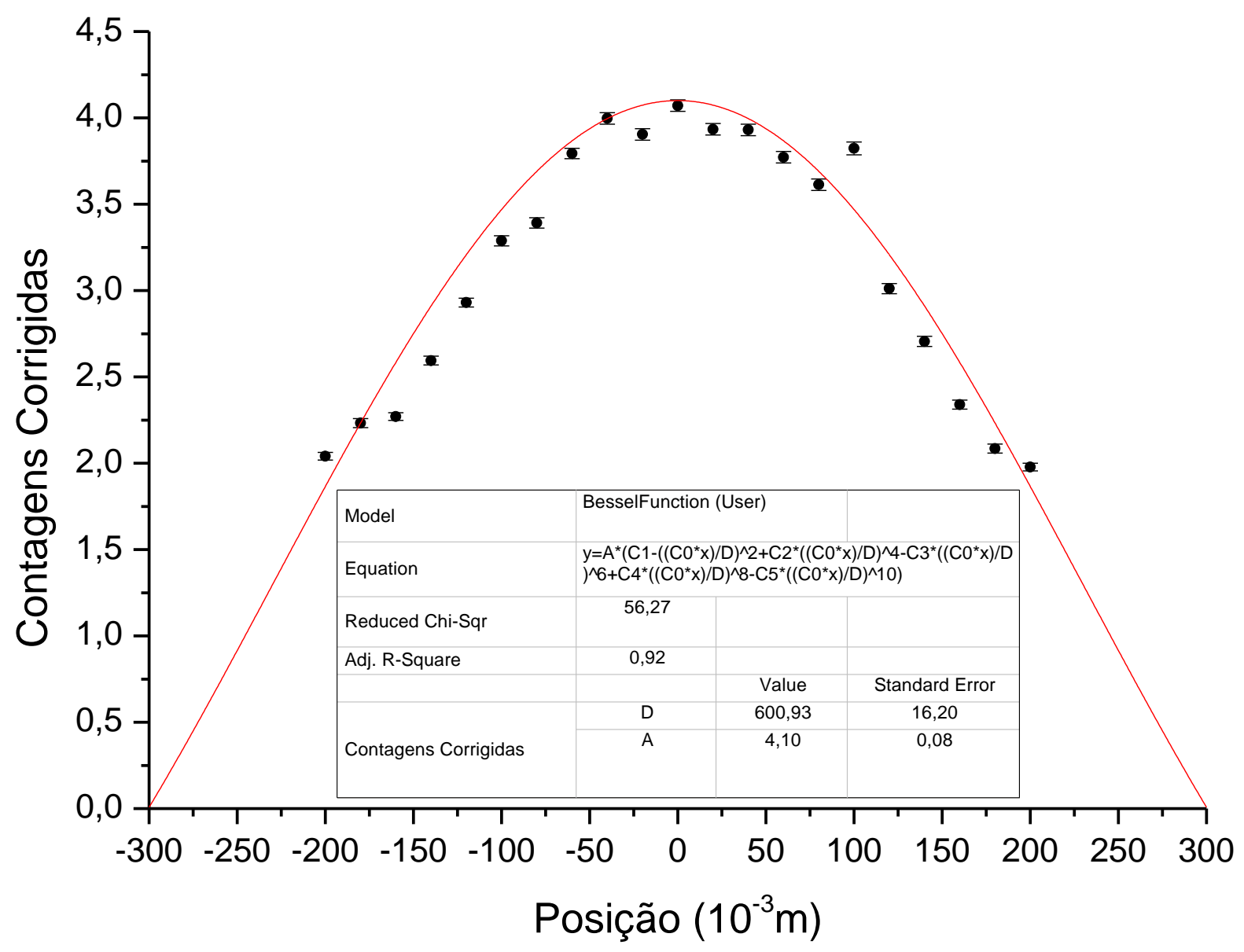

Figura 4.22: Perfil de distribuição do fluxo de neutrons térmicos na direção radial leste - oeste para o fio de ouro 02 


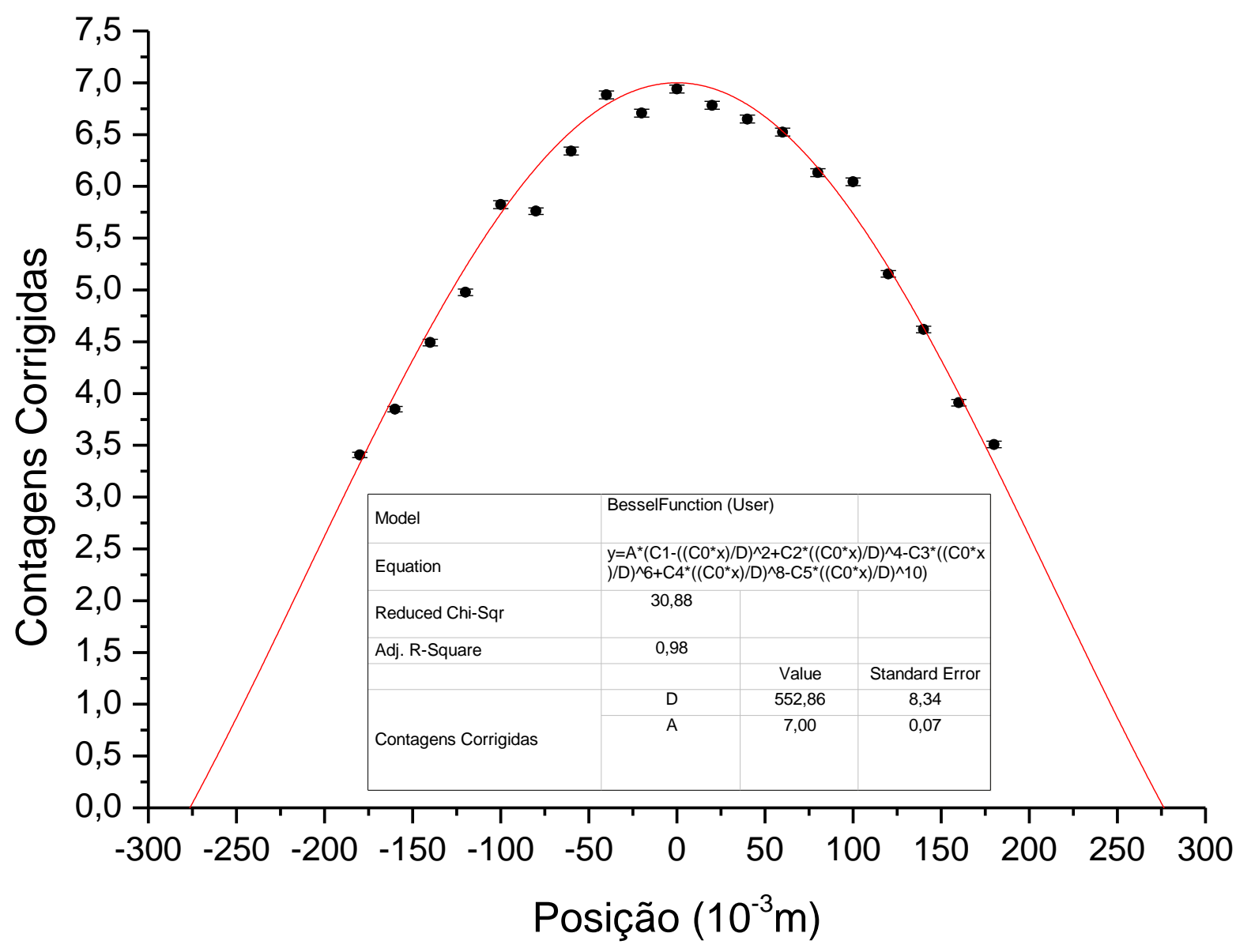

Figura 4.23: Perfil de distribuição do fluxo de neutrons epitérmicos na direção radial leste - oeste para o fio de ouro um (01). 


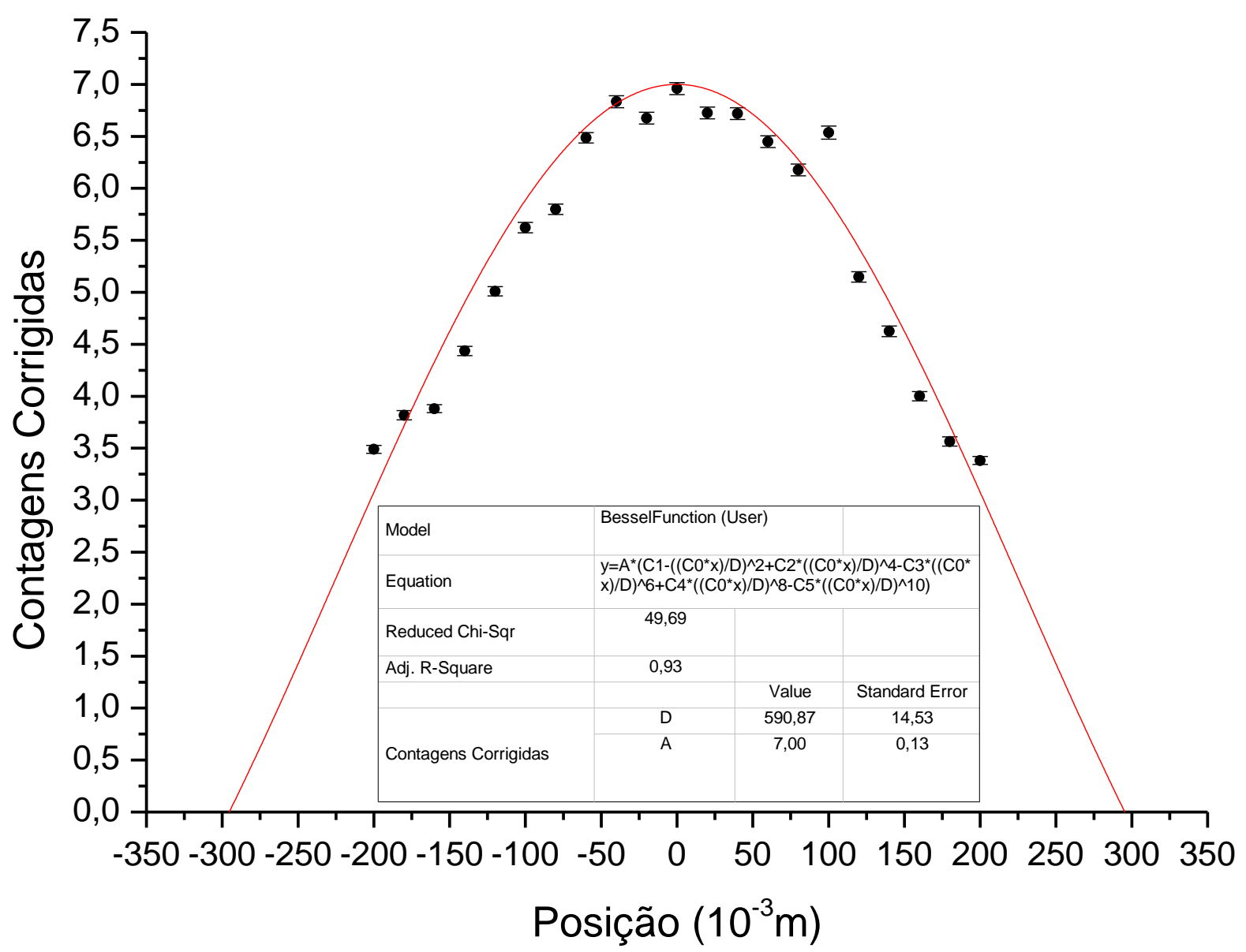

Figura 4.24: Perfil de distribuição do fluxo de neutrons epitérmicos na direção radial leste - oeste para o fio de ouro 02 . 


\subsubsection{Direção Axial ao longo do Núcleo do Reator}

Na Figura 4.25 é mostrado o perfil de distribuição do fluxo de neutrons térmicos e epitérmicos na direção axial para o fio um (01) e também o ajuste efetuado para determinar o raio efetivo, a partir das taxas de contagem corrigidas do fotopico gaam de $411,80 \mathrm{keV}$ do ${ }^{198} \mathrm{Au}$.

Na Figura 4.26 é mostrado o perfil de distribuição do fluxo de neutrons térmicos e epitérmicos na direção axial para o fio 02 e também o ajuste efetuado para determinar o raio efetivo, a partir das taxas de contagem corrigidas do fotopico gama de $411,80 \mathrm{keV}$ do ${ }^{198} \mathrm{Au}$.

Nas Figuras 4.27 e 4.28 são mostrados os perfis de distribuição do fluxo de neutrons térmicos na direção axial para os fios 01 e 02, respectivamente, e também o ajuste efetuado para determinar o raio efetivo, a partir das taxas de contagem corrigidas do fotopico gama de $411,80 \mathrm{keV}$ do ${ }^{198} \mathrm{Au}$.

Nas Figuras 4.29 e 4.30 são mostrados os perfis de distribuição do fluxo de neutrons térmicos e epitérmicos na direção radial axial para os fios 01 e 02 , respectivamente, e também o ajuste efetuado para determinar o raio efetivo, a partir das taxas de contagem corrigidas do fotopico gama de $411,80 \mathrm{keV}$ do ${ }^{198} \mathrm{Au}$. 


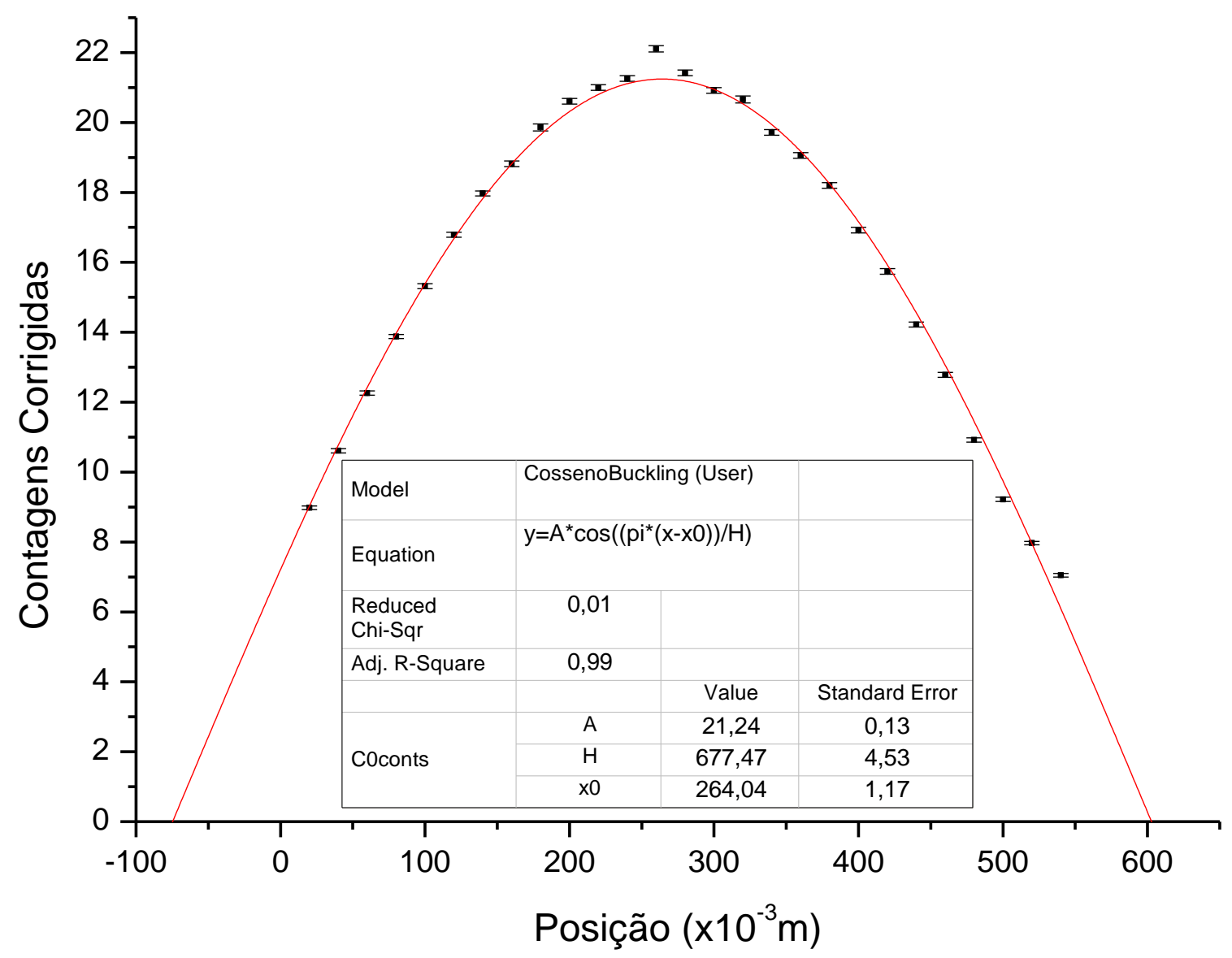

Figura 4.25: Perfil de distribuição do fluxo de neutrons térmicos e epitérmicos na direção axial para o fio de ouro um (01). 


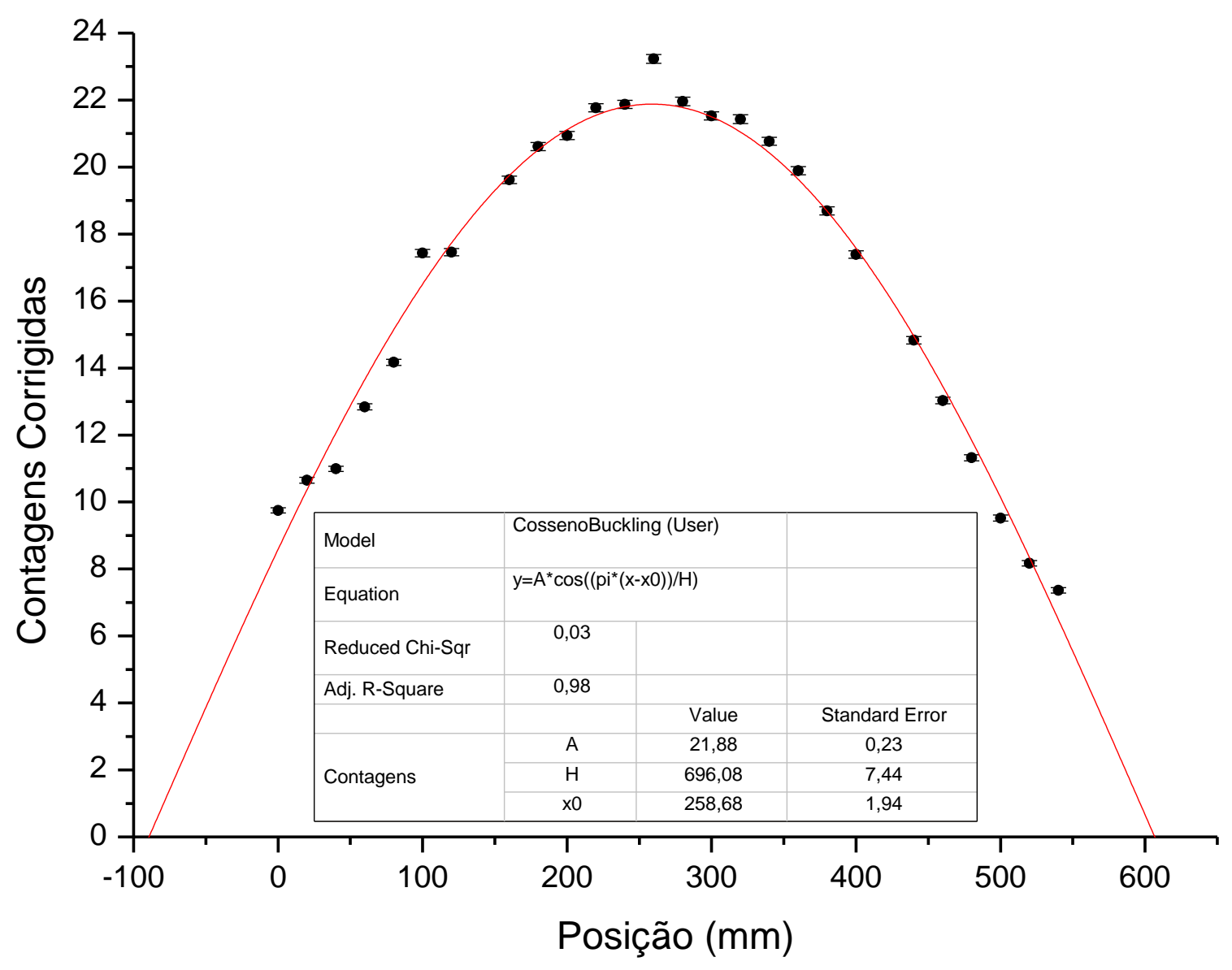

Figura 4.26: Perfil de distribuição do fluxo de neutrons térmicos e epitérmicos na direção axial para o fio de ouro 02. 


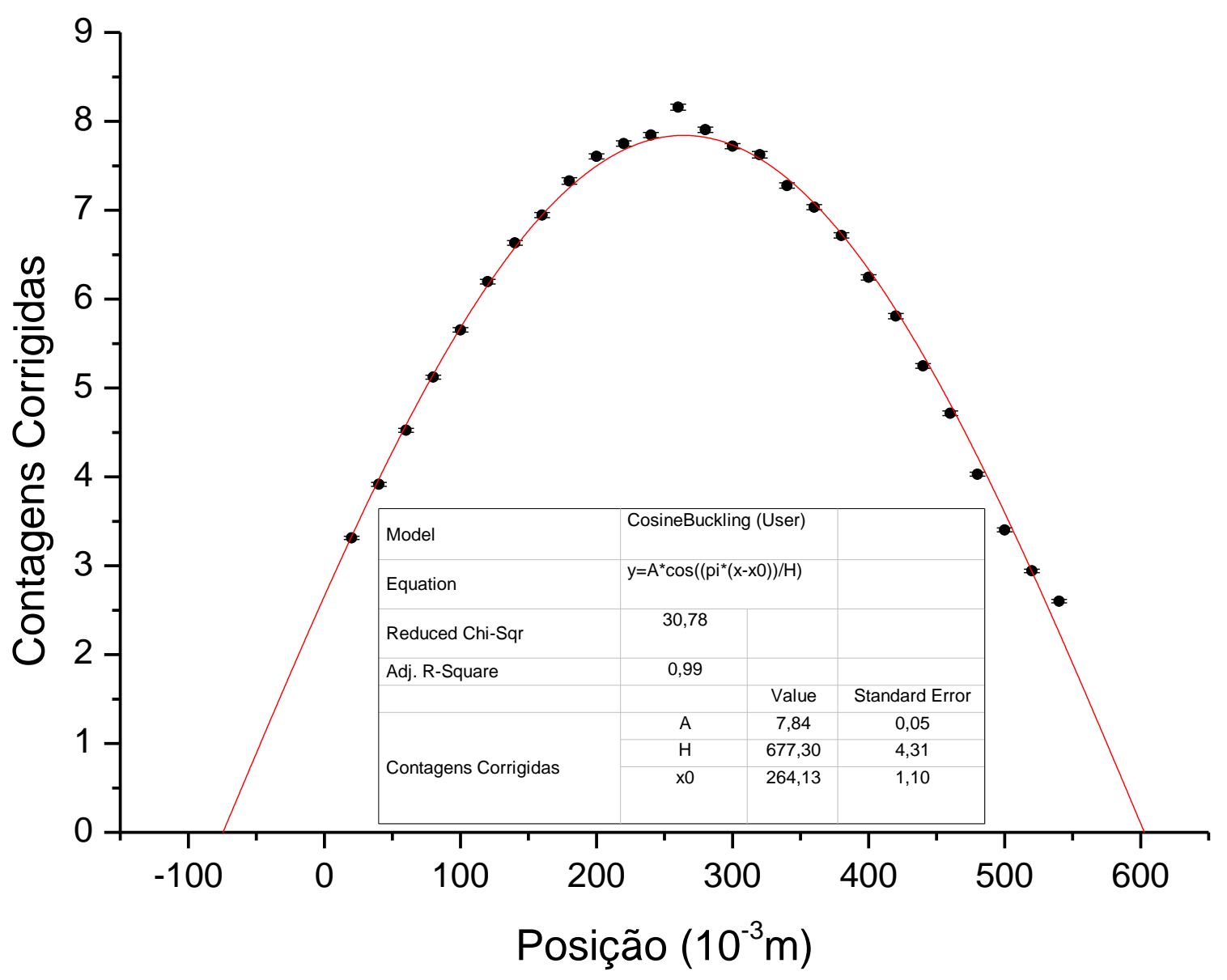

Figura 4.27: Perfil de distribuição do fluxo de neutrons térmicos na direção axial para o fio de ouro um (01). 


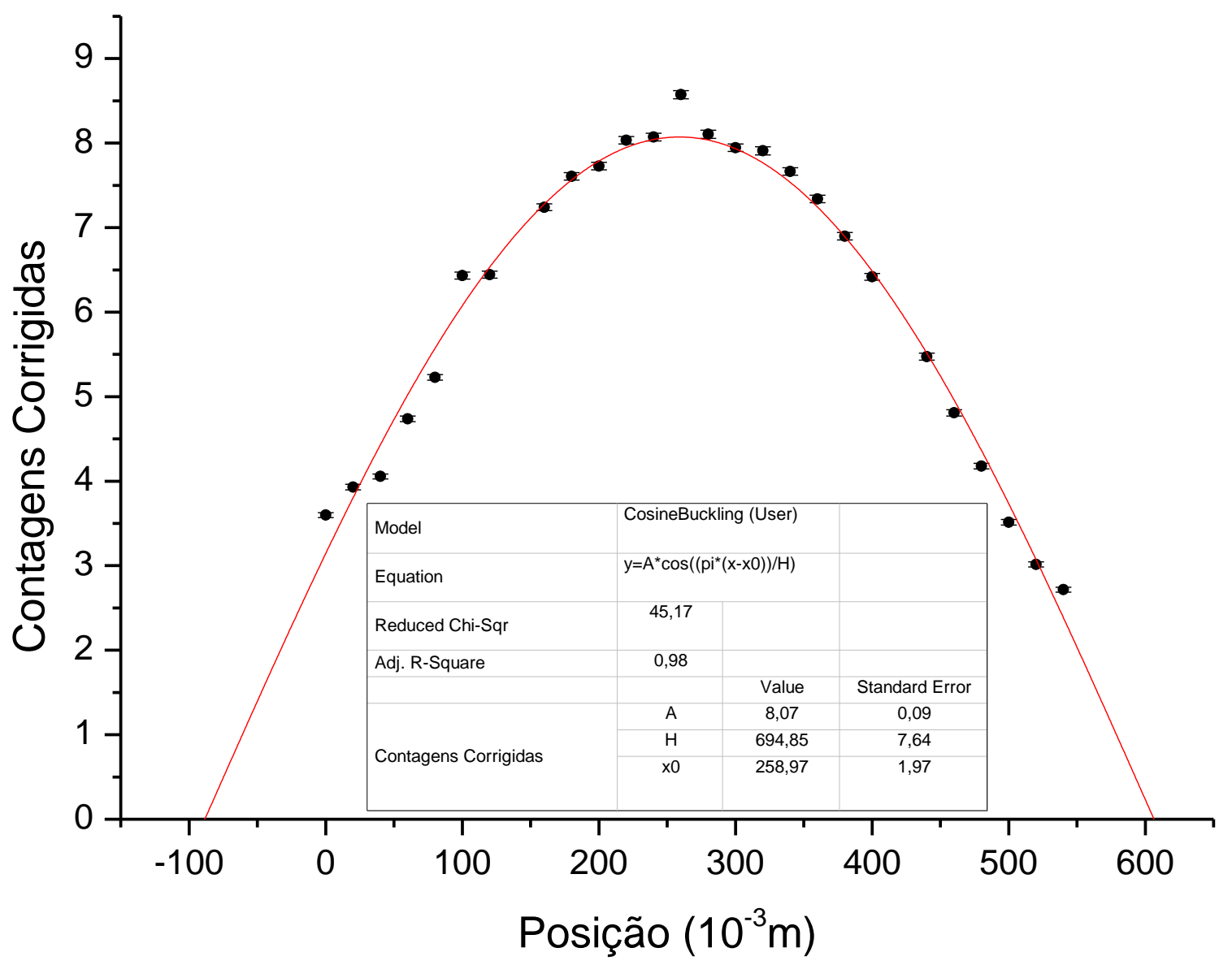

Figura 4.28: Perfil de distribuição do fluxo de neutrons térmicos na direção axial para o fio de ouro 02. 


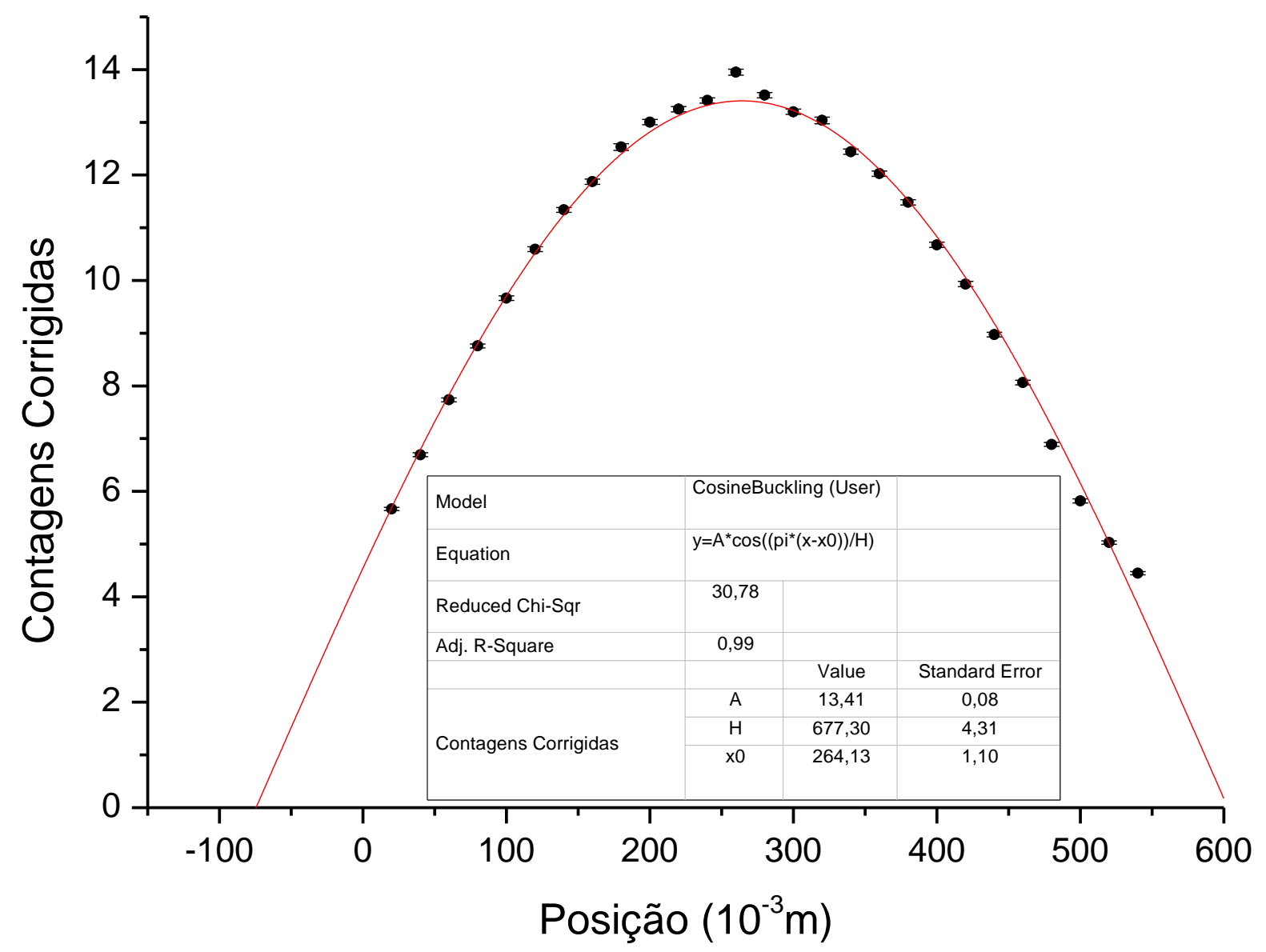

Figura 4.29: Perfil de distribuição do fluxo de neutrons epitérmicos na direção axial para o fio de ouro um (01). 


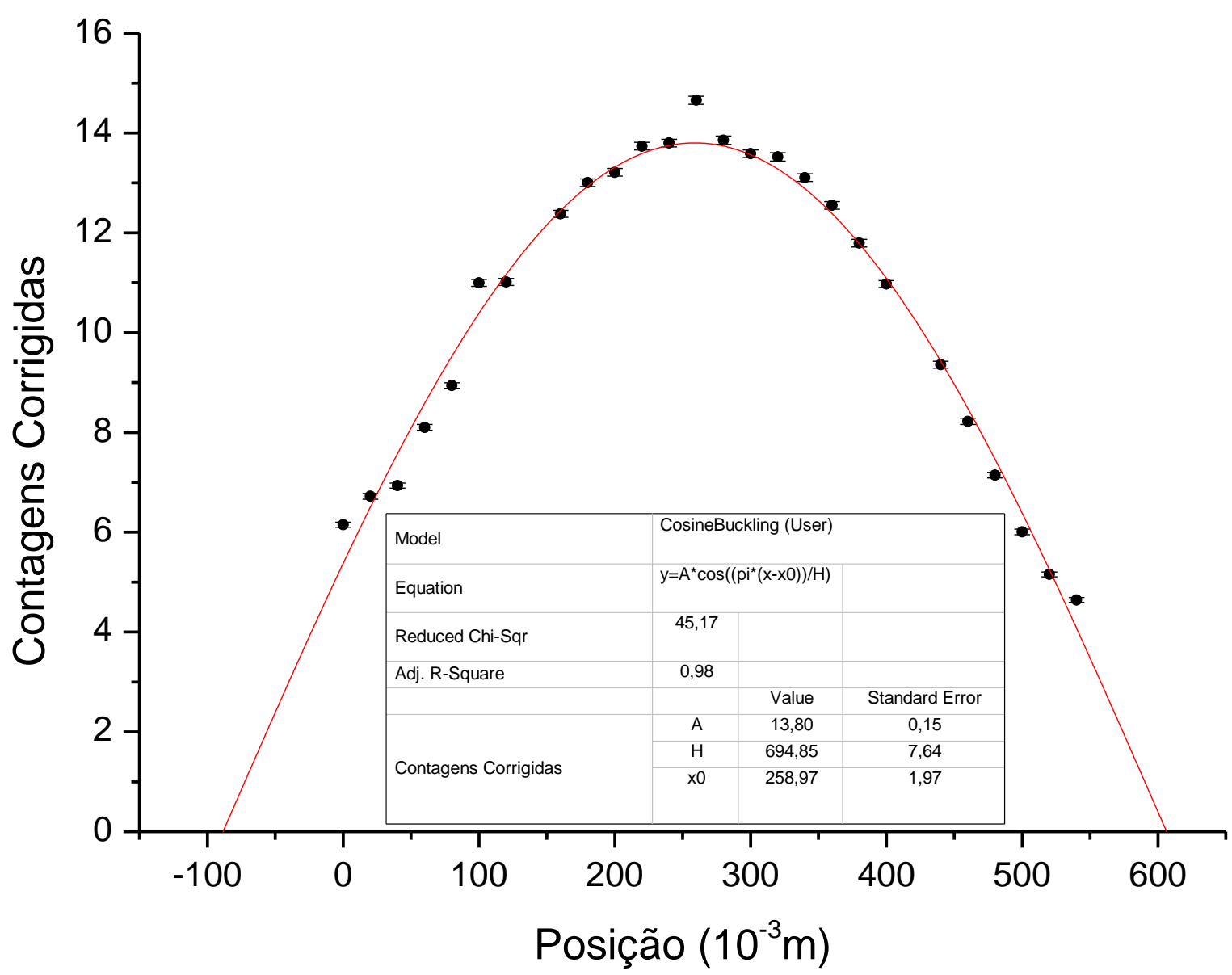

Figura 4.30: Perfil de distribuição do fluxo de neutrons epitérmicos na direção axial para o fio de ouro 02.

\subsubsection{Buckling Obtido Para os Fios de Ouro Irradiados}

A partir dos gráficos e ajustes das Figuras de 4.19 a 4.30 foram obtidos os raios e altura efetivos e o Buckling total para os neutrons térmicos e epitérmicos para as medidas com os fios de ouro inseridos no núcleo do reator.

A Tabela 4.4 apresenta os dados gerais obtidos para os fios de ouro, ou seja, sem separação dos neutrons térmicos e epitérmicos. Os dados são apresentados para as medidas com os fotopicos gama do ${ }^{198} \mathrm{Au}$. 
Tabela 4.4: Dados obtidos e calculo do Buckling para neutrons térmicos e epitérmicos para os fios de ouro

\begin{tabular}{|c|c|c|c|}
\hline Geral & Raio $\left(\mathbf{1 0}^{-\mathbf{2}} \mathbf{m}\right)$ & Altura $\left(\mathbf{1 0}^{-\mathbf{2}} \mathbf{~}\right)$ & $\mathbf{B}^{\mathbf{2}}$ Geral $\left(\mathbf{m}^{-\mathbf{2}}\right)$ \\
\hline Fio 1 & $28,04 \pm 0,39$ & $67,75 \pm 0,45$ & $\mathbf{9 5 , 0 9} \pm \mathbf{2 , 0 4}$ \\
\hline Fio 2 & $30,14 \pm 0,71$ & $69,61 \pm 0,74$ & $\mathbf{8 4 , 0 6} \pm \mathbf{3 , 0 1}$ \\
\hline
\end{tabular}

A Tabela 4.5 apresenta os dados gerais obtidos para os fios de ouro para neutrons térmicos.

Tabela 4.5: Dados obtidos e calculo do Buckling para neutrons térmicos para os fios de ouro

\begin{tabular}{|c|c|c|c|}
\hline Térmico & Raio $\left(\mathbf{1 0}^{-\mathbf{2}} \mathbf{m}\right)$ & Altura $\left(\mathbf{1 0}^{-\mathbf{2}} \mathbf{~}\right)$ & $\mathbf{B}^{\mathbf{2}}{ }_{\text {Térmico }}\left(\mathbf{m}^{-\mathbf{2}}\right)$ \\
\hline Fio 1 & $27,62 \pm 0,42$ & $67,73 \pm 0,43$ & $\mathbf{9 7 , 3 3} \pm \mathbf{2 , 3 4}$ \\
\hline Fio 2 & $30,05 \pm 0,81$ & $69,48 \pm 0,76$ & $\mathbf{8 4 , 5 1} \pm \mathbf{3 , 4 8}$ \\
\hline
\end{tabular}

A Tabela 4.6 apresenta os dados gerais obtidos para os fios de ouro para neutrons epitérmicos.

Tabela 4.6: Dados obtidos e calculo do Buckling para neutrons epitérmicos para os fios de ouro

\begin{tabular}{|c|c|c|c|}
\hline Epitérmico & Raio $\left(10^{-2} \mathrm{~m}\right)$ & Altura $\left(10^{-2} \mathrm{~m}\right)$ & $\mathrm{B}^{2}$ Epitérm \\
\hline Fio 1 & $27,65 \pm 0,22$ & $67,73 \pm 0,43$ & $97,20 \pm 1,21$ \\
\hline Fio 2 & $29,55 \pm 0,73$ & $69,49 \pm 0,76$ & $86,70 \pm 3,29$ \\
\hline
\end{tabular}

\subsection{Medidas obtidas para folhas de ouro}

As medidas e resultados obtidos para as folhas de ouro serão apresentadas em separado no Apêndice $C$, uma vez que não foram consideradas no calculo do 
Buckling total do núcleo do reator IPEN/MB-01 por apresentarem divergencias de valores em relação as medidas com as varetas combustíveis e os fios de ouro.

\subsection{Buckling Total do Reator IPEN/MB-01 para a Configuração Cilindrica de 28 varetas ao longo do Diâmetro do Núcleo}

Com base nos dados obtidos nos cálculos realizados para a determinação do Buckling do reator IPEN/MB-01 das varetas combustíveis e dos fios de ouro, foi determinado o Buckling total do reator a partir do calculo da média ponderada nas incertezas, bem como a incerteza associada ao cálculo ${ }^{19}$. No Anexo B são apresentadas as equações utilizadas no cálculo. A Tabela 4.7, apresenta um resumo de todos os valores obtidos e as respectivas incertezas, bem como o Buckling total calculado.

Tabela 4.7: Resumo dos resultados obtidos para Buckling do reator IPEN/MB-01 para as varetas combustíveis e fios de ouro e o Buckling total do reator.

\begin{tabular}{|c|r|}
\hline MÉTODO & $\mathbf{B}^{\mathbf{2}} \mathbf{( m}^{-\mathbf{2}} \mathbf{~}$ \\
\hline${ }^{239} \mathrm{ONp}$ (Térmico + Epitérmico) & $103,37 \pm 3,57$ \\
\hline${ }^{143} \mathrm{Ce},($ Térmico + Epitérmico) & $99,45 \pm 3,84$ \\
\hline${ }^{239} \mathrm{~Np}$ (Térmico) & $103,63 \pm 3,66$ \\
\hline${ }^{143} \mathrm{Ce}$ (Térmico) & $99,72 \pm 3,93$ \\
\hline${ }^{239} \mathrm{~Np}$ (Epitérmico) & $103,63 \pm 3,66$ \\
\hline${ }^{143} \mathrm{Ce}$ (Epitérmico) & $99,72 \pm 3,93$ \\
\hline Fio (Térmico + Epitérmico) & $95,09 \pm 2,04$ \\
\hline Fio 2 (Térmico + Epitérmico) & $84,06 \pm 3,01$ \\
\hline Fio 1 (Térmico) & $97,33 \pm 2,34$ \\
\hline Fio 2 (Térmico) & $84,51 \pm 3,48$ \\
\hline Fio 1 (Epitérmico) & $97,20 \pm 1,21$ \\
\hline Fio 2 (Epitérmico) & $86,70 \pm 3,29$ \\
\hline Total & $\mathbf{9 6 , 5 5} \pm \mathbf{7 , 4 7}$ \\
\hline
\end{tabular}


A partir da Tabela 4.7, observa-se que o Buckling total obtido para o reator IPEN/MB-01 na configuração cilíndrica de 28 varetas ao longo do diâmetro foi de $96,55 \pm 7,47 \mathrm{~m}^{-2}$. Observa-se que os resultados de Buckling apontam que dentro da margem de erro, não existe diferença entre o Buckling térmico e epitérmico, fato esse que corrobora a teoria pois dentro da regiãp assintótica se espera que os parãmetros integrais se mantenham constantes.e, portanto, pode - se calcular o Buckling total como sendo a média ponderada dos Buckling obtidos para as varetas combustiveis e para os fios de ouro.

\subsection{Determinação da probabilidade de fuga de neutrons}

Uma vez obtido os valor do Buckling para as varetas de combustível e para os fios de ouro, por meio das equações (25) e (26), pode-se calcular as probabilidades de não fuga térmica $\left(P_{T}\right)$ e não fuga rápida $\left(P_{F}\right)$, bem como a probabilidade de não fuga térmica e rápida $\left(P_{T F}\right)$, a partir da multiplicação de $P_{T}$ e $P_{F}$. Sabendo que $L^{2}=$ $30,5879 \mathrm{~cm}^{2}$ e $\mathrm{T}=1,90763 \mathrm{~cm}^{2}$ para $\mathrm{H}_{2} \mathrm{O}$ (moderador) ${ }^{31}$, a Tabela 4.8 apresenta os resultados das probabilidades calculadas e a média ponderada das probabilidades.

A probabilidade de não fuga térmica e rápida $\left(\mathrm{P}_{\mathrm{TF}}\right)$ geral foi de $76,16 \pm$ $1,50 \%$, a partir desse resultado pode - se concluir que a probabilidade de fuga dos nêutrons do núcleo do reator está em torno de $1-\mathrm{P}_{\mathrm{TF}} \approx 24 \%$, ou que, aproximadamente $1 / 4$ (um quarto) dos nêutrons, entre rápidos e térmicos, fogem do reator (mais nêutrons rápidos que térmicos, uma vez que a probabilidade de não fuga é menor). 
Tabela 4.8 - Resultados para probabilidades de não fuga para nêutrons térmicos e epitérmicos a partir do Buckling obtido para as varetas combustíveis e para os fios de ouro.

\begin{tabular}{|c|c|c|c|}
\hline & $P_{T}(\%)$ & $P_{F}(\%)$ & $P_{T F}(\%)$ \\
\hline $\begin{array}{c}{ }^{239} \mathrm{~Np} \\
\text { Contagens } \\
\text { Integrais }\end{array}$ & $75,98 \pm 2,63$ & $98,07 \pm 3,46$ & $74,51 \pm 3,68$ \\
\hline $\begin{array}{c}{ }^{143} \mathrm{Ce} \\
\text { Contagens } \\
\text { Integrais }\end{array}$ & $76,68 \pm 2,96$ & $98,14 \pm 3,87$ & $75,25 \pm 4,15$ \\
\hline $\begin{array}{c}{ }^{239} \mathrm{~Np} \\
\text { Contagens } \\
\text { Separadas }\end{array}$ & $75,93 \pm 2,69$ & $98,74 \pm 3,54$ & $74,98 \pm 3,77$ \\
\hline $\begin{array}{l}{ }^{143} \mathrm{Ce} \\
\text { Contagens } \\
\text { Separadas }\end{array}$ & $76,63 \pm 3,02$ & $98,77 \pm 3,94$ & $75,69 \pm 4,24$ \\
\hline $\begin{array}{c}\text { Fio } 1 \\
\text { Contagens } \\
\text { Integrais }\end{array}$ & $77,47 \pm 1,66$ & $98,22 \pm 2,15$ & $76,09 \pm 2,33$ \\
\hline $\begin{array}{c}\text { Fio } 2 \\
\text { Contagens } \\
\text { Integrais }\end{array}$ & $79,55 \pm 2,85$ & $98,42 \pm 3,58$ & $78,29 \pm 4,00$ \\
\hline $\begin{array}{c}\text { Fio } 1 \\
\text { Contagens } \\
\text { Separadas }\end{array}$ & $77,06 \pm 1,85$ & $98,18 \pm 1,24$ & $75,66 \pm 2,05$ \\
\hline $\begin{array}{c}\text { Fio } 2 \\
\text { Contagens } \\
\text { Separadas }\end{array}$ & $79,46 \pm 3,28$ & $98,37 \pm 3,79$ & $78,17 \pm 4,41$ \\
\hline $\begin{array}{c}\text { Média } \\
\text { Ponderada }\end{array}$ & $77,41 \pm 1,51$ & $98,39 \pm 0,28$ & $76,16 \pm 1,50$ \\
\hline
\end{tabular}




\section{Conclusões do Trabalho}

O resultado obtido neste trabalho experimental é a medida do Buckling $\left(\mathrm{B}^{2}\right)$ do Reator IPEN/MB-01 para a configuração cilindrica de menor excesso de reatividade, ou seja, aquela que possue apenas 28 varetas ao longo do seu diãmetro. $O \mathrm{~B}^{2}$ é uma medida da Curvatura do Fluxo de nêutrons até se anular, ou seja atingir o valor zero e indiretamente nos fornece uma estimativa da fuga de neutrons do núcleo do reator. Assim quanto menor o tamanho de um núcleo, maior a deformação, isto é, quanto maior for a curvatura do fluxo de neutrons maior será a fuga de nêutrons do sistema.

Pela forma geométrica do núcleo, ou seja, pela forma cilindrica seria de se esperar uma probabilidade de fuga dos nêutrons menor que a configuração padrão retangular que utiliza 680 varetas combustíveis. De fato, por este motivo a configuração cilindrica possue um excesso de reatividade maior $(3271 \mathrm{pcm})$ que a configuração padrão retangular $(2457 \mathrm{pcm})$ com a mesma quantidade de combustível ${ }^{24}$. No entanto devido as pequenas dimensões do núcleo cilindrico $28 \times 28$ (menos 112 varetas que a padrão retangular e a cilindrica $30 \times 30$ ), a forma geométrica mais eficiente no quesito não fuga de nêutrons do sistema não chega a compensar a forma geom[etrica mais eficaz, razão pela qual a seu Buckling é maior que 0 obtido em trabalhos anteriores com a configuração retangular ${ }^{25,29}$.

Para a direção radial foram observados valores mais elevados de Buckling no sentido da diminuição do núcleo, o que indica uma maior fuga de nêutrons do sistema núcleo, o que é de se esperar dada a sua menor dimensão neste sentido do núcleo.

Verifica-se também que a curvatura é independente do nível de potência, uma vez que, quando ocorrem mudanças de saída, as variações do fluxo de neutrons no núcleo ocorrem em todas as dimensões proporcionalmente, isto é, a forma da distribuição do fluxo de neutrons é inalterada. Fato esse que foram utilizadas irradiações com potencias de $30 \mathrm{~W}$ e $100 \mathrm{~W}$ e o padrão de curvatura se manteve.

Os resultados para as folhas de ouro não foram considerados para calculo do Buckling do reator, uma vez que os valores de Buckling térmico e epitérmico divergiram para além das incertezas, os dados e resultados obtido são apresentados no Apêndice C.

A média ponderada dos quatro resultados permitiu a determinação de Buckling total do nucleo cilindrico de menor excesso de reatividade do reator IPEN/MB-01 contendo apenas 568 varetas combustíveis e este valor é de $96,55 \pm 7,47 \mathrm{~m}^{-2}$. 
O valor obtido para a probabilidade de não fuga de neutrons térmicos e rápidos foi de $\mathbf{7 6 , 1 6} \pm \mathbf{1 , 5 0} \%$ e esse resultado indica que em torno de $24 \%$ dos neutrons fogem do nucleo do reator IPEN/MB-01 na configuração cilindrica com 28 varetas combustíveis ao longo do diâmetro (28×28).

O trabalho assim cumpriu a sua missão de fornecer um conjunto de dados experimentais que possam servir de padrão de comparação e servirem como uma descrição do nucleo do reator IPEN/MB-01 em sua configuração cilindrica de menor excesso de reatividade.

Como sugestão de trabalhos futuros sugerimos que os dados obtidos neste trabalho sejam comparados por calculos realizados por métodos computacionais utilizados em Física de Reatores, tais como: CITATION ${ }^{26,27}$ e o método estatístico de monte carlo a partir do programa MCNP (Monte Carlo N-Particle Transport Code $)^{28,35}$. As medidas com as folhas de ouro poderão ser refeitas considerando um maior número de folhas, assim como já realizado no núcleo do reator IPEN/MB01 para a configuração padrão retangular em que se utilizaram 11 folhas de ouro nas direções radiais do núcleo ${ }^{29,32}$. Outra sugestão é realizar as medidas do Buckling para a configuração cilíndrica de maior excesso de reatividade (30×30) e comparar diretamente os valores obtidos experimentais de Buckling e probabilidade de não fuga e fuga de nêutrons com os resultados obtidos neste trabalho. 


\section{APÊNDICE A - Dados obtidos na espectrometria das varetas combustível}

Neste apêndice, são apresentados os dados obtidos experimentalmente para as varetas combustíveis e seus respectivos valores corrigidos. Esses dados foram utilizados como referência para os ajustes realizados para as varetas combustíveis e consequentemente para a obtenção dos valores de Buckling e as probabilidades de fuga de nêutrons do sistema.

A Tabela A.1 apresenta os dados obtidos a partir da operação para a direção radial norte - sul do reator tais como: código da vareta combustível, raio e posição considerada para o ajuste, tempo de espera, tempo de vida, tempo morto e as contagens e as respectivas incertezas.

Tabela A.1- Resultados para posição Radial Norte-Sul

\begin{tabular}{|c|c|c|c|c|c|c|c|c|c|}
\hline N-S & & & & & & \multicolumn{3}{|c|}{ Contagens } & \\
\hline Vareta & Raio & $\begin{array}{c}\text { Posicao } \\
(\mathrm{cm})\end{array}$ & $\begin{array}{c}\text { Tempo } \\
\text { de } \\
\text { Espera } \\
\text { (s) }\end{array}$ & $\begin{array}{l}\text { Live } \\
\text { Time } \\
\text { (s) }\end{array}$ & $\begin{array}{c}\text { Tempo } \\
\text { Morto } \\
(\%)\end{array}$ & $\begin{array}{l}\mathrm{Np}- \\
239\end{array}$ & $\begin{array}{c}\text { Incerteza } \\
\mathrm{Np}\end{array}$ & Ce-143 & $\begin{array}{c}\text { Incerteza } \\
\mathrm{Ce}\end{array}$ \\
\hline M-01 & 20,25 & 40,5 & 14220 & 1627,94 & 9,56 & 4418 & 388,78 & 4261 & 259,92 \\
\hline M-02 & 18,75 & 39 & 80340 & 1784,28 & 0,87 & 3851 & & 2604 & 122,91 \\
\hline M-04 & 15,75 & 36 & 85140 & 782,46 & 0,97 & 3828 & & 880 & \\
\hline M-06 & 12,75 & 33 & 90000 & 779,65 & ,13 & 5477 & & 625 & \\
\hline-08 & & 30 & 96060 & 777,14 & , 27 & 59 & & 4219 & \\
\hline-10 & & 2 & 184340 & 1787,04 & 0,72 & 512 & & & \\
\hline-12 &, 75 & 24 & 253800 & 1790,67 & 0,52 & 4218 & & 2088 & \\
\hline $\mathrm{M}-16$ & $-2,25$ & 18 & 257910 & 790,72 & 0,52 & 4141 & 122,16 & 1748 & 14 \\
\hline $\mathrm{M}-18$ & $-5,25$ & 15 & 188520 & 1786,76 & 0,74 & 5001 & 138,03 & 2859 & 109,50 \\
\hline M-20 & $-8,25$ & 12 & 180000 & 1787,46 & 0,70 & 4546 & 140,02 & 2768 & 108,78 \\
\hline M-22 & $-11,25$ & 9 & 98100 & 1779,22 & 1,15 & 5404 & 172,39 & 3815 & 139,63 \\
\hline M-24 & $-14,25$ & 6 & 92940 & 1781,21 & 1,04 & 4823 & 160,12 & 3606 & 129,82 \\
\hline M-26 & $-17,25$ & 3 & 87900 & 1783,75 & 0,90 & 3611 & 330,05 & 2963 & 118,82 \\
\hline M-27 & $-18,75$ & 1,5 & 82800 & 1784,41 & 0,87 & 3162 & 151,46 & 2250 & 124,20 \\
\hline M-28 & $-20,25$ & 0 & 77940 & 1781 & 1,06 & 3481 & 153,86 & 3207 & 129,56 \\
\hline
\end{tabular}


A Tabela A.2 apresentam os dados obtidos para a direção radial leste - oeste.

Tabela A.2- Resultados para posição Radial Leste-Oeste.

\begin{tabular}{|c|c|c|c|c|c|c|c|c|c|}
\hline L-O & & & & & & & Contagens & & \\
\hline Vareta & Raio & $\begin{array}{l}\text { Posição } \\
\text { (cm) }\end{array}$ & $\begin{array}{c}\text { Tempo } \\
\text { de } \\
\text { Espera } \\
\text { (s) }\end{array}$ & $\begin{array}{l}\text { Live } \\
\text { Time } \\
\text { (s) }\end{array}$ & $\begin{array}{c}\text { Tempo } \\
\text { Morto } \\
(\%)\end{array}$ & $\begin{array}{l}\mathrm{Np}- \\
239\end{array}$ & Incerteza & $\begin{array}{l}\mathrm{Ce}- \\
143\end{array}$ & Incerteza \\
\hline$a b-14$ & $-20,25$ & 0 & 16320 & 1654,58 & 8,08 & 3194 & 363,80 & 4638 & 243,03 \\
\hline A-14 & $-18,75$ & 1,5 & 102120 & 1787,2 & 0,71 & 3318 & 137,37 & 2357 & 111,96 \\
\hline C-14 & $-15,75$ & 4,5 & 167640 & 1791,49 & 0,47 & 3160 & 117,24 & 1880 & 92,50 \\
\hline E-14 & $-12,75$ & 7,5 & 171660 & 1789,95 & 0,56 & 4021 & 127,06 & 2182 & 102,77 \\
\hline G-14 & $-9,75$ & 10,5 & 176040 & 1788,03 & 0,67 & 4648 & 136,65 & 2609 & 109,32 \\
\hline $\mathrm{I}-14$ & $-6,75$ & 13,5 & 182400 & 1787,93 & 0,67 & 4758 & 142,26 & 2753 & 112,60 \\
\hline $\mathrm{K}-14$ & $-3,75$ & 16,5 & 251700 & 1790,53 & 0,53 & 4407 & 122,96 & 1994 & 96,51 \\
\hline $0-14$ & 2,25 & 22,5 & 255780 & 1790,73 & 0,51 & 4148 & 124,03 & 2217 & 94,44 \\
\hline Q-14 & 5,25 & 25,5 & 186480 & 1787,66 & 0,69 & 4886 & 140,72 & 2816 & 110,39 \\
\hline S-14 & 8,25 & 28,5 & 177960 & 1787,63 & 0,69 & 4436 & 138,85 & 2792 & 107,49 \\
\hline U-14 & 11,25 & 31,5 & 173640 & 1788,71 & 0,63 & 4436 & 136,63 & 2456 & 108,06 \\
\hline W-14 & 14,25 & 34,5 & 169680 & 1790,94 & 0,50 & 3430 & 122,79 & 2004 & 98,00 \\
\hline $\mathrm{Y}-14$ & 17,25 & 37,5 & 165480 & 1792,09 & 0,44 & 2323 & 116,85 & 1709 & 89,04 \\
\hline Z-14 & 18,75 & 39 & 100140 & 1786,46 & 0,75 & 3163 & 139,49 & 2374 & 113,24 \\
\hline$z a-14$ & 20,25 & 40,5 & 11880 & 1576,62 & 12,41 & 5886 & 430,86 & 4208 & 286,99 \\
\hline
\end{tabular}


A Tabela A.3 apresenta os dados obtidos para a direção axial.

Tabela A.3- Resultados para posição Axial da vareta M14.

\begin{tabular}{|r|r|r|r|r|r|r|r|}
\hline Posição & $\begin{array}{r}\text { Tempo de } \\
\text { Espera (s) }\end{array}$ & $\begin{array}{r}\text { Live Time } \\
(\mathrm{s})\end{array}$ & $\begin{array}{c}\text { Tempo } \\
\text { Morto (\%) }\end{array}$ & Np-239 & Incerteza & Ce-143 & Incerteza \\
\hline 0 & 15904 & 1697,37 & 5,7 & 4012 & 308,12 & 4360 & 245,03 \\
\hline 2 & 17705 & 1701,68 & 5,46 & 5450 & 309,02 & 3090 & 254,00 \\
\hline 4 & 19506 & 1697,29 & 5,71 & 5712 & 312,45 & 4131 & 256,12 \\
\hline 6 & 21307 & 1693,38 & 5,92 & 5887 & 317,90 & 6410 & 254,48 \\
\hline 8 & 23108 & 1685,32 & 6,37 & 7517 & 316,47 & 5595 & 256,81 \\
\hline 10 & 24909 & 1682,98 & 6,5 & 7825 & 318,48 & 6319 & 259,71 \\
\hline 12 & 26710 & 1676,72 & 6,85 & 6875 & 319,00 & 6504 & 258,86 \\
\hline 14 & 28511 & 1621,69 & 9,91 & 7277 & 319,46 & 6600 & 256,08 \\
\hline 16 & 30312 & 1664,37 & 7,54 & 8046 & 314,60 & 7535 & 253,18 \\
\hline 18 & 32114 & 1611,83 & 10,45 & 8168 & 312,83 & 6180 & 252,14 \\
\hline 20 & 33915 & 1672,32 & 7,09 & 8387 & 309,48 & 7694 & 249,29 \\
\hline 22 & 35716 & 1535,65 & 14,69 & 8584 & 303,02 & 7359 & 245,05 \\
\hline 24 & 37517 & 1625,55 & 9,69 & 8306 & 296,52 & 8053 & 237,56 \\
\hline 26 & 39319 & 1525,62 & 15,24 & 8944 & 289,79 & 7617 & 235,37 \\
\hline 28 & 41120 & 1603,61 & 10,91 & 7948 & 281,36 & 7853 & 226,17 \\
\hline 30 & 42921 & 1509,86 & 16,12 & 8070 & 273,57 & 7487 & 220,12 \\
\hline 32 & 44722 & 1580,06 & 12,22 & 7873 & 263,75 & 7052 & 212,27 \\
\hline 34 & 46523 & 1428,76 & 20,62 & 7527 & 252,91 & 5877 & 206,28 \\
\hline 36 & 48324 & 1533,21 & 14,82 & 6665 & 243,94 & 6123 & 197,16 \\
\hline 38 & 50125 & 1468,24 & 18,43 & 5911 & 235,26 & 5818 & 186,18 \\
\hline 40 & 51926 & 1514,22 & 15,88 & 6136 & 217,83 & 4627 & 180,45 \\
\hline 42 & 53727 & 1746,82 & 2,95 & 5784 & 207,65 & 4803 & 167,14 \\
\hline 44 & 55528 & 1766,3 & 1,87 & 5031 & 195,71 & 4242 & 156,53 \\
\hline 46 & 57330 & 1751,84 & 2,68 & 4605 & 177,75 & 3797 & 144,29 \\
\hline 48 & 59131 & 1771,85 & 1,56 & 3680 & 166,70 & 3079 & 132,40 \\
\hline 50 & 60932 & 1763,1 & 2,05 & 2413 & 156,60 & 2326 & 124,21 \\
\hline 52 & 62733 & 1769,86 & 1,67 & 2483 & 137,81 & 2218 & 113,34 \\
\hline 54 & 64534 & 1782,13 & 0,99 & 1031 & 87,94 & 843 & 73,68 \\
\hline 56 & 66335 & 1658,49 & 7,86 & 1789 & 128,09 & 1666 & 103,79 \\
\hline & & & & & & & \\
\hline
\end{tabular}


As Tabelas A.4, A.5, A.6 e A.7 apresentam as contagens corrigidas integrais (nêutrons térmicos mais epitérmicos), contagens corrigidas para nêutrons térmicos e contagens corrigidas para nêutrons epitérmicos para o ${ }^{239} \mathrm{~Np}$ e ${ }^{143} \mathrm{Ce}$ nas direções radiais leste - oeste e norte - sul.

Tabela A.4: Dados de posição e das contagens corrigidas para a direção radial leste - oeste para o ${ }^{239} \mathrm{~Np}$.

\begin{tabular}{|r|r|r|r|r|r|r|}
\hline Np239 & Geral & & Epitérmico & & \multicolumn{1}{|l|}{ Térmico } & \\
\hline $\begin{array}{r}\text { Posição } \\
\text { (cm) }\end{array}$ & $\begin{array}{c}\text { Contagens } \\
\text { Corrigidas }\end{array}$ & $\begin{array}{c}\text { Incerteza } \\
\text { Contagens } \\
\text { Corrigidas }\end{array}$ & $\begin{array}{c}\text { Contagens } \\
\text { Corrigidas }\end{array}$ & $\begin{array}{c}\text { Incerteza } \\
\text { Contagens } \\
\text { Corrigidas }\end{array}$ & $\begin{array}{l}\text { Contagens } \\
\text { Corrigidas }\end{array}$ & $\begin{array}{c}\text { Incerteza } \\
\text { Contagens } \\
\text { Corrigidas }\end{array}$ \\
\hline$-20,25$ & 2,04074 & 0,23244 & 1,428518 & 0,162708 & 0,612222 & 0,069732 \\
\hline$-18,75$ & 2,62881 & 0,10883 & 1,840167 & 0,076181 & 0,788643 & 0,032649 \\
\hline$-15,75$ & 3,1221 & 0,11583 & 2,18547 & 0,081081 & 0,93663 & 0,034749 \\
\hline$-12,75$ & 4,03101 & 0,12738 & 2,821707 & 0,089166 & 1,209303 & 0,038214 \\
\hline$-9,75$ & 4,73468 & 0,1392 & 3,314276 & 0,09744 & 1,420404 & 0,04176 \\
\hline$-6,75$ & 4,95315 & 0,1481 & 3,467205 & 0,10367 & 1,485945 & 0,04443 \\
\hline$-3,75$ & 5,80067 & 0,16184 & 4,060469 & 0,113288 & 1,740201 & 0,048552 \\
\hline 2,25 & 5,53554 & 0,16551 & 3,874878 & 0,115857 & 1,660662 & 0,049653 \\
\hline 5,25 & 5,15835 & 0,14856 & 3,610845 & 0,103992 & 1,547505 & 0,044568 \\
\hline 8,25 & 4,54939 & 0,1424 & 3,184573 & 0,09968 & 1,364817 & 0,04272 \\
\hline 11,25 & 4,48024 & 0,13799 & 3,136168 & 0,096593 & 1,344072 & 0,041397 \\
\hline 14,25 & 3,41354 & 0,1222 & 2,389478 & 0,08554 & 1,024062 & 0,03666 \\
\hline 17,25 & 2,27755 & 0,11456 & 1,594285 & 0,080192 & 0,683265 & 0,034368 \\
\hline
\end{tabular}


Tabela A.5: Dados de posição e das contagens corrigidas para a direção radial leste - oeste para o ${ }^{143} \mathrm{Ce}$.

\begin{tabular}{|r|r|r|r|r|r|r|}
\hline Ce143 & Geral & & Epitérmico & & Térmico & \\
\hline $\begin{array}{r}\text { Posição } \\
\text { (cm) }\end{array}$ & $\begin{array}{r}\text { Contagens } \\
\text { Corrigidas }\end{array}$ & $\begin{array}{c}\text { Incerteza } \\
\text { Contagens } \\
\text { Corrigidas }\end{array}$ & $\begin{array}{c}\text { Contagens } \\
\text { Corrigidas }\end{array}$ & $\begin{array}{c}\text { Incerteza } \\
\text { Contagens } \\
\text { Corrigidas }\end{array}$ & $\begin{array}{c}\text { Contagens } \\
\text { Corrigidas }\end{array}$ & $\begin{array}{c}\text { Incerteza } \\
\text { Contagens } \\
\text { Corrigidas }\end{array}$ \\
\hline$-18,75$ & 2,39315 & 0,11367 & 0,263247 & 0,012504 & 2,129904 & 0,101166 \\
\hline$-15,75$ & 2,79101 & 0,13732 & 0,307011 & 0,015105 & 2,483999 & 0,122215 \\
\hline$-12,75$ & 3,31909 & 0,15633 & 0,3651 & 0,017196 & 2,95399 & 0,139134 \\
\hline$-9,75$ & 4,07571 & 0,17077 & 0,448328 & 0,018785 & 3,627382 & 0,151985 \\
\hline$-6,75$ & 4,46352 & 0,18256 & 0,490987 & 0,020082 & 3,972533 & 0,162478 \\
\hline$-3,75$ & 4,83703 & 0,23411 & 0,532073 & 0,025752 & 4,304957 & 0,208358 \\
\hline 2,25 & 5,50693 & 0,2346 & 0,605762 & 0,025806 & 4,901168 & 0,208794 \\
\hline 5,25 & 4,67636 & 0,18331 & 0,5144 & 0,020164 & 4,16196 & 0,163146 \\
\hline 8,25 & 4,41172 & 0,16985 & 0,485289 & 0,018684 & 3,926431 & 0,151167 \\
\hline 11,25 & 3,78191 & 0,1664 & 0,41601 & 0,018304 & 3,3659 & 0,148096 \\
\hline 14,25 & 3,01165 & 0,14727 & 0,331282 & 0,0162 & 2,680369 & 0,13107 \\
\hline 17,25 & 2,50453 & 0,13049 & 0,275498 & 0,014354 & 2,229032 & 0,116136 \\
\hline 18,75 & 2,38371 & 0,1137 & 0,262208 & 0,012507 & 2,121502 & 0,101193 \\
\hline
\end{tabular}


Tabela A.6: Dados de posição e das contagens corrigidas para a direção radial norte - sul para o ${ }^{239} \mathrm{~Np}$.

\begin{tabular}{|r|r|r|r|r|r|r|}
\hline Np239 & Geral & & Epitérmico & & \multicolumn{1}{l|}{ Térmico } & \\
\hline $\begin{array}{r}\text { Posição } \\
\text { (cm) }\end{array}$ & $\begin{array}{r}\text { Contagens } \\
\text { Corrigidas }\end{array}$ & $\begin{array}{c}\text { Incerteza } \\
\text { Contagens } \\
\text { Corrigidas }\end{array}$ & $\begin{array}{r}\text { Contagens } \\
\text { Corrigidas }\end{array}$ & $\begin{array}{r}\text { Incerteza } \\
\text { Contagens } \\
\text { Corrigidas }\end{array}$ & $\begin{array}{l}\text { Contagens } \\
\text { Corrigidas }\end{array}$ & $\begin{array}{l}\text { Contagens } \\
\text { Corrigidas }\end{array}$ \\
\hline 15,75 & 2,87007 & 0,12026 & 2,009049 & 0,084182 & 0,861021 & 0,036078 \\
\hline 12,75 & 4,18154 & 0,13005 & 2,927078 & 0,091035 & 1,254462 & 0,039015 \\
\hline 9,75 & 4,67517 & 0,13558 & 3,272619 & 0,094906 & 1,402551 & 0,040674 \\
\hline 6,75 & 5,37534 & 0,1446 & 3,762738 & 0,10122 & 1,612602 & 0,04338 \\
\hline 3,75 & 5,59131 & 0,16606 & 3,913917 & 0,116242 & 1,677393 & 0,049818 \\
\hline$-2,25$ & 5,56647 & 0,16421 & 3,896529 & 0,114947 & 1,669941 & 0,049263 \\
\hline$-5,25$ & 5,31925 & 0,14681 & 3,723475 & 0,102767 & 1,595775 & 0,044043 \\
\hline$-8,25$ & 4,69516 & 0,14461 & 3,286612 & 0,101227 & 1,408548 & 0,043383 \\
\hline$-11,25$ & 4,24225 & 0,13533 & 2,969575 & 0,094731 & 1,272675 & 0,040599 \\
\hline$-14,25$ & 3,71603 & 0,12337 & 2,601221 & 0,086359 & 1,114809 & 0,037011 \\
\hline$-17,25$ & 2,73096 & 0,24961 & 1,911672 & 0,174727 & 0,819288 & 0,074883 \\
\hline$-18,75$ & 2,34934 & 0,11253 & 1,644538 & 0,078771 & 0,704802 & 0,033759 \\
\hline
\end{tabular}

Tabela A.7: Dados de posição e das contagens corrigidas para a direção radial norte - sul para o ${ }^{143} \mathrm{Ce}$.

\begin{tabular}{|r|r|r|r|r|r|r|}
\hline Ce143 & Geral & & Epitérmico & & Térmico & \\
\hline $\begin{array}{r}\text { Posição } \\
\text { (cm) }\end{array}$ & $\begin{array}{r}\text { Contagens } \\
\text { Corrigidas }\end{array}$ & $\begin{array}{c}\text { Incerteza } \\
\text { Contagens } \\
\text { Corrigidas }\end{array}$ & $\begin{array}{l}\text { Contagens } \\
\text { Corrigidas }\end{array}$ & $\begin{array}{c}\text { Incerteza } \\
\text { Contagens } \\
\text { Corrigidas }\end{array}$ & $\begin{array}{c}\text { Contagens } \\
\text { Corrigidas }\end{array}$ & $\begin{array}{c}\text { Contagens } \\
\text { Corrigidas }\end{array}$ \\
\hline 18,75 & 2,33221 & 0,11008 & 0,256543 & 0,012109 & 2,075667 & 0,097971 \\
\hline 15,75 & 2,65538 & 0,11923 & 0,292092 & 0,013115 & 2,363288 & 0,106115 \\
\hline 12,75 & 3,44384 & 0,13121 & 0,378822 & 0,014433 & 3,065018 & 0,116777 \\
\hline 9,75 & 4,15829 & 0,14055 & 0,457412 & 0,015461 & 3,700878 & 0,12509 \\
\hline 6,75 & 4,78728 & 0,18144 & 0,526601 & 0,019958 & 4,260679 & 0,161482 \\
\hline 3,75 & 5,1271 & 0,23431 & 0,563981 & 0,025774 & 4,563119 & 0,208536 \\
\hline$-5,25$ & 4,80704 & 0,18411 & 0,528774 & 0,020252 & 4,278266 & 0,163858 \\
\hline$-8,25$ & 4,42659 & 0,17396 & 0,486925 & 0,019136 & 3,939665 & 0,154824 \\
\hline$-11,25$ & 3,80068 & 0,1391 & 0,418075 & 0,015301 & 3,382605 & 0,123799 \\
\hline$-14,25$ & 3,48201 & 0,12535 & 0,383021 & 0,013789 & 3,098989 & 0,111562 \\
\hline$-17,25$ & 2,77425 & 0,11125 & 0,305168 & 0,012238 & 2,469083 & 0,099013 \\
\hline$-18,75$ & 2,04415 & 0,11284 & 0,224857 & 0,012412 & 1,819294 & 0,100428 \\
\hline
\end{tabular}


As Tabelas A.8 e A.9 apresentam as contagens corrigidas integrais (nêutrons térmicos mais epitérmicos), contagens corrigidas para nêutrons térmicos e contagens corrigidas para nêutrons epitérmicos para $0{ }^{239} \mathrm{~Np} \mathrm{e}{ }^{143} \mathrm{Ce}$ na direção axial.

Tabela A.8: Dados de posição e das contagens corrigidas para a direção axial para o ${ }^{239} \mathrm{~Np}$.

\begin{tabular}{|c|c|c|c|c|c|c|}
\hline Np239 & Geral & & Epitérmico & & Térmico & \\
\hline $\begin{array}{c}\text { Posição } \\
\text { (cm) }\end{array}$ & $\begin{array}{c}\text { Contagens } \\
\text { Corrigidas }\end{array}$ & $\begin{array}{c}\text { Incerteza } \\
\text { Contagens } \\
\text { Corrigidas }\end{array}$ & $\begin{array}{c}\text { Contagens } \\
\text { Corrigidas }\end{array}$ & $\begin{array}{c}\text { Incerteza } \\
\text { Contagens } \\
\text { Corrigidas }\end{array}$ & $\begin{array}{c}\text { Contagens } \\
\text { Corrigidas }\end{array}$ & $\begin{array}{c}\text { Contagens } \\
\text { Corrigidas }\end{array}$ \\
\hline 4 & 3,59655 & 0,19673 & 2,517585 & 0,137711 & 1,078965 & 0,059019 \\
\hline 6 & 3,73815 & 0,20186 & 2,616705 & 0,141302 & 1,121445 & 0,060558 \\
\hline 8 & 4,82552 & 0,20315 & 3,377864 & 0,142205 & 1,447656 & 0,060945 \\
\hline 10 & 5,06117 & 0,20599 & 3,542819 & 0,144193 & 1,518351 & 0,061797 \\
\hline 12 & 4,49078 & 0,20837 & 3,143546 & 0,145859 & 1,347234 & 0,062511 \\
\hline 14 & 4,94491 & 0,21708 & 3,461437 & 0,151956 & 1,483473 & 0,065124 \\
\hline 16 & 5,36004 & 0,20958 & 3,752028 & 0,146706 & 1,608012 & 0,062874 \\
\hline 18 & 5,65327 & 0,21652 & 3,957289 & 0,151564 & 1,695981 & 0,064956 \\
\hline 20 & 5,6293 & 0,20772 & 3,94051 & 0,145404 & 1,68879 & 0,062316 \\
\hline 22 & 6,3129 & 0,22285 & 4,41903 & 0,155995 & 1,89387 & 0,066855 \\
\hline 24 & 5,80613 & 0,20728 & 4,064291 & 0,145096 & 1,741839 & 0,062184 \\
\hline 26 & 6,70265 & 0,21717 & 4,691855 & 0,152019 & 2,010795 & 0,065151 \\
\hline 28 & 5,70143 & 0,20183 & 3,991001 & 0,141281 & 1,710429 & 0,060549 \\
\hline 30 & 6,18623 & 0,20971 & 4,330361 & 0,146797 & 1,855869 & 0,062913 \\
\hline 32 & 5,80256 & 0,19439 & 4,061792 & 0,136073 & 1,740768 & 0,058317 \\
\hline 34 & 6,17277 & 0,2074 & 4,320939 & 0,14518 & 1,851831 & 0,06222 \\
\hline 36 & 5,12483 & 0,18757 & 3,587381 & 0,131299 & 1,537449 & 0,056271 \\
\hline 38 & 4,77539 & 0,19006 & 3,342773 & 0,133042 & 1,432617 & 0,057018 \\
\hline 40 & 4,83622 & 0,17169 & 3,385354 & 0,120183 & 1,450866 & 0,051507 \\
\hline 42 & 3,97607 & 0,14274 & 2,783249 & 0,099918 & 1,192821 & 0,042822 \\
\hline 44 & 3,44134 & 0,13387 & 2,408938 & 0,093709 & 1,032402 & 0,040161 \\
\hline 46 & 3,19549 & 0,12335 & 2,236843 & 0,086345 & 0,958647 & 0,037005 \\
\hline 48 & 2,54032 & 0,11508 & 1,778224 & 0,080556 & 0,762096 & 0,034524 \\
\hline 50 & 1,68427 & 0,10931 & 1,178989 & 0,076517 & 0,505281 & 0,032793 \\
\hline 52 & 1,73713 & 0,09641 & 1,215991 & 0,067487 & 0,521139 & 0,028923 \\
\hline 54 & 0,72074 & 0,06148 & 0,504518 & 0,043036 & 0,216222 & 0,018444 \\
\hline 56 & 1,35214 & 0,09681 & 0,946498 & 0,067767 & 0,405642 & 0,029043 \\
\hline & & & & & & \\
\hline
\end{tabular}


Tabela A.9: Dados de posição e das contagens corrigidas para a direção axial para $0{ }^{143} \mathrm{Ce}$.

\begin{tabular}{|c|c|c|c|c|c|c|}
\hline Ce143 & Geral & & Epitérmico & & Térmico & Incerteza \\
\hline $\begin{array}{c}\text { Posição } \\
\text { (cm) }\end{array}$ & $\begin{array}{c}\text { Contagens } \\
\text { Corrigidas }\end{array}$ & $\begin{array}{c}\text { Incerteza } \\
\text { Contagens } \\
\text { Corrigidas }\end{array}$ & $\begin{array}{c}\text { Contagens } \\
\text { Corrigidas }\end{array}$ & $\begin{array}{c}\text { Incerteza } \\
\text { Contagens } \\
\text { Corrigidas }\end{array}$ & $\begin{array}{c}\text { Contagens } \\
\text { Corrigidas }\end{array}$ & $\begin{array}{c}\text { Contagens } \\
\text { Corrigidas }\end{array}$ \\
\hline 4 & 2,72728 & 0,16909 & 0,300001 & 0,0186 & 2,427279 & 0,15049 \\
\hline 6 & 4,28645 & 0,17017 & 0,47151 & 0,018719 & 3,814941 & 0,151451 \\
\hline 8 & 3,79906 & 0,17438 & 0,417897 & 0,019182 & 3,381163 & 0,155198 \\
\hline 10 & 4,34202 & 0,17846 & 0,477622 & 0,019631 & 3,864398 & 0,158829 \\
\hline 12 & 4,53321 & 0,18042 & 0,498653 & 0,019846 & 4,034557 & 0,160574 \\
\hline 14 & 4,80647 & 0,18649 & 0,528712 & 0,020514 & 4,277758 & 0,165976 \\
\hline 16 & 5,40315 & 0,18155 & 0,594347 & 0,019971 & 4,808804 & 0,16158 \\
\hline 18 & 4,62434 & 0,18867 & 0,508677 & 0,020754 & 4,115663 & 0,167916 \\
\hline 20 & 5,6076 & 0,18169 & 0,616836 & 0,019986 & 4,990764 & 0,161704 \\
\hline 22 & 5,90248 & 0,19655 & 0,649273 & 0,021621 & 5,253207 & 0,17493 \\
\hline 24 & 6,16637 & 0,18191 & 0,678301 & 0,02001 & 5,488069 & 0,1619 \\
\hline 26 & 6,28024 & 0,19406 & 0,690826 & 0,021347 & 5,589414 & 0,172713 \\
\hline 28 & 6,225 & 0,17928 & 0,68475 & 0,019721 & 5,54025 & 0,159559 \\
\hline 30 & 6,36997 & 0,18728 & 0,700697 & 0,020601 & 5,669273 & 0,166679 \\
\hline 32 & 5,79387 & 0,1744 & 0,637326 & 0,019184 & 5,156544 & 0,155216 \\
\hline 34 & 5,39623 & 0,18941 & 0,593585 & 0,020835 & 4,802645 & 0,168575 \\
\hline 36 & 5,29445 & 0,17048 & 0,58239 & 0,018753 & 4,712061 & 0,151727 \\
\hline 38 & 5,30883 & 0,16988 & 0,583971 & 0,018687 & 4,724859 & 0,151193 \\
\hline 40 & 4,13711 & 0,16135 & 0,455082 & 0,017749 & 3,682028 & 0,143602 \\
\hline 42 & 3,76196 & 0,13092 & 0,413816 & 0,014401 & 3,348144 & 0,116519 \\
\hline 44 & 3,32063 & 0,12253 & 0,365269 & 0,013478 & 2,955361 & 0,109052 \\
\hline 46 & 3,02849 & 0,11508 & 0,333134 & 0,012659 & 2,695356 & 0,102421 \\
\hline 48 & 2,45373 & 0,10551 & 0,26991 & 0,011606 & 2,18382 & 0,093904 \\
\hline 50 & 1,88253 & 0,10053 & 0,207078 & 0,011058 & 1,675452 & 0,089472 \\
\hline 52 & 1,80715 & 0,09235 & 0,198787 & 0,010159 & 1,608364 & 0,082192 \\
\hline 54 & 0,68933 & 0,06025 & 0,075826 & 0,006628 & 0,613504 & 0,053623 \\
\hline 56 & 1,47932 & 0,09216 & 0,162725 & 0,010138 & 1,316595 & 0,082022 \\
\hline & & & & & & \\
\hline
\end{tabular}




\section{APÊNDICE B - Dados obtidos na espectrometria dos fios de ouro}

As Tabelas B.1 e B.2 apresentam as contagens corrigidas integrais (nêutrons térmicos mais epitérmicos), contagens corrigidas para nêutrons térmicos e contagens corrigidas para nêutrons epitérmicos para os dois fios de ouro na direção radial.

Tabela B.1: Dados de posição e das contagens corrigidas para a direção radial para o fio de ouro um (01).

\begin{tabular}{|c|c|c|c|c|c|c|}
\hline $\begin{array}{c}\text { Fio 1 } \\
\text { Radial }\end{array}$ & Geral & Epitérmico & & Térmico & \\
\hline $\begin{array}{c}\text { Posição } \\
(\mathrm{mm})\end{array}$ & $\begin{array}{c}\text { Contagens } \\
\text { Corrigidas }\end{array}$ & $\begin{array}{c}\text { Incerteza } \\
\text { Contagens } \\
\text { Corrigidas }\end{array}$ & $\begin{array}{c}\text { Contagens } \\
\text { Corrigidas }\end{array}$ & $\begin{array}{c}\text { Incerteza } \\
\text { Contagens } \\
\text { Corrigidas }\end{array}$ & $\begin{array}{c}\text { Incerteza } \\
\text { Contagens } \\
\text { Corrigidas }\end{array}$ & $\begin{array}{c}\text { Contagens } \\
\text { Corrigidas }\end{array}$ \\
\hline-180 & 5,4 & 0,04 & 3,41 & 0,03 & 1,99 & 0,01 \\
\hline-160 & 6,1 & 0,04 & 3,85 & 0,03 & 2,25 & 0,01 \\
\hline-140 & 7,12 & 0,05 & 4,49 & 0,03 & 2,63 & 0,02 \\
\hline-120 & 7,89 & 0,05 & 4,98 & 0,03 & 2,91 & 0,02 \\
\hline-100 & 9,23 & 0,06 & 5,82 & 0,04 & 3,41 & 0,02 \\
\hline-80 & 9,13 & 0,05 & 5,76 & 0,03 & 3,37 & 0,02 \\
\hline-60 & 10,05 & 0,06 & 6,34 & 0,04 & 3,71 & 0,02 \\
\hline-40 & 10,91 & 0,06 & 6,88 & 0,04 & 4,03 & 0,02 \\
\hline-20 & 10,63 & 0,06 & 6,71 & 0,04 & 3,92 & 0,02 \\
\hline 0 & 11 & 0,06 & 6,94 & 0,04 & 4,06 & 0,02 \\
\hline 20 & 10,75 & 0,06 & 6,78 & 0,04 & 3,97 & 0,02 \\
\hline 40 & 10,54 & 0,06 & 6,65 & 0,04 & 3,89 & 0,02 \\
\hline 60 & 10,34 & 0,06 & 6,52 & 0,04 & 3,82 & 0,02 \\
\hline 80 & 9,72 & 0,06 & 6,13 & 0,04 & 3,59 & 0,02 \\
\hline 100 & 9,58 & 0,06 & 6,04 & 0,04 & 3,54 & 0,02 \\
\hline 120 & 8,17 & 0,05 & 5,15 & 0,03 & 3,02 & 0,02 \\
\hline 140 & 7,32 & 0,05 & 4,62 & 0,03 & 2,70 & 0,02 \\
\hline 160 & 6,2 & 0,05 & 3,91 & 0,03 & 2,29 & 0,02 \\
\hline 180 & 5,56 & 0,05 & 3,51 & 0,03 & 2,05 & 0,02 \\
\hline
\end{tabular}


Tabela B.2: Dados de posição e das contagens corrigidas para a direção radial para o fio de ouro 02.

\begin{tabular}{|c|c|c|c|c|c|c|}
\hline $\begin{array}{c}\text { Fio 2 } \\
\text { Radial }\end{array}$ & Geral & & Epitérmico & & Térmico & \\
\hline $\begin{array}{c}\text { Posição } \\
(\mathrm{mm})\end{array}$ & $\begin{array}{c}\text { Contagens } \\
\text { Corrigidas }\end{array}$ & $\begin{array}{c}\text { Incerteza } \\
\text { Contagens } \\
\text { Corrigidas }\end{array}$ & $\begin{array}{c}\text { Contagens } \\
\text { Corrigidas }\end{array}$ & $\begin{array}{c}\text { Incerteza } \\
\text { Contagens } \\
\text { Corrigidas }\end{array}$ & $\begin{array}{c}\text { Contagens } \\
\text { Corrigidas }\end{array}$ & $\begin{array}{c}\text { Incerteza } \\
\text { Contagens } \\
\text { Corrigidas }\end{array}$ \\
\hline-200 & 5,53 & 0,06 & 3,49 & 0,04 & 2,04 & 0,02 \\
\hline-180 & 6,05 & 0,07 & 3,82 & 0,04 & 2,23 & 0,03 \\
\hline-160 & 6,15 & 0,06 & 3,88 & 0,04 & 2,27 & 0,02 \\
\hline-140 & 7,03 & 0,07 & 4,44 & 0,04 & 2,59 & 0,03 \\
\hline-120 & 7,94 & 0,07 & 5,01 & 0,04 & 2,93 & 0,03 \\
\hline-100 & 8,91 & 0,08 & 5,62 & 0,05 & 3,29 & 0,03 \\
\hline-80 & 9,19 & 0,08 & 5,80 & 0,05 & 3,39 & 0,03 \\
\hline-60 & 10,28 & 0,08 & 6,49 & 0,05 & 3,79 & 0,03 \\
\hline-40 & 10,83 & 0,09 & 6,83 & 0,06 & 4,00 & 0,03 \\
\hline-20 & 10,58 & 0,09 & 6,68 & 0,06 & 3,90 & 0,03 \\
\hline 0 & 11,03 & 0,09 & 6,96 & 0,06 & 4,07 & 0,03 \\
\hline 20 & 10,66 & 0,09 & 6,73 & 0,06 & 3,93 & 0,03 \\
\hline 40 & 10,65 & 0,09 & 6,72 & 0,06 & 3,93 & 0,03 \\
\hline 60 & 10,22 & 0,09 & 6,45 & 0,06 & 3,77 & 0,03 \\
\hline 80 & 9,79 & 0,09 & 6,18 & 0,06 & 3,61 & 0,03 \\
\hline 100 & 10,36 & 0,1 & 6,54 & 0,06 & 3,82 & 0,04 \\
\hline 120 & 8,16 & 0,08 & 5,15 & 0,05 & 3,01 & 0,03 \\
\hline 140 & 7,33 & 0,08 & 4,62 & 0,05 & 2,71 & 0,03 \\
\hline 160 & 6,34 & 0,07 & 4,00 & 0,04 & 2,34 & 0,03 \\
\hline 180 & 5,65 & 0,07 & 3,56 & 0,04 & 2,09 & 0,03 \\
\hline 200 & 5,36 & 0,06 & 3,38 & 0,04 & 1,98 & 0,02 \\
\hline
\end{tabular}


As Tabelas B.3 e B.4 apresentam as contagens corrigidas integrais (nêutrons térmicos mais epitérmicos), contagens corrigidas para nêutrons térmicos e contagens corrigidas para nêutrons epitérmicos para os fios de ouro na direção axial.

Tabela B.3: Dados de posição e das contagens corrigidas para a direção radial para o fio de ouro um (01).

\begin{tabular}{|c|c|c|c|c|c|c|}
\hline $\begin{array}{c}\text { Fio } 1 \\
\text { Axial }\end{array}$ & Geral & & Epitérmico & & Térmico & \\
\hline $\begin{array}{c}\text { Posição } \\
\text { (cm) }\end{array}$ & $\begin{array}{c}\text { Contagens } \\
\text { Corrigidas }\end{array}$ & $\begin{array}{c}\text { Incerteza } \\
\text { Contagens } \\
\text { Corrigidas }\end{array}$ & $\begin{array}{c}\text { Contagens } \\
\text { Corrigidas }\end{array}$ & $\begin{array}{c}\text { Incerteza } \\
\text { Contagens } \\
\text { Corrigidas }\end{array}$ & $\begin{array}{c}\text { Contagens } \\
\text { Corrigidas }\end{array}$ & $\begin{array}{c}\text { Incerteza } \\
\text { Contagens } \\
\text { Corrigidas }\end{array}$ \\
\hline 20 & 8,98 & 0,05 & 5,67 & 0,03 & 3,31 & 0,02 \\
\hline 40 & 10,61 & 0,06 & 6,69 & 0,04 & 3,92 & 0,02 \\
\hline 60 & 12,26 & 0,06 & 7,74 & 0,04 & 4,52 & 0,02 \\
\hline 80 & 13,88 & 0,06 & 8,76 & 0,04 & 5,12 & 0,02 \\
\hline 100 & 15,32 & 0,07 & 9,67 & 0,04 & 5,65 & 0,03 \\
\hline 120 & 16,79 & 0,07 & 10,59 & 0,04 & 6,20 & 0,03 \\
\hline 140 & 17,97 & 0,07 & 11,34 & 0,04 & 6,63 & 0,03 \\
\hline 160 & 18,82 & 0,08 & 11,87 & 0,05 & 6,95 & 0,03 \\
\hline 180 & 19,86 & 0,1 & 12,53 & 0,06 & 7,33 & 0,04 \\
\hline 200 & 20,61 & 0,08 & 13,00 & 0,05 & 7,61 & 0,03 \\
\hline 220 & 21 & 0,08 & 13,25 & 0,05 & 7,75 & 0,03 \\
\hline 240 & 21,26 & 0,08 & 13,41 & 0,05 & 7,85 & 0,03 \\
\hline 260 & 22,11 & 0,09 & 13,95 & 0,06 & 8,16 & 0,03 \\
\hline 280 & 21,42 & 0,08 & 13,52 & 0,05 & 7,91 & 0,03 \\
\hline 300 & 20,92 & 0,08 & 13,20 & 0,05 & 7,72 & 0,03 \\
\hline 320 & 20,66 & 0,1 & 13,04 & 0,06 & 7,62 & 0,04 \\
\hline 340 & 19,72 & 0,08 & 12,44 & 0,05 & 7,28 & 0,03 \\
\hline 360 & 19,06 & 0,08 & 12,03 & 0,05 & 7,03 & 0,03 \\
\hline 380 & 18,2 & 0,08 & 11,48 & 0,05 & 6,72 & 0,03 \\
\hline 400 & 16,92 & 0,08 & 10,68 & 0,05 & 6,24 & 0,03 \\
\hline 420 & 15,74 & 0,08 & 9,93 & 0,05 & 5,81 & 0,03 \\
\hline 440 & 14,22 & 0,07 & 8,97 & 0,04 & 5,25 & 0,03 \\
\hline 460 & 12,78 & 0,07 & 8,06 & 0,04 & 4,72 & 0,03 \\
\hline 480 & 10,92 & 0,06 & 6,89 & 0,04 & 4,03 & 0,02 \\
\hline 500 & 9,22 & 0,06 & 5,82 & 0,04 & 3,40 & 0,02 \\
\hline 520 & 7,97 & 0,05 & 5,03 & 0,03 & 2,94 & 0,02 \\
\hline 540 & 7,05 & 0,05 & 4,45 & 0,03 & 2,60 & 0,02 \\
\hline & & & & & & \\
\hline
\end{tabular}


Tabela B.4: Dados de posição e das contagens corrigidas para a direção radial para o fio de ouro 02.

\begin{tabular}{|c|c|c|c|c|c|c|}
\hline $\begin{array}{c}\text { Fio 2 } \\
\text { Axial }\end{array}$ & Geral & & Epitérmico & & Térmico & \\
\hline $\begin{array}{c}\text { Posição } \\
\text { (cm) }\end{array}$ & $\begin{array}{c}\text { Contagens } \\
\text { Corrigidas }\end{array}$ & $\begin{array}{c}\text { Incerteza } \\
\text { Contagens } \\
\text { Corrigidas }\end{array}$ & $\begin{array}{c}\text { Contagens } \\
\text { Corrigidas }\end{array}$ & $\begin{array}{c}\text { Incerteza } \\
\text { Contagens } \\
\text { Corrigidas }\end{array}$ & $\begin{array}{c}\text { Contagens } \\
\text { Corrigidas }\end{array}$ & $\begin{array}{c}\text { Contagens } \\
\text { Corrigidas }\end{array}$ \\
\hline 0 & 9,75 & 0,08 & 6,15 & 0,05 & 3,60 & 0,03 \\
\hline 20 & 10,65 & 0,09 & 6,72 & 0,06 & 3,93 & 0,03 \\
\hline 40 & 10,99 & 0,08 & 6,93 & 0,05 & 4,06 & 0,03 \\
\hline 60 & 12,84 & 0,09 & 8,10 & 0,06 & 4,74 & 0,03 \\
\hline 80 & 14,17 & 0,09 & 8,94 & 0,06 & 5,23 & 0,03 \\
\hline 100 & 17,43 & 0,11 & 11,00 & 0,07 & 6,43 & 0,04 \\
\hline 120 & 17,46 & 0,11 & 11,02 & 0,07 & 6,44 & 0,04 \\
\hline 160 & 19,62 & 0,11 & 12,38 & 0,07 & 7,24 & 0,04 \\
\hline 180 & 20,61 & 0,12 & 13,00 & 0,08 & 7,61 & 0,04 \\
\hline 200 & 20,94 & 0,12 & 13,21 & 0,08 & 7,73 & 0,04 \\
\hline 220 & 21,77 & 0,12 & 13,74 & 0,08 & 8,03 & 0,04 \\
\hline 240 & 21,87 & 0,12 & 13,80 & 0,08 & 8,07 & 0,04 \\
\hline 260 & 23,23 & 0,13 & 14,66 & 0,08 & 8,57 & 0,05 \\
\hline 280 & 21,96 & 0,13 & 13,86 & 0,08 & 8,10 & 0,05 \\
\hline 300 & 21,53 & 0,12 & 13,58 & 0,08 & 7,95 & 0,04 \\
\hline 320 & 21,43 & 0,13 & 13,52 & 0,08 & 7,91 & 0,05 \\
\hline 340 & 20,77 & 0,12 & 13,10 & 0,08 & 7,67 & 0,04 \\
\hline 360 & 19,89 & 0,12 & 12,55 & 0,08 & 7,34 & 0,04 \\
\hline 380 & 18,69 & 0,12 & 11,79 & 0,08 & 6,90 & 0,04 \\
\hline 400 & 17,39 & 0,11 & 10,97 & 0,07 & 6,42 & 0,04 \\
\hline 440 & 14,83 & 0,11 & 9,36 & 0,07 & 5,47 & 0,04 \\
\hline 460 & 13,03 & 0,1 & 8,22 & 0,06 & 4,81 & 0,04 \\
\hline 480 & 11,32 & 0,09 & 7,14 & 0,06 & 4,18 & 0,03 \\
\hline 500 & 9,52 & 0,09 & 6,01 & 0,06 & 3,51 & 0,03 \\
\hline 520 & 8,17 & 0,08 & 5,15 & 0,05 & 3,02 & 0,03 \\
\hline 540 & 7,36 & 0,08 & 4,64 & 0,05 & 2,72 & 0,03 \\
\hline & & & & & & \\
\hline
\end{tabular}




\section{APÊNDICE C - Dados obtidos na espectrometria das folhas de ouro}

A Tabela C.1 apresenta os dados de fluxo de nêutrons térmicos e epitérmicos na direção radial para as folha de ouro e as respectivas cotas em que foram inseridas e irradiadas ${ }^{11,18}$.

Tabela C.1: Dados de fluxo de nêutrons térmicos e epitérmicos para os fios de ouro na direção radial.

\begin{tabular}{|c|c|c|c|c|c|}
\hline $\begin{array}{c}\text { Cotas } \\
\text { Radiais } \\
(\mathrm{mm})\end{array}$ & $\begin{array}{c}\text { Posição } \\
(\mathrm{mm})\end{array}$ & $\begin{array}{c}\text { Fluxo de } \\
\text { Nêutrons } \\
\text { Térmicos } \\
\left(\mathrm{N} / \mathrm{cm}^{2} \mathrm{~s}\right)\end{array}$ & $\begin{array}{c}\text { Incerteza } \\
\left(\mathrm{N} / \mathrm{cm}^{2} \mathrm{~s}\right)\end{array}$ & $\begin{array}{c}\text { Fluxo de } \\
\text { Nêutrons } \\
\text { Epitérmicos } \\
\left(\mathrm{N} / \mathrm{cm}^{2} \mathrm{~s}\right)\end{array}$ & $\begin{array}{c}\text { Incerteza } \\
\left(\mathrm{N} / \mathrm{cm}^{2} \mathrm{~s}\right)\end{array}$ \\
\hline 15 & -195 & $1,30 \mathrm{E}+08$ & $3,33 \mathrm{E}+07$ & $8,10 \mathrm{E}+08$ & $1,79 \mathrm{E}+07$ \\
\hline 112,5 & $-97,5$ & $6,08 \mathrm{E}+08$ & $4,25 \mathrm{E}+07$ & $1,03 \mathrm{E}+09$ & $2,02 \mathrm{E}+07$ \\
\hline 210 & 0 & $8,22 \mathrm{E}+08$ & $5,23 \mathrm{E}+07$ & $1,36 \mathrm{E}+09$ & $2,60 \mathrm{E}+07$ \\
\hline 307,5 & 97,5 & $9,68 \mathrm{E}+08$ & $5,75 \mathrm{E}+07$ & $1,04 \mathrm{E}+09$ & $2,89 \mathrm{E}+07$ \\
\hline 405 & 195 & $7,23 \mathrm{E}+08$ & $2,67 \mathrm{E}+07$ & $3,90 \mathrm{E}+08$ & $1,32 \mathrm{E}+07$ \\
\hline
\end{tabular}

A Tabela C.2 apresenta os dados de fluxo de nêutrons térmicos e epitérmicos na direção axial para as folha de ouro e as respectivas cotas em que foram inseridas e irradiadas.

Tabela C.2: Dados de fluxo de nêutrons térmicos e epitérmicos para os fios de ouro na direção radial.

\begin{tabular}{|r|c|c|c|c|}
\hline $\begin{array}{c}\text { Cotas } \\
\text { Axiais } \\
(\mathrm{mm})\end{array}$ & $\begin{array}{c}\text { Fluxo de } \\
\text { Nêutrons } \\
\text { Térmicos } \\
\left(\mathrm{N} / \mathrm{cm}^{2} \mathrm{~s}\right)\end{array}$ & $\begin{array}{c}\text { Incerteza } \\
\left(\mathrm{N} / \mathrm{cm}^{2} \mathrm{~s}\right)\end{array}$ & $\begin{array}{c}\text { Fluxo de } \\
\text { Nêutrons } \\
\text { Epitérmicos } \\
\left(\mathrm{N} / \mathrm{cm}^{2} \mathrm{~s}\right)\end{array}$ & $\begin{array}{c}\text { Incerteza } \\
\left(\mathrm{N} / \mathrm{cm}^{2} \mathrm{~s}\right)\end{array}$ \\
\hline 91 & $3,93 \mathrm{E}+08$ & $2,46 \mathrm{E}+07$ & $4,97 \mathrm{E}+08$ & $1,22 \mathrm{E}+07$ \\
\hline 182 & $5,76 \mathrm{E}+08$ & $4,29 \mathrm{E}+07$ & $9,78 \mathrm{E}+08$ & $2,28 \mathrm{E}+07$ \\
\hline 273 & $6,37 \mathrm{E}+08$ & $7,44 \mathrm{E}+07$ & $1,32 \mathrm{E}+09$ & $3,59 \mathrm{E}+07$ \\
\hline 364 & $8,22 \mathrm{E}+08$ & $5,23 \mathrm{E}+07$ & $1,36 \mathrm{E}+09$ & $2,60 \mathrm{E}+07$ \\
\hline 455 & $7,97 \mathrm{E}+08$ & $5,61 \mathrm{E}+07$ & $1,18 \mathrm{E}+09$ & $2,79 \mathrm{E}+07$ \\
\hline 546 & $6,08 \mathrm{E}+08$ & $4,25 \mathrm{E}+07$ & $8,29 \mathrm{E}+08$ & $2,02 \mathrm{E}+07$ \\
\hline 637 & $3,81 \mathrm{E}+08$ & $2,22 \mathrm{E}+07$ & $3,54 \mathrm{E}+08$ & $9,68 \mathrm{E}+06$ \\
\hline
\end{tabular}


A partir dos dados das folhas de ouro apresentados nas Tabelas C.1 e C.2, foram realizados os ajustes para obtenção do raio e altura efetivos e consequentemente o Buckling para as folhas de ouro. O gráfico da Figura C.1 apresenta o ajuste para nêutrons térmicos na direção radial.

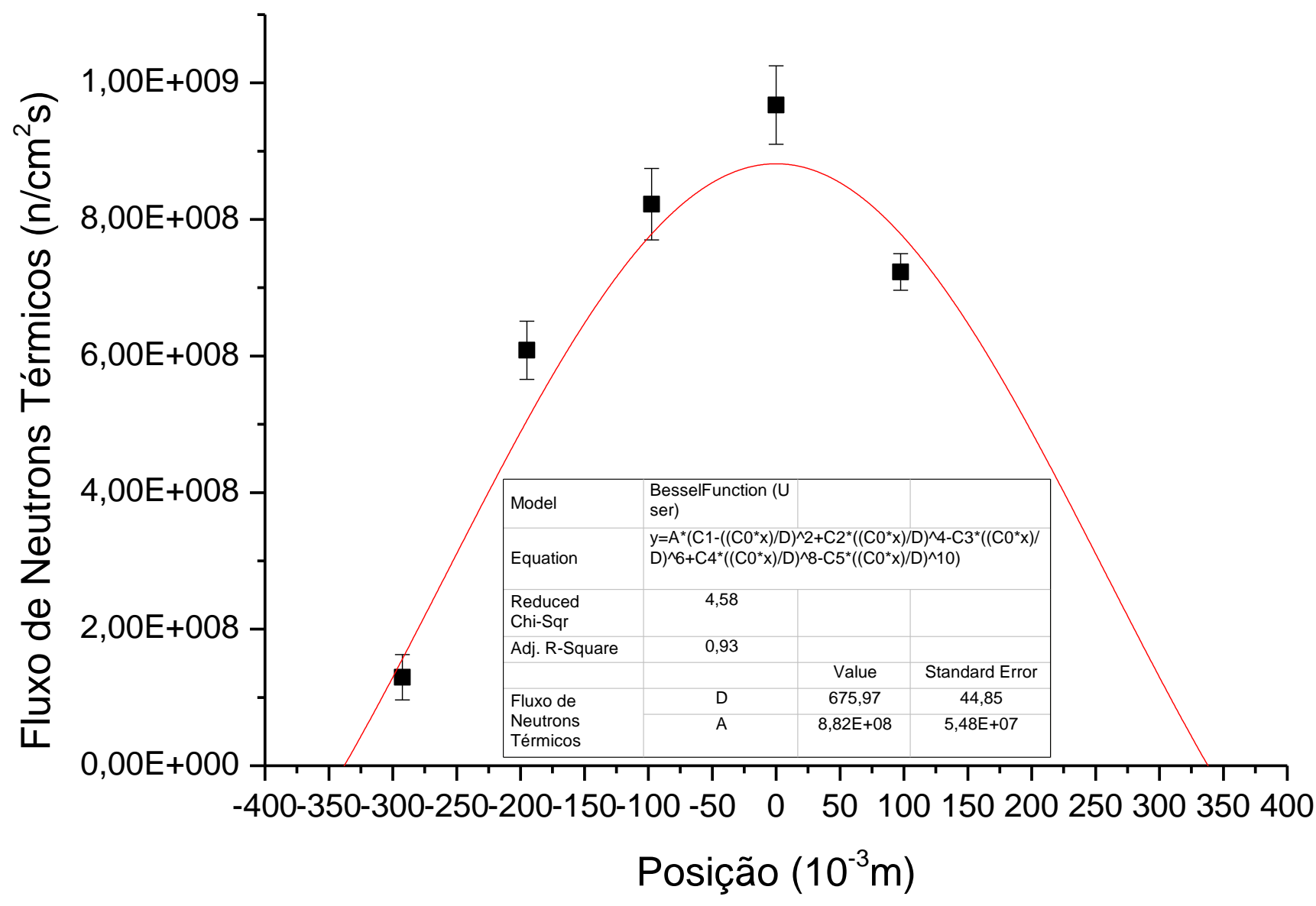

Figura C.1: Perfil do fluxo de nêutrons térmicos na direção radial para as folhas de ouro.

O gráfico da Figura C.2 apresenta o ajuste para nêutrons epitérmicos na direção radial. 


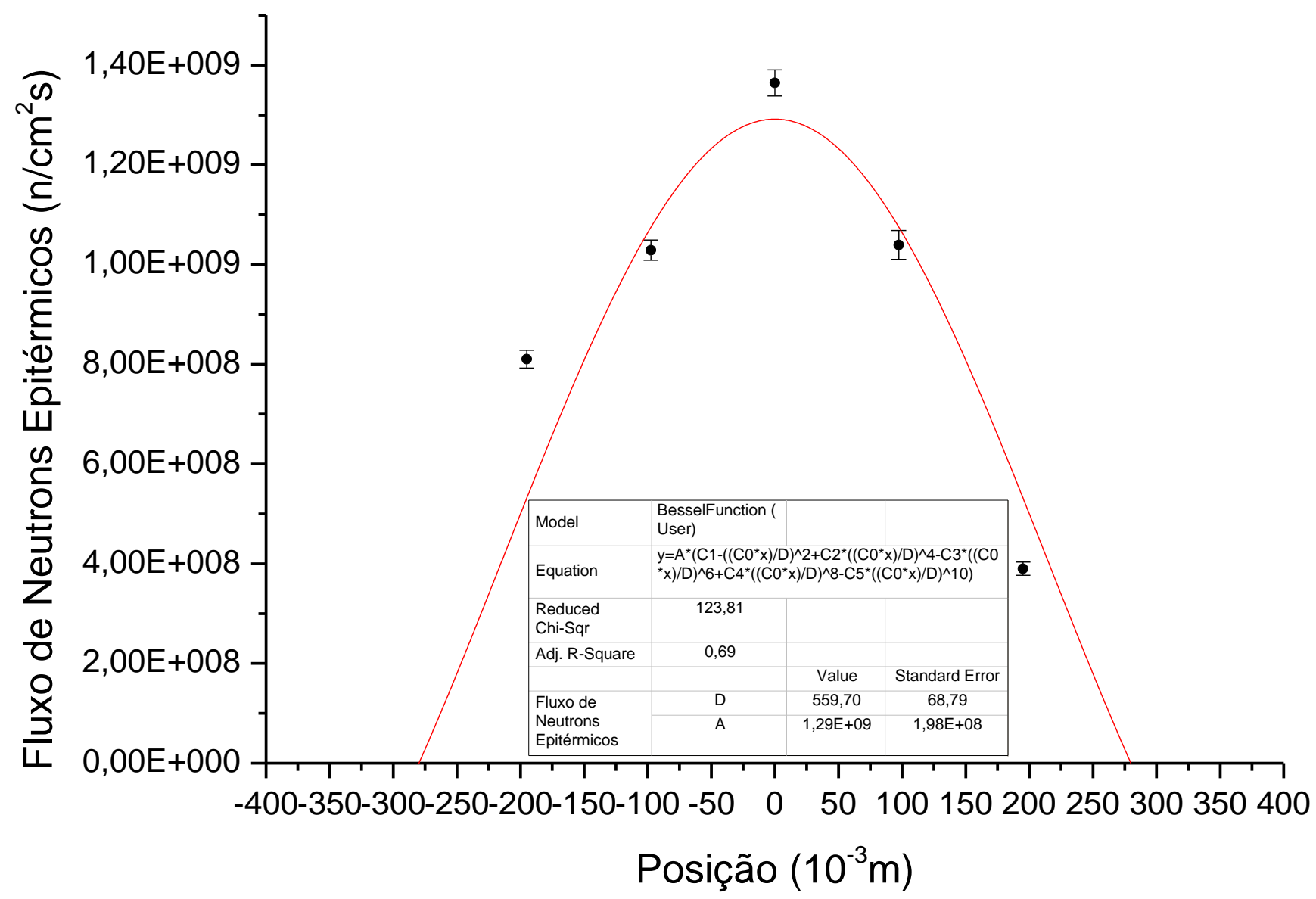

Figura C.2: Perfil do fluxo de nêutrons epitérmicos na direção radial para as folhas de ouro. direção axial. 


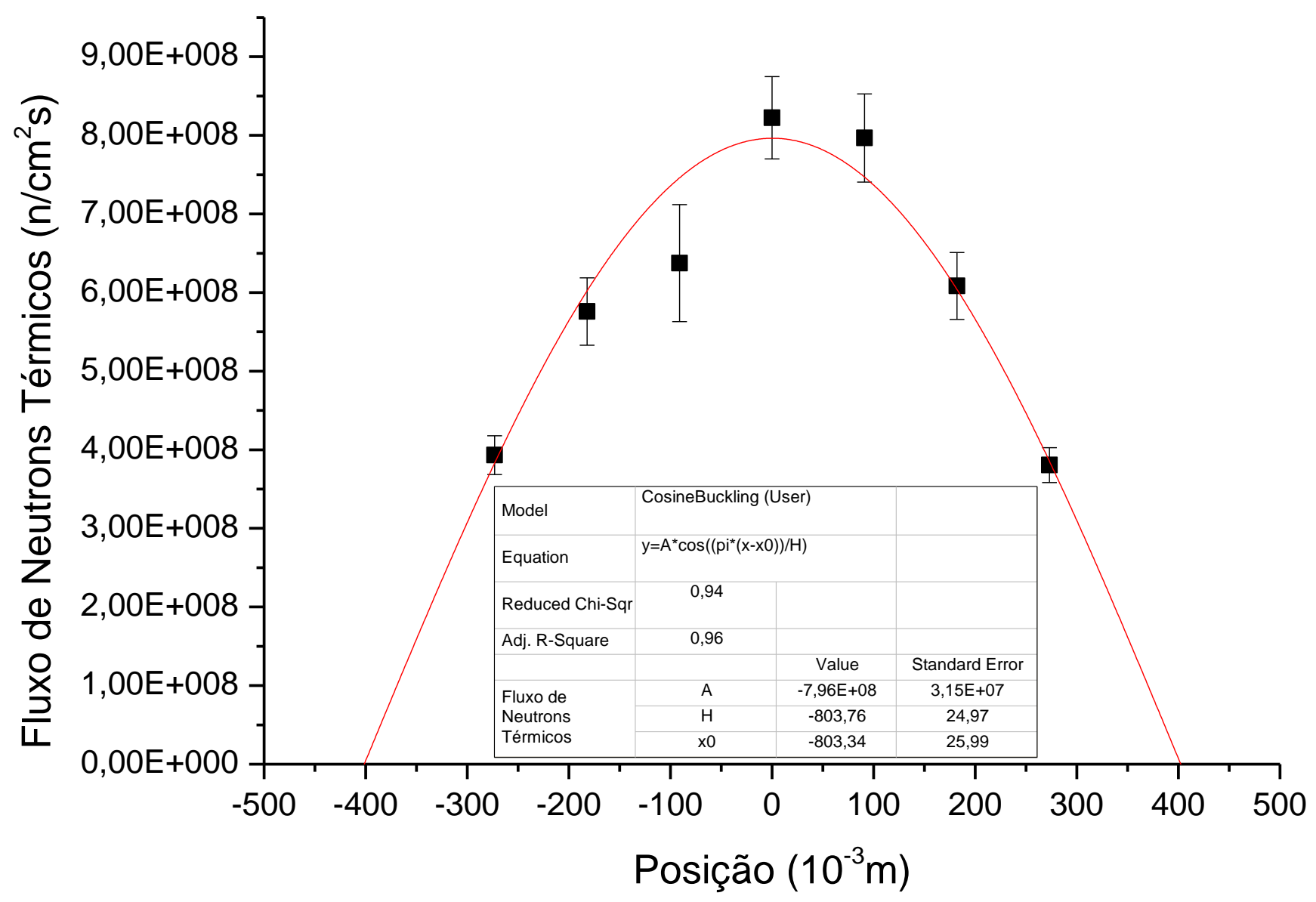

Figura C.3: Perfil do fluxo de nêutrons térmicos na direção axial para as folhas de ouro.

O gráfico da Figura C.4 apresenta o ajuste para nêutrons epitérmicos na direção axial. 


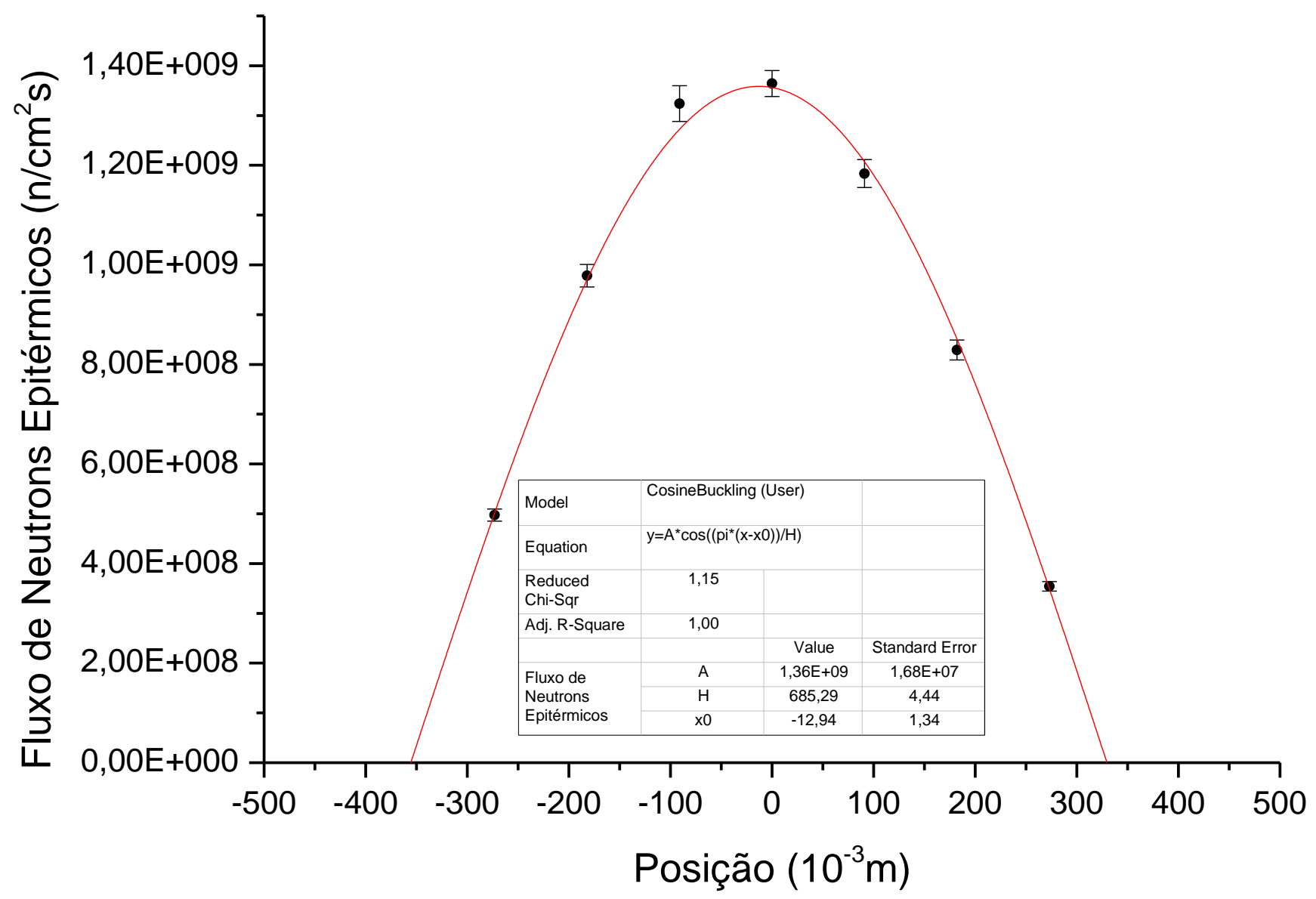

Figura C.4: Perfil do fluxo de nêutrons epitérmicos na direção axial para as folhas de ouro.

A partir dos ajustes dos gráficos apresentados nas Figuras de C.1 a C.4, os resultados obtidos para raio e altura efetivos, bem como para o Buckling térmico e epitérmico do reator IPEN/MB-01 para as folhas de ouro. A Tabela C.3 apresenta esses dados.

Tabela C.3: Resultados obtidos a partir dos dados dos fios de ouro.

\begin{tabular}{|l|c|c|c|}
\hline Nêutrons & $\begin{array}{c}\text { Raio } \\
\left(10^{-2} \mathrm{~m}\right)\end{array}$ & $\begin{array}{c}\text { Altura } \\
\left(10^{-2} \mathrm{~m}\right)\end{array}$ & $\begin{array}{c}\text { Buckling } \\
\left(\mathrm{m}^{-2}\right)\end{array}$ \\
\hline Térmico & $33,8 \pm 2,24$ & $80,38 \pm 2,50$ & $65,90 \pm 6,78$ \\
\hline Epitérmico & $27,98 \pm 3,44$ & $68,53 \pm 0,44$ & $94,87 \pm 18,16$ \\
\hline
\end{tabular}


Observa-se a partir dos dados da Tabela C.3 que existe uma divergência entre os valores obtidos para o Buckling térmico e para o epitérmico, tais resultados não convergem mesmo se consideradas as incertezas dos cálculos. Nesse sentido, as medidas com as folhas de ouro precisam ser mais bem estudadas e a sugestão de se refazer as medidas considerando uma quantidade maior de folhas nas direções radial e axial foram apresentadas na conclusão do trabalho. 


\section{APÊNDICE D - OBTENÇÃO DA FUNÇÃO DE BESSEL PARA O AJUSTE DA CURVATURA DO FLUXO DE NEUTRONS}

Neste apêndice são apresentadas as equações que possibilitaram fazer o ajuste da função de Bessel no software Origin e com isso determinar o raio efetivo para as medidas radiais.

Função de Bessel

$$
J_{n}(x)=\sum_{s=0}^{\infty} \frac{(-1)^{s}}{s !(n+s) !}\left(\frac{x}{2}\right)^{n+2 s}
$$

Função de Bessel de ordem zero

$$
J_{0}(x)=\sum_{s=0}^{\infty} \frac{(-1)^{s}}{(s !)^{2}}\left(\frac{x}{2}\right)^{2 s}
$$

Para o caso de um reator no formato cilíndrico a função de Bessel fica de acordo com a equação abaixo:

$$
J_{0}\left(\frac{2,405 r}{R_{e x}}\right)=\sum_{s=0}^{\infty} \frac{(-1)^{s}}{(s !)^{2}}\left(\frac{2,405 r}{2 R_{e x}}\right)^{2 s}=\sum_{s=0}^{\infty} \frac{(-1)^{s}}{(s !)^{2}}\left(\frac{2,405 r}{D_{e x}}\right)^{2 s}
$$

onde Rex é o raio extrapolado e Dex=2Rex que é o diâmetro extrapolado.

Para o reator IPEN/MB-01 no formato cilíndrico a função de Bessel foi expandida até a quinta ordem, pois já se obtém um bom ajuste com $0 \mathrm{X}^{2}$ bem próximo de 1. A equação inserida no programa Origin 8.5.1 para a obtenção do ajuste automático está expresso abaixo:

$$
y=A\left[C 1-\left(\frac{C 0 x}{D}\right)+\left(\frac{C 0 x}{D}\right)^{2}+C 2\left(\frac{C 0 x}{D}\right)^{4}-C 3\left(\frac{C 0 x}{D}\right)^{6}+C 4\left(\frac{C 0 x}{D}\right)^{8}-C 5\left(\frac{C 0 x}{D}\right)^{10}\right]
$$

onde y é a função de Bessel multiplicada pela amplitude do fluxo de nêutrons, $x$ é a distância radial, $A$ é amplitude de fluxo, D é o diâmetro extrapolado $D_{\text {ex }}$ e as constantes C0, C1, C2, C3, C4 e C5 são respectivamente os valores 2,405, 1, $1 /(2 !)^{2}, 1 /(3 !)^{2}, 1 /(4 !)^{2}$ e $1 /(5 !)^{2}$. 


\section{APÊNDICE E - O ENSINO DO TEMA ENERGIA NUCLEAR NO ENSINO MÉDIO}

O presente projeto teve como parceira a Secretaria Estadual de Educação do Estado de São Paulo que através do programa Bolsa Mestrado, financiou parte do presente estudo.

O mestrando é professor da rede estadual de ensino e recebeu bolsa incentivo do programa para realização do mestrado, como um dos requisitos, esta dissertação deverá apresentar aspectos pedagógicos que possam contribuir para o ensino de Física nas escolas estaduais. Nesse sentido, o trabalho foi ampliado para além das medidas e analises da Física de Reatores.

\section{E.1 Objetivo}

Essa parte pedagógica tem como objetivo apresentar um retrato da compreensão de estudantes do terceiro ano do ensino médio de uma escola da rede estadual de ensino de São Paulo. Será apresentado um diagnostico de como os alunos interagem com o tema Energia Nuclear após passarem por pelo menos 10 anos pelo sistema de ensino oficial.

\section{E.2 Introdução}

Desde 2008, o governo do Estado de São Paulo, por meio da Secretaria Estadual de Educação, implantou no terceiro ano do ensino médio temas relacionados à física moderna, sobretudo temas que envolvem a utilização da energia nuclear. 
Tal inserção de conteúdo está em consonância com os parâmetros curriculares nacionais, uma vez que são temas atuais, muito presentes no cotidiano dos cidadãos. No que se refere ao ensino de Física, temos a partir do $P C N+q u e^{21}$ :

"A Física deve apresentar-se, portanto, como um conjunto de competências específicas que permitam perceber e lidar com os fenômenos naturais e tecnológicos, presentes tanto no cotidiano mais imediato quanto na compreensão do universo distante [...] Trata-se de construir uma visão da Física que esteja voltada para a formação de um cidadão contemporâneo, atuante e solidário, com instrumentos para compreender, intervir e participar na realidade". p.2.

Estudos demonstram que existe uma dificuldade de compreensão dessa temática por parte dos estudantes e nesse sentido, é necessário buscar a superação do conhecimento superficial e ineficiente que os alunos detêm sobre o tema Energia Nuclear, incluindo-o como um dos temas atuais de Física ${ }^{22}$.

\section{E.3 Metodologia}

Para a obtenção de informações dos conhecimentos adquiridos ao longo do processo escolar pelos alunos, foram realizadas duas atividades especificas: a primeira consistiu de redação cujo tema era energia nuclear; a segunda se baseou na realização de questionário prévio com alunos do terceiro ano do Ensino Médio sobre questões básicas associadas à Energia Nuclear. A Figura E.1 apresenta o questionário que foi utilizado como referência ${ }^{22}$. 


\section{Questionário}

\begin{tabular}{|l|l|l|}
\hline None & Idade \\
\hline Escols & Senie: & \\
\hline
\end{tabular}

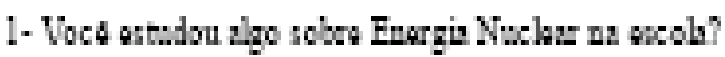

(j) $\sin ()$ No

Se su reppots foi sim, rolus o qua foi aprenetado pols protencr:

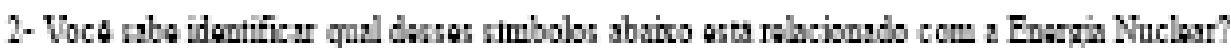

i)

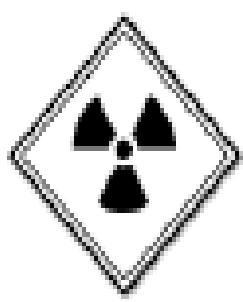

b)

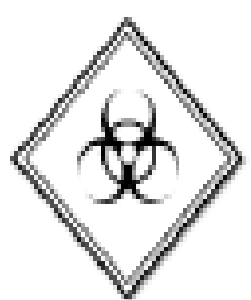

Ej

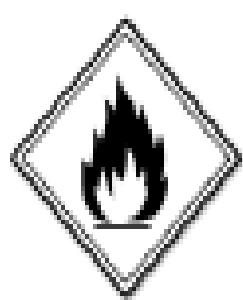

d]

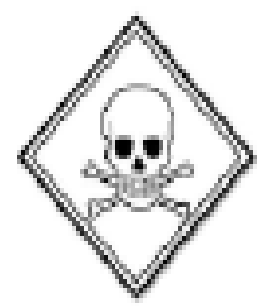

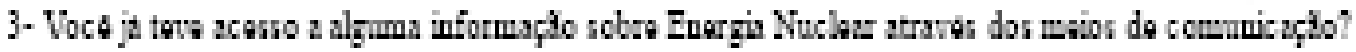

(j) $\sin ()$ No

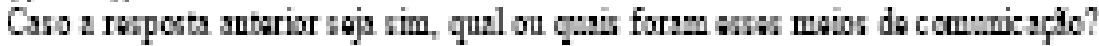

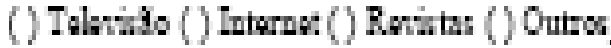

4 0 qua :a far lombre a palana Enogin Nochar?

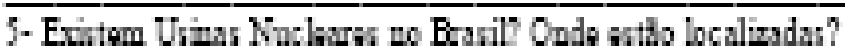

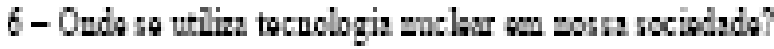

7. Qmal a ma opinito sobro o wo da Enarga Nuclas pan 2 acia duda?

Figura E.1: Questionário submetido aos alunos 
Importante salientar que a redação e o questionário foram realizados pelos alunos sem que houvesse qualquer introdução ao tema por parte do professor a fim de evitar possiveis interferencias e induções aos alunos.

Participaram das atividades 77 alunos de faixa etária de 16 a 18 anos. A partir das redações e dos questionários foram elaborados gráficos comparativos.

\section{E.4 Resultados}

As informações obtidas com as redações e com as respostas ao questionário foram separadas em categorias e inseridas em gráficos do tipo "pizza" para um comparativo percentual.

O primeiro gráfico, Figura E.2, esta associado a lembrança que os estudantes tem de o tema energia nuclear ter sido abordado ao longo de sua vida escola.

\section{Você estudou sobre Energia Nuclear na escola?}

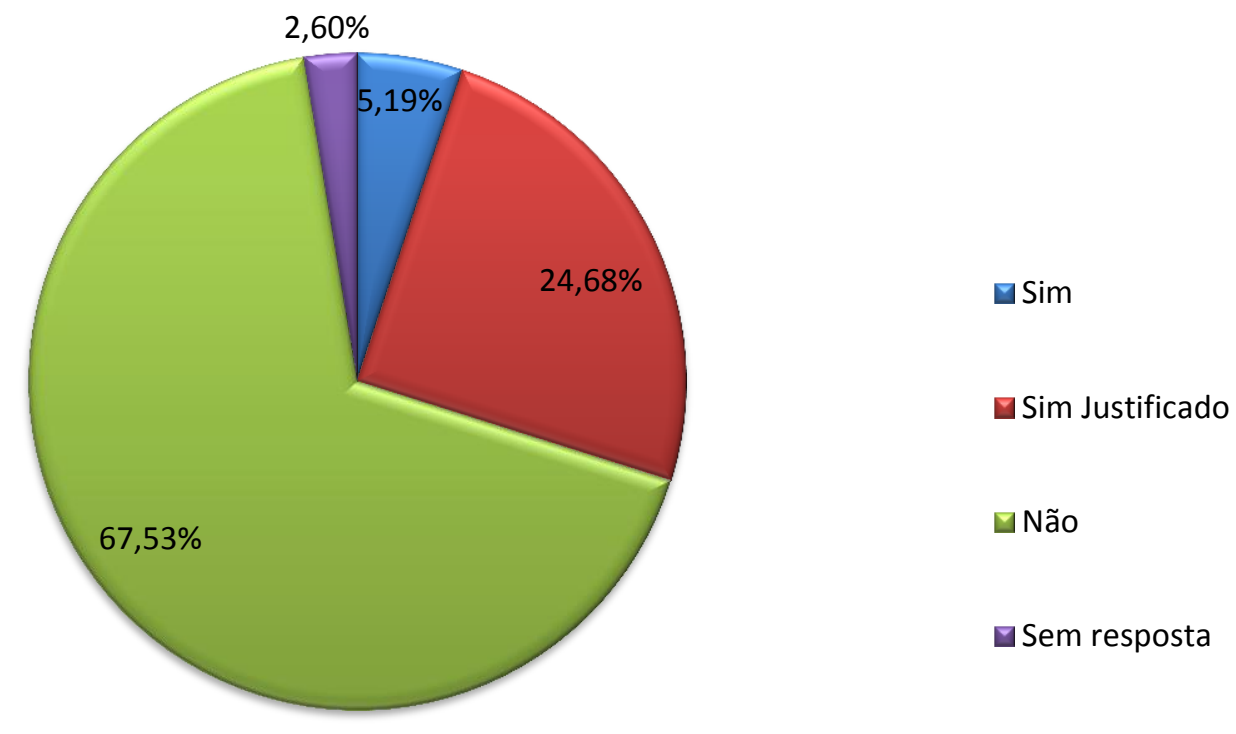

Figura E.2: Representação percentual dos estudantes que lembram de ter estudado sobre energia nuclear 
Pode-se constatar que $67,53 \%$ relatam não ter estudado sobre o tema na escola e dos que afirmam ter estudado a grande maioria deles $24,68 \%$ conseguem citar os assuntos abordados.

A Figura E.3, apresenta o reconhecimento do simbolo que indica o simbolo de radioatividade / radiação.

\section{Reconhecimento do Simbolo}

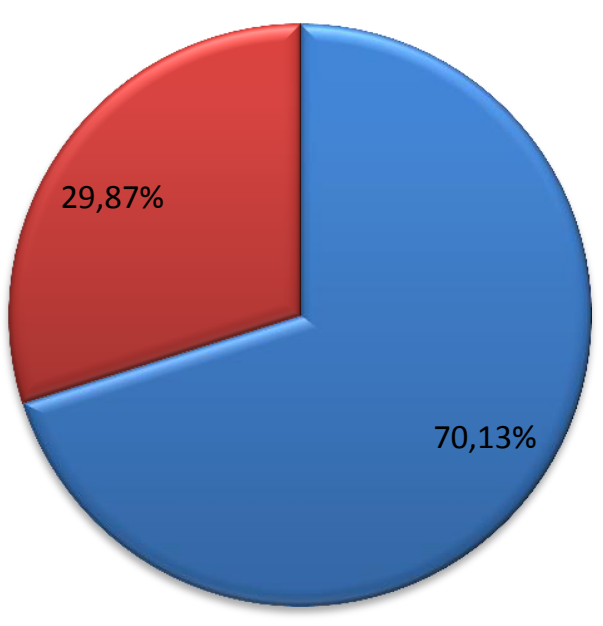

$\square$ Correto

DErrado

Figura E.3: Reconhecimento do Simbolo de Radiação

Em relação ao simbolo, a grande maioria, $70,13 \%$, conseguiram identificar o correto. Não é possivel identificar se o acerto se deu ao fato de o simbolo ter sido apresentado na escola ou se o acerto foi por eliminação dos demais. De qualquer forma, como no gráfico anterior, Figura E.2, tivemos um grande número de estudantes que afirmavam não terem estudado sobre energia nuclear na escola, é provavel que o reconhecimento do simbolo ocorreu por influencia de algum meio de comunicação.

Exatamente sobre isso a Figura E.4 apresenta os dados sobre a obtenção de informação sobre energia nuclear em meios de comunicação. 


\section{Acesso a Informação sobre Energia Nuclear}

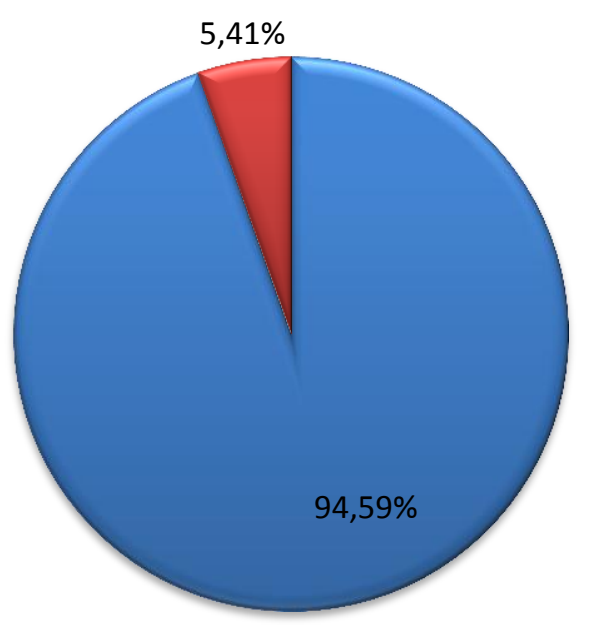

Figura E.4: Acesso a informação sobre energia nuclear em meios de comunicação

A partir da figura E.4, observa-se que os meios de comunicação tais como: televisão, internet, revistas e outros são os grandes responsaveis pelas informações obtidas sobre energia nuclear e, portanto, são os principais instrumentos divulgadores desse campo do conhecimento. O resultado dos estudantes que afirmam ter obtido informações sobre energia nuclear através dos meios de comunicação é de $94,59 \%$.

A Figura E.5, indica entre os meios de comunicação, qual é o meio de comunicação mais influente, bem como o percentual de estudantes que obtiveram iformações sobre energia nuclear em dois ou mais meios. 


\section{Obtenção de Informação}

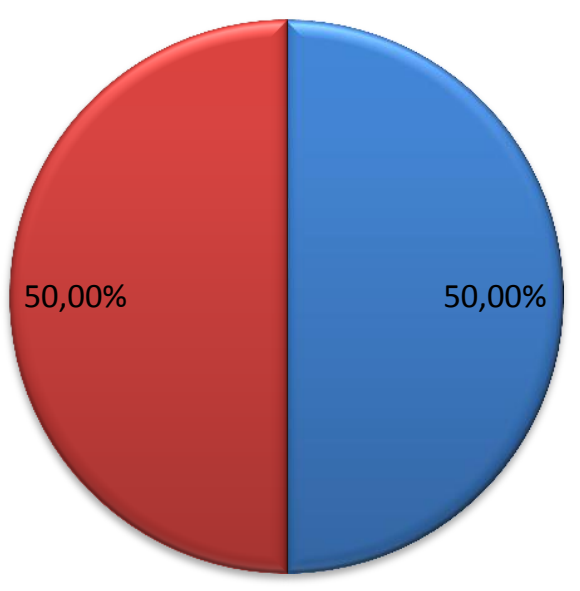

$\square$ TV Dois ou mais meios

Figura E.5: Meios de comunicação nos quais foram obtidas as informações sobre energia nuclear

A partir da Figura E.5, pode-se constatar que a televisão é o mais influente e principal meio de comunicação responsavel por divulgar e registrar o tema energia nuclear junto aos estudantes, uma vez que 50\% deles afirmam que a obtenção de informação foi exclusivamente atraves da televisão. Os outros $50 \%$ dos estudantes afirmaram ter obtido informações sobre energia nuclear em mais de um meio de comunicação, dado relevante que indica que o tema vem sendo abordado por diversos meios de comunicação, fato esse que contribui para a popularização do tema.

Com o sentido de identificar quais dos temas relacionados a energia nuclear os estudantes se recordam, a Figura E.6 apresenta os dados obtidos em relação a esta questão. 


\section{O que lembra a palavra Energia Nuclear?}

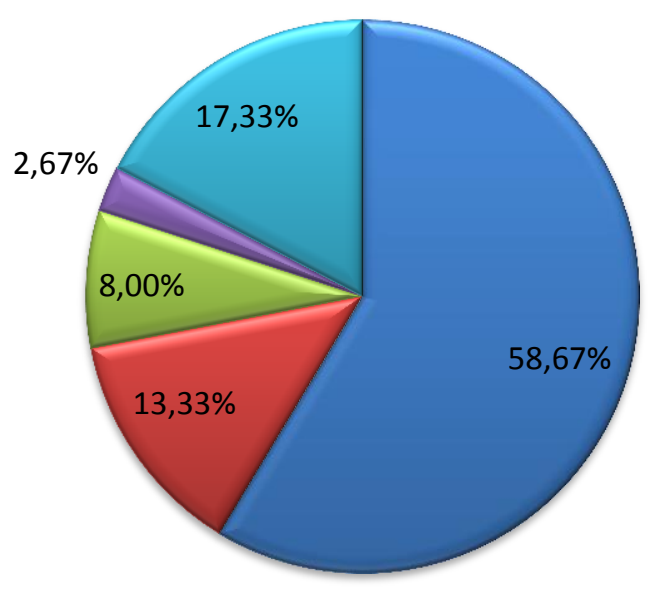

\Bombas/Destruição/Guerra

• Geração de Energia

$\square$ Bombas + Energia

Acidentes

$\square$ Outros/Não Sabem/Não responderam

Figura E.6: Temas relacionados a energia nuclear que os estudantes recordam

A Figura E.6 indica que quando se fala em energia nuclear o principal tema que surge e esta registrado no escopo de informações obtidas pelos estudantes por $58,67 \%$ deles, está associado a bombas nucleares, ações destrutivas e guerras. Ainda, a geração de energia elétrica aparece como uma segunda associação do tema.

Em relação a geração de energia elétrica a partir de fontes de energia nuclear, a Figura E.7 indica o conhecimento dos estudantes sobre a existencia de usinas nucleares no Brasil e onde estão localizadas. 


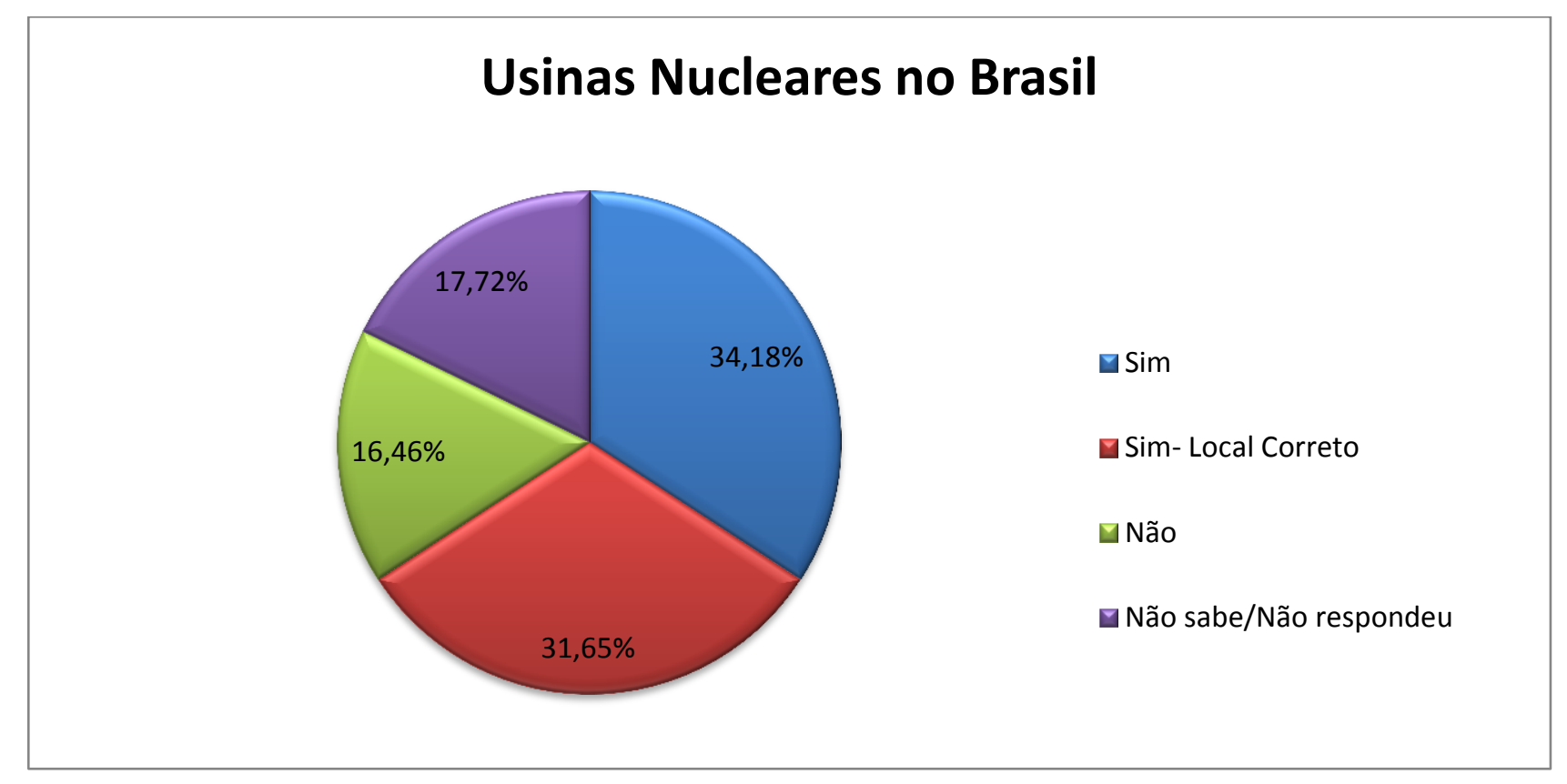

Figura E.7: Indicação da existencia de usina nuclear no Brasil e sua localização

A Figura E.7, indica que a maioria dos estudantes sabe que existe usinas nucleares no Brasil. Entre os que sabem que existe mas não sabem precisar 0 local onde se encontram, $34,18 \%$, e os que sabem que existe e onde se localizam, $31,65 \%$, tem-se que $65,83 \%$ sabem que existem usinas nucleares no Brasil, ou seja, praticamente dois terços dos estudantes sabem que existe usinas nucleares no Brasil e um terço não sabem ou afirmam não ter. Esse ultimo dado é importante, pois indica que $34,18 \%$ dos estudantes desconhecem que o Brasil se utiliza também de energia nuclear para obter energia elétrica.

A Figura E.8, indica quais foram as respostas dos estudantes quando perguntados em quais áreas se utiliza energia nuclear. 


\section{Utilização de Tecnologia Nuclear}

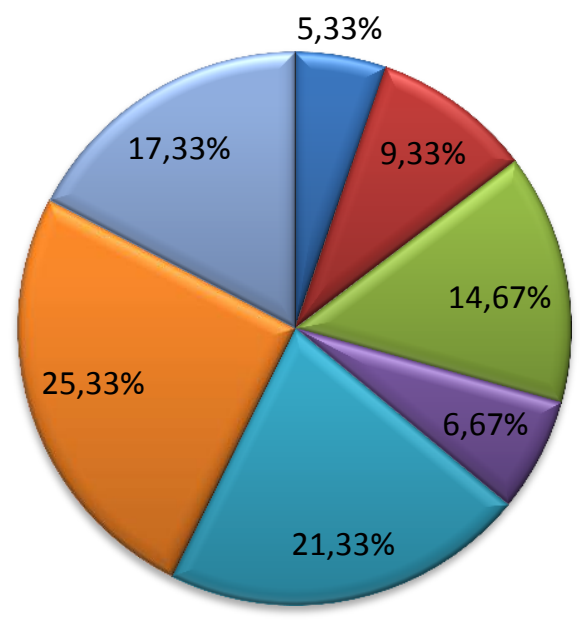

Desquisas

Bombas

$\square$ Energia

$\square$ Bombas + Medicina ou Energia

$\square$ Medicina

$\square$ Outros

$\square$ Não sabe/Não respondeu

Figura E.8: Indicativo de quais áreas utilizam energia nuclear

Da observação da Figura E.8, no que se refere as áreas nas quais se utilizam energia nuclear, as respostas foram bastante variadas. Foram citadas pesquisas cientificas, bombas, geração de energia, medicina e outras áreas. A medicina que atualmente é uma das áreas que utiliza muita tecnologia nuclear em tratamentos e diagnosticos é uma das mais citadas, com 21,33\%. O que aparece como mais citado identificado como outros, $25,33 \%$, estão associados a aparelhos e componentes eletronicos, o que indica um desconhecimento dos estudantes desses elementos e a atribuição da utilização de energia nuclear em áreas que não são de seu dominio.

Por fim, a figura E.9 apresenta a opinião pessoal dos estudantes sobre a utilização de energia nuclear. 


\section{Opinião}

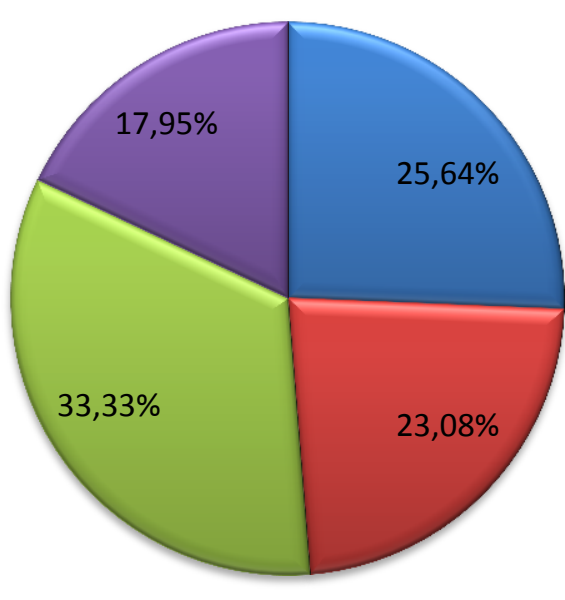

$\square$ Bom

$\square$ Ruim

$\square$ Equilibrado

Q Não sabe/Não respondeu

Figura E.9: Opinião dos estudantes quanto a utilização de energia nuclear em nossa sociedade

Pela Figura E.9, fica evidenciado que em torno de um quarto dos estudantes, 25,64\%, consideram como positiva, boa, a utilização de energia nuclear em nossa sociedade, $23,08 \%$ consideram como ruim essa utilização e ainda, 33,33\% consideram que existe aspectos bons e também ruins mantendo um equilibrio de opinião.

\section{E.5 Conclusões}

O conjunto dos dados obtidos permite afirmar que os estudantes do terceiro ano do ensino médio que responderam ao questionário, bem como realizaram a redação, ao longo de sua vida escolar interagiram com o tema energia nuclear, porém não foi a escola o principal responsavel por essa interação e sim os meios de comunicação.

A forma como as informações foram obtidas faz com que os estudantes cheguem ao final de um ciclo escolar importante, conclusão do ensino médio, com um conhecimento superficial e fragmentado do tema energia nuclear. Eles conseguem identificar diversas áreas em que são utilizadas tecnologias nucleares, mas não conseguem do ponto de vista cientifico aglutinar todas essas áreas em um conhecimento teórico único, ou seja, não conseguem relacionar a utilização da 
energia nuclear com aspectos de física nuclear. Isso faz com que o tema energia nuclear seja identificado como um conjunto de informações e não como um campo do conhecimento cientifico indispensável para a vida moderna e que se relaciona com as aulas de física e de outras ciências que os estudantes tiveram ao longo de sua formação escolar.

Os dados apresentados sugerem que é fundamental a escola resgatar seu papel formador e articulador de conhecimentos e para isso o tema Energia Nuclear precisa ser desmistificado para os alunos e também para os professores, é necessário inserir no contexto da formação docente esse tema, para que os professores tenham maior compreensão e familiaridade com o assunto e como consequencia possam ensinar seus alunos de forma mais qualificada e adequada. 


\section{ANEXO A - O Reator Nuclear IPEN/MB-01}

\section{A.1 Introdução}

O IPEN/MB-01 é um reator nuclear genuinamente brasileiro, concebido por pesquisadores e Engenheiros do Instituto de Pesquisas Energéticas e Nucleares (IPEN-CNEN/SP) e da antiga COPESP (Coordenadoria para Projetos Especiais), atual CTMSP (Centro Tecnológico da Marinha em São Paulo), financiado e construído pela Marinha do Brasil, atingiu sua primeira criticalidade às 15 horas e 35 minutos do dia 9 de Novembro de 1988, sendo oficialmente entregue para operação ao IPEN - CNEN/SP em 28 de Novembro daquele ano.

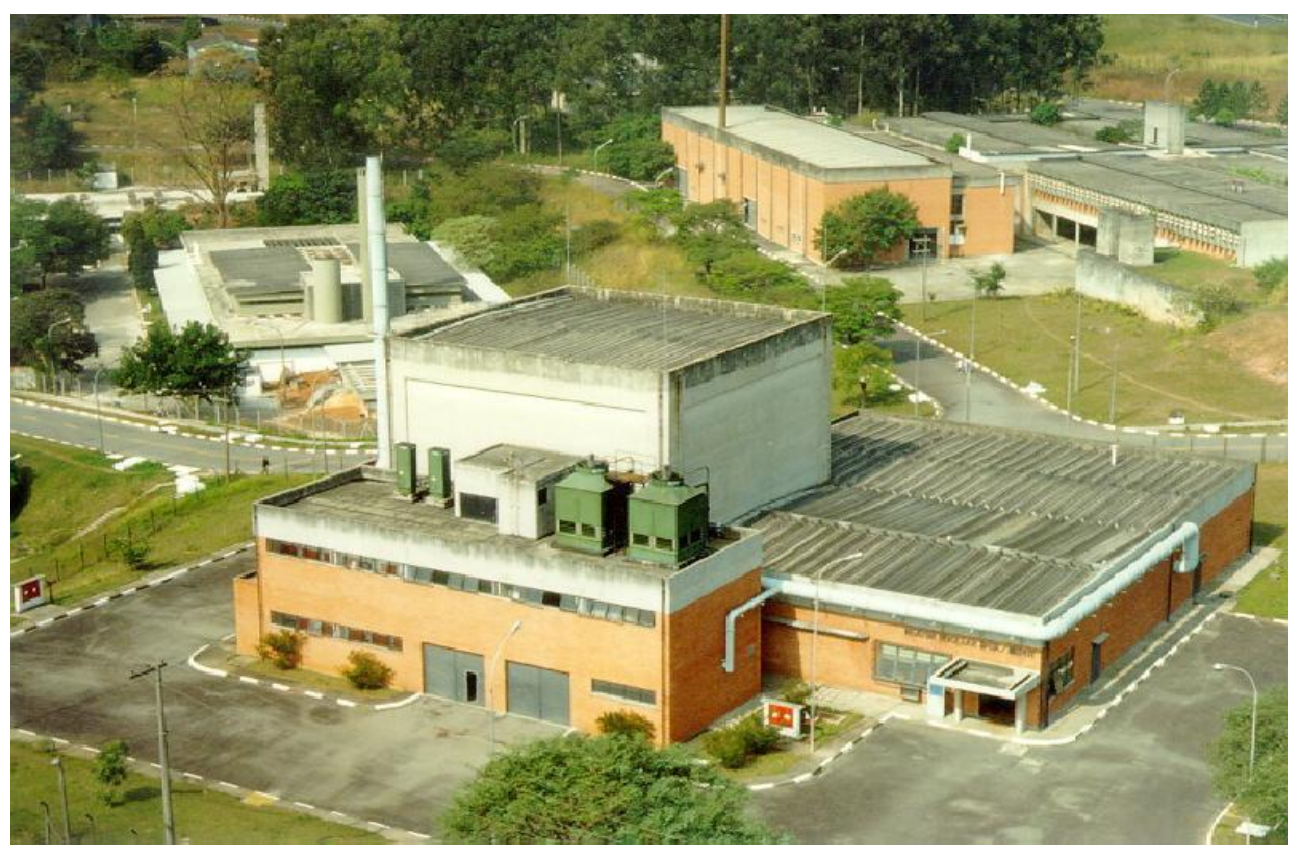

FIGURA A.1Vista aérea do Reator Nuclear IPEN/MB-01.

O projeto do Reator IPEN/MB-01 foi iniciado em 1983 e suas obras foram concluídas em Julho de 1988. No mesmo mês iniciaram-se os testes dos seus vários sistemas. Cumpridas as exigências legais necessárias para o seu licenciamento, foi concedida em 19 de Outubro de 1988, pelas resoluções CNEN 23 e 25 a autorização para a sua operação inicial.

O Reator IPEN/MB-01 é uma instalação nuclear que permite a simulação 
de todas as características nucleares de um reator de grande porte em escala reduzida, sem que haja a necessidade de se construir um complexo sistema de remoção de calor. Esse tipo de reator é conhecido mundialmente como Reator de Potência Zero ou Unidade Crítica, sendo o IPEN/MB-01, projetado para operar a uma potência máxima de 100 watts. Esses reatores representam uma ferramenta básica, que permitem aos pesquisadores estudarem não apenas por cálculos teóricos, mas também com medidas experimentais, o desempenho e as características do núcleo de um reator de potência ou de propulsão naval, antes da sua efetiva instalação, simulando as condições de projeto na própria instalação.

A filosofia que norteou o projeto do reator IPEN/MB-01 foi no sentido de se projetar e testar um núcleo típico para uso em propulsão naval, ou seja, que o controle de reatividade se desse a partir da inserção ou retirada de barras de controle, contrariando o modelo de muitas unidades críticas em que o controle se dá pelo nível d'água no tanque moderador. Esse controle de reatividade por barras de controle é típico de reatores navais, em que se necessita de rápidas variações de potência, a fim de se empreenderem manobras de fuga ou de perseguição.

\section{A.2 Descrição do Reator}

O primeiro núcleo do Reator IPEN/MB-01 possui a forma de paralelepípedo com dimensões ativas de $39 \times 42 \times 54,6 \mathrm{~cm}$, sendo constituído de um arranjo de $28 \times 26$ varetas combustíveis e 48 tubos guias, destinados a inserção das varetas de controle/segurança, responsáveis pelo controle da reação em cadeia e desligamento do reator. Nesta configuração, dita retangular, tem-se um total de 680 varetas e um excesso de reatividade de aproximadamente 2415 pcm.

No entanto o núcleo do Reator Nuclear IPEN/MB-01 possibilita a montagem de diferentes arranjos críticos, ou seja, configurações de núcleos, uma vez que foi projetado para que apresentasse a versatilidade e a flexibilidade necessárias para tais finalidades. Para tal, a placa matriz que sustenta o núcleo do reator possui 900 furos espaçados entre si por $15 \mathrm{~mm}$, em um arranjo de 30×30. Nesta placa matriz foram montados os arranjos críticos retangulares, quadrado e cilindrizado. 


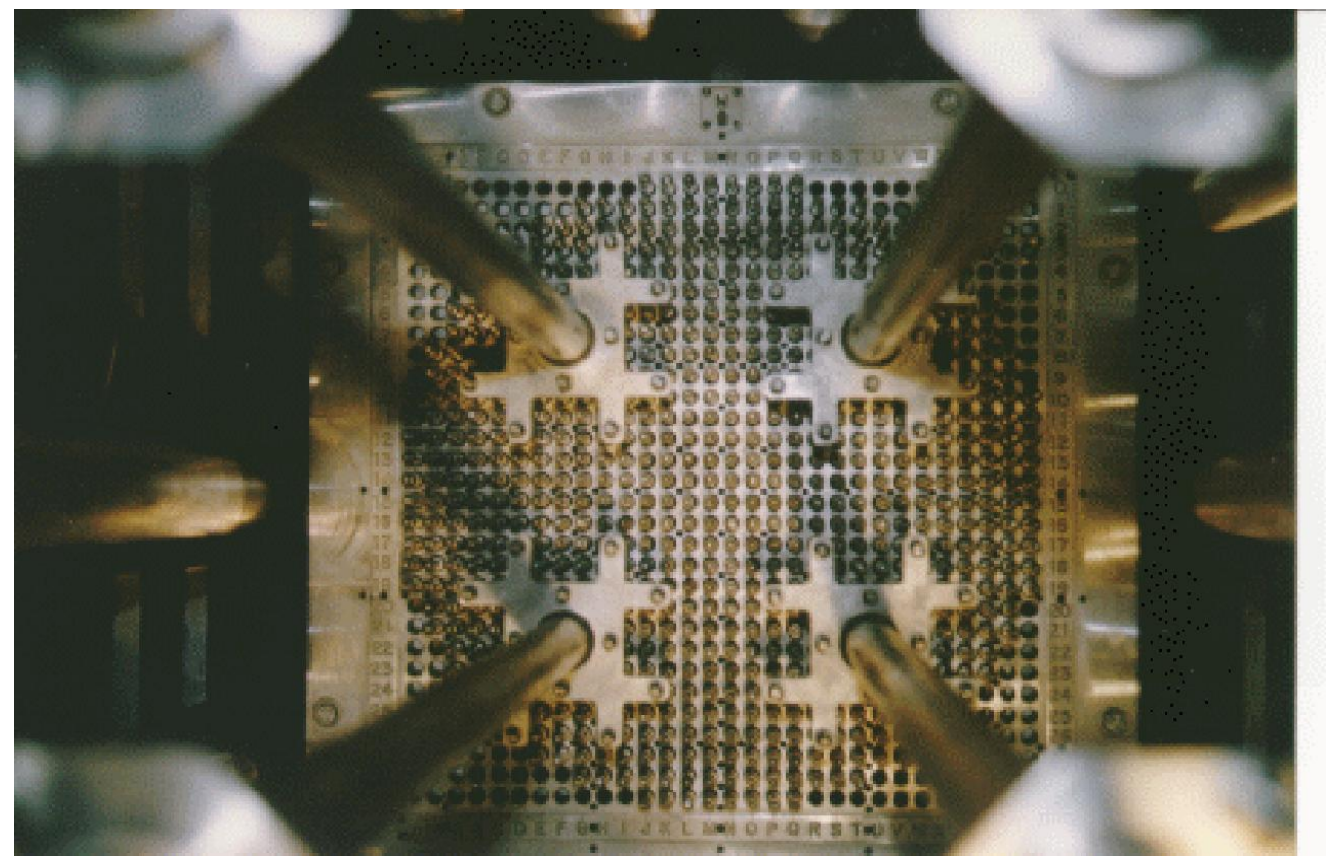

FIGURA A.2 Vista do Núcleo: Configuração Retangular do Reator IPEN/MB-01.

As varetas combustíveis do reator são constituídas de tubos de aço inox AISI-304, contendo em seu interior um total de 52 pastilhas combustíveis de $\mathrm{UO}_{2}$ enriquecidas a 4,3\%. A altura ativa da coluna de pastilhas é de $54,6 \mathrm{~cm}$, sendo que cada pastilha possui uma altura de $1,05 \mathrm{~cm}$ e diâmetro de 0,849 cm. As extremidades não ativas das varetas são preenchidas com pastilhas de $\mathrm{Al}_{2} \mathrm{O}_{3}$. Os 48 tubos guias para as varetas absorvedoras de nêutrons (barras de controle e segurança) estão dispostos em 4 grupos, contendo cada um deles 12 varetas absorvedoras, sendo dois grupos de barras de segurança e 2 grupos de controle, dispostos cada um deles em um quadrante do núcleo do reator. Cada conjunto de 12 varetas absorvedoras é unido através de um corpo central, denominado aranha, o qual é ligado a uma haste de acionamento, que por sua vez é conectada a mecanismos acionados por magnetos energizados.

Para efeito de possível modelagem em cálculos neutrônicos, apresentam-se as tabelas A.1, A.2, A.3 e A.4 dadas a seguir, em que são apresentadas detalhadamente as composições, bem como as geometrias das varetas combustíveis e de controle do Reator IPEN/MB-01.O diagrama 
esquemático da vareta combustível e de controle, podem ser vistos na figura A.3 a seguir.
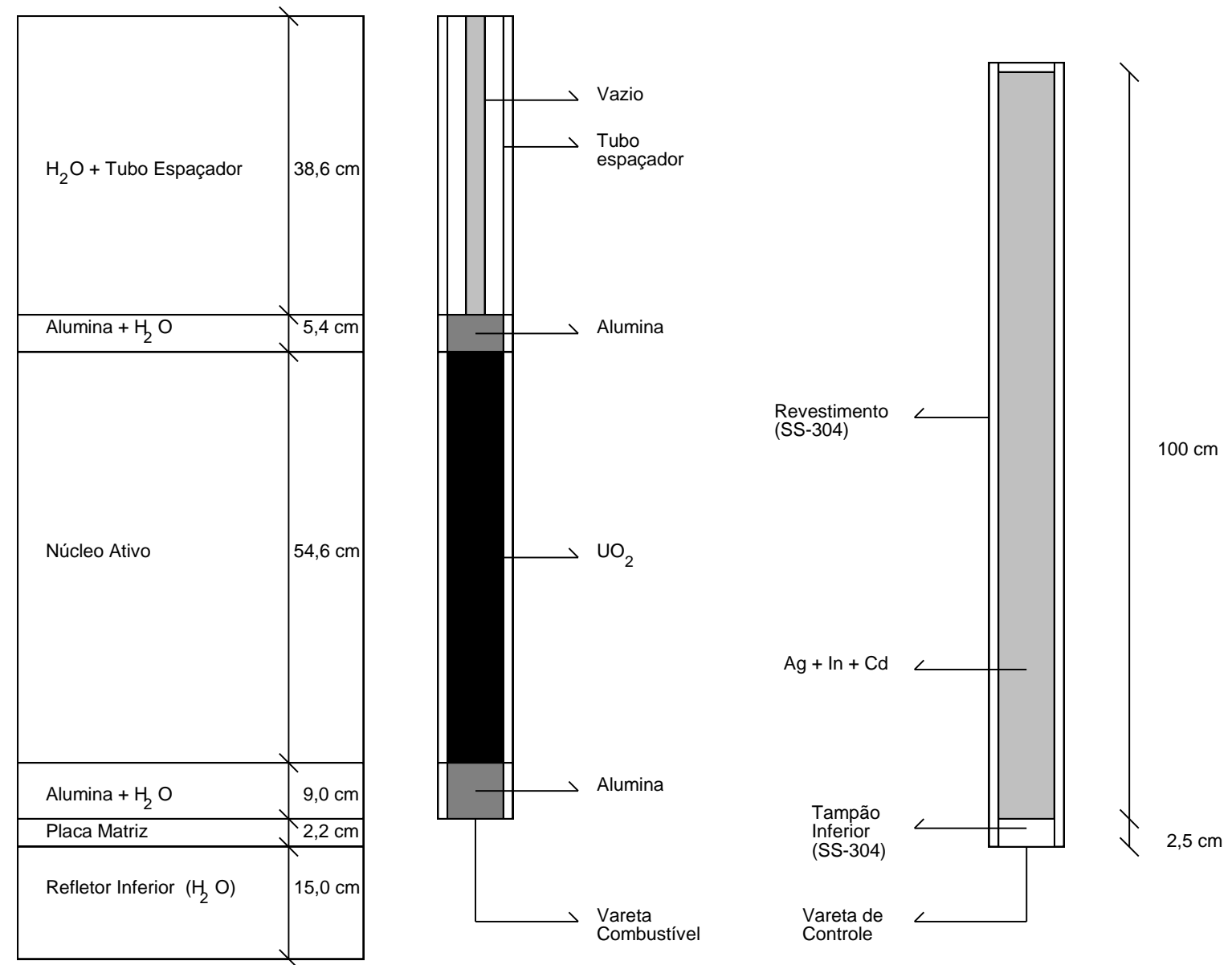

FIGURAA.3 Diagrama Esquemático das Varetas Combustíveis e de Controle.

A reatividade integral de cada barra de controle/segurança é suficiente para desligar o reator, ou seja, é de aproximadamente 3200 pcm. As barras de segurança apresentam as mesmas características geométricas das barras de controle, diferenciando das mesmas pelo material absorvedor de nêutrons utilizado, no caso $\mathrm{B}_{4} \mathrm{C}$ e pelo fato de que durante a operação normal do reator, serem mantidas totalmente retiradas do núcleo ativo do mesmo, com o objetivo de desligá-lo com grande margem de segurança. As barras de controle são as responsáveis, por manterem constante a população de nêutrons, quando o mesmo atinge um certo nível fixo de potência.

Quando inseridas no núcleo, as barras de controle, mantém o nível de população neutrônica, através da absorção dos mesmos em seu material estrutural 
composto de uma liga de Ag-In-Cd, encapsulada num revestimento de aço inox austenítico.

TABELAA.1 Dados Geométricos da Vareta de Controle do Reator IPEN/MB-01.

\begin{tabular}{|l|l|}
\hline Material Absorvedor & Ag-In-Cd \\
\hline Diâmetro do Absorvedor & $0,832 \mathrm{~cm}$ \\
\hline Diâmetro Externo do Revestimento & $0,980 \mathrm{~cm}$ \\
\hline Espessura do Revestimento & $0,060 \mathrm{~cm}$ \\
\hline Diâmetro Externo do Tubo Guia & $1,200 \mathrm{~cm}$ \\
\hline Espessura do Tubo Guia & $0,035 \mathrm{~cm}$ \\
\hline
\end{tabular}

TABELA A.2 Dados geométricos da Vareta Combustível do Reator IPEN/MB-01.

\begin{tabular}{|l|l|}
\hline Região Ativa & $\mathrm{UO}_{2}$ \\
\hline Combustível & $0,849 \mathrm{~cm}$ \\
\hline Diâmetro da Pastilha & $0,980 \mathrm{~cm}$ \\
\hline Diâmetro Externo do Revestimento & $0,060 \mathrm{~cm}$ \\
\hline Espessura do Revestimento & $1,500 \mathrm{~cm}$ \\
\hline Passo da Rede & \\
\hline Região de Alumina & $0,949 \mathrm{~cm}$ \\
\hline Diâmetro da Pastilha & $0,980 \mathrm{~cm}$ \\
\hline Diâmetro Externo do Revestimento & $0,060 \mathrm{~cm}$ \\
\hline Espessura do Revestimento & \\
\hline Região do Tubo Espaçador & $0,730 \mathrm{~cm}$ \\
\hline Diâmetro Interno & $0,849 \mathrm{~cm}$ \\
\hline Diâmetro Externo & \\
\hline
\end{tabular}

TABELAA.3 Composição isotópica da Vareta Combustível.

\begin{tabular}{|l|l|}
\hline Pastilha Combustível & Concentração (atomos/barn-cm) \\
\hline${ }^{235} U$ & $1,0034 \mathrm{E}-03$ \\
\hline${ }^{238} \mathrm{U}$ & $2,17938 \mathrm{E}-02$ \\
\hline
\end{tabular}




\begin{tabular}{|l|l|}
\hline${ }^{16} \mathrm{O}$ & $4,55138 \mathrm{E}-02$ \\
\hline Revestimento, Tubo Guia & Concentração (atomos/barn-cm) \\
\hline $\mathrm{Fe}$ & $5,67582 \mathrm{E}-02$ \\
\hline $\mathrm{Ni}$ & $8,64435 \mathrm{E}-03$ \\
\hline $\mathrm{Cr}$ & $1,72649 \mathrm{E}-02$ \\
\hline${ }^{55} \mathrm{Mn}$ & $1,59898 \mathrm{E}-03$ \\
\hline $\mathrm{Si}$ & $3,34513 \mathrm{E}-04$ \\
\hline Pastilha de Alumina & Concentração (atomos/barn-cm) \\
\hline $\mathrm{Al}$ & $4,30049 \mathrm{E}-02$ \\
\hline${ }^{16} \mathrm{O}$ & $6,45074 \mathrm{E}-02$ \\
\hline
\end{tabular}

TABELAA.4 Composição isotópica da Vareta de Controle.

\begin{tabular}{|l|l|}
\hline Absorvedor & Concentração (atomos/barn-cm) \\
\hline${ }^{107} \mathrm{Ag}$ & $2,35462 \mathrm{E}-02$ \\
\hline${ }^{109} \mathrm{Ag}$ & $2,18835 \mathrm{E}-02$ \\
\hline${ }^{113} \mathrm{In}$ & $3,42506 \mathrm{E}-04$ \\
\hline${ }^{115} \mathrm{In}$ & $7,6599 \mathrm{E}-03$ \\
\hline $\mathrm{Cd}$ & $2,72492 \mathrm{E}-03$ \\
\hline $\begin{array}{l}\text { Revestimento, Tubo guia, Tampão } \\
\text { Inferior }\end{array}$ & Concentração (atomos/barn-cm) \\
\hline $\mathrm{Fe}$ & $5,67582 \mathrm{E}-02$ \\
\hline $\mathrm{Ni}$ & $8,64435 \mathrm{E}-03$ \\
\hline $\mathrm{Cr}$ & $1,72649 \mathrm{E}-02$ \\
\hline $55 \mathrm{Mn}$ & $1,59898 \mathrm{E}-03$ \\
\hline $\mathrm{Si}$ & $3,34513 \mathrm{E}-04$ \\
\hline
\end{tabular}

Todo o núcleo do reator, bem como os mecanismos de acionamento de barras, as guias para as aranhas e o amortecedor de queda de barras, são apoiados por uma estrutura suporte, fixados na parte superior por uma plataforma metálica, e na parte inferior mantida suspensa no interior do tanque moderador, o qual contém água tratada e desmineralizada, utilizada como elemento moderador da energia dos nêutrons. 
Além das barras de controle e segurança, o sistema de controle de reatividade inclui um sistema de esvaziamento rápido do tanque moderador que provoca o desligamento do reator por perda do fluído moderador. No desligamento por barras, dito de primeiro nível, as 4 barras caem por gravidade no núcleo, a partir do sinal de corte de energia dos magnetos enquanto no desligamento de segundo nível, além de todas as 4 barras caírem, são abertas duas válvulas tipo borboletas de abertura rápida de $50,8 \mathrm{~cm}$ de diâmetro, situadas na parte inferior do tanque moderador, causando a retirada de toda água em aproximadamente 4 segundos. A água como se sabe, é um elemento fundamental para a moderação da energia dos nêutrons rápidos de fissão, termalizando-os e com isso tornando a probabilidade de fissão dos núcleos de Urânio-235, muito maiores para os nêutrons de baixa energia, os chamados nêutrons térmicos. A água drenada caindo por gravidade é estocada no primeiro subsolo do reator, mais propriamente no tanque de estocagem, onde ficará armazenada até ser novamente bombeada para o tanque moderador numa futura operação do reator, ou mesmo para tratamento da mesma, através de filtragem e controle de seu nível de condutividade em um vaso trocador de leito de resina mista ou mesmo para o controle de sua temperatura em trocadores de calor aquecedores ou resfriadores.

A instrumentação nuclear utilizada no controle e segurança do reator é constituída de 10 canais nucleares, divididos por função em 2 canais de partida (detetores BF3), 2 de potência (Câmaras de Ionização Compensadas-CIC), 2 canais lineares (Câmaras de Ionização Não Compensadas-CINC), 3 canais de segurança na faixa de potência (2 CINC e 1 detetor B-10) e 1 canal de segurança na faixa de partida (Detetor BF3). Estes canais nucleares estão situados ao redor do núcleo, dentro do tanque moderador em diversas cotas axiais, posicionados dentro de tubos de alumínio estanques á água.

A instrumentação nuclear é responsável pelo processamento dos sinais gerados nos detectores nucleares. Após o processamento, estes sinais são enviados para os indicadores de potência e de período na mesa de controle do reator e para os comparadores de sinais que fazem a lógica de proteção do reator. Existem vários valores de limiar operacionais ("set points") que constituem a rede de intertravamento dos canais nucleares. 
Assim, só para citar alguns exemplos, temos:

- Contagem mínima de 2 cps nos canais de partida e seu respectivo canal de segurança, para habilitar a malha de partida;

- Desligamento de sobrepotência (110 mwatts) de primeiro nível dos canais de partida;

- Desligamento por sobrepotência (120 mwatts) de segundo dos canais de partida;

- Desligamento por sobrepotência de primeiro nível (110 watts) para os canais de potência;

- Desligamento por sobrepotência de segundo nível (120 watts) para os canais de potência.

Para se atingir a contagem mínima nos canais lineares e liberar a partida do reator é necessária a utilização de uma fonte de nêutrons de Am-Be de atividade de $1 \mathrm{Ci}$ e intensidade de $2,5.10^{6}$ nêutrons/s. Esta fonte fica armazenada no segundo subsolo do prédio do reator e durante a partida do mesmo é levada através de um pequeno carrinho preso a um cabo de aço a se posicionar na base inferior do tanque moderador, onde pode então sensibilizar os canais nucleares citados, evitando-se assim que a partida do reator se dê as cegas, ou seja numa faixa operacional em que os detectores dos canais de partida e de segurança não estejam aptos a monitorar a taxa de crescimento da população de nêutrons, quando do início de sua operação (partida do reator).

Outros intertravamentos se fazem presentes nos canais nucleares. Talvez o mais importante seja aquele referente ao período de crescimento da população neutrônica quando da supercriticalidade do reator, quando a população de nêutrons cresce exponencialmente. Assim, para períodos menores ou iguais a 17 segundos ocorrem o desligamento involuntário ("Scram") de primeiro nível, com a correspondente queda das 4 barras. Para períodos menores ou iguais a 14 segundos ocorre o "Scram" de segundo nível, ou seja a abertura das válvulas para escoamento da água do tanque moderador.

Existem vários outros intertravamentos que impedem que o reator seja ligado numa condição insegura (Intertravamentos de Segurança), a até intertravamentos que provocam o desligamento do reator (Operacionais). Podemos 
citar vários que vão desde a abertura da porta de acesso da Célula Crítica (Saguão onde está o núcleo do reator), até condições inadequadas da água moderadora, que vai desde a baixa temperatura da mesma (menor de 17 graus) até um nível inadequado de condutividade.

Todos os sistemas citados (núcleo, tanque moderador, detectores dos canais nucleares, controle das barras, etc) estão situados dentro de um prédio estanque, mantido à pressão negativa, situada na faixa de -50 a $-200 \mathrm{~Pa}$ (caso haja uma perda de estanqueidade o ar de fora é que entra), denominado de célula crítica, construído com paredes de concreto, com funções de confinamento e blindagem. Um dos intertravamentos de segurança é impedir a partida do reator caso a pressão negativa no interior da célula crítica não atinja a valores operacionais pré-estabelecidos em projeto, ou mesmo provocar o seu desligamento automático, caso a pressão negativa diminua em sua magnitude.

Dentre os inúmeros experimentos realizados nestes 26 anos de operação podemos destacar alguns deles, como teses de doutorado (medidas de índices espectrais, determinação da fração de nêutrons atrasados pela técnica de análise de ruído), mestrado (mapeamento de fluxo com Câmaras de fissão miniatura, determinação de densidade de potência através da varredura gama de varetas combustíveis, etc), cursos de graduação fornecidos a USP (IPN0025Física de Reatores: Experimentos no Reator Nuclear IPEN/MB-01), cursos de pósgraduação (Medidas de Parâmetros Nucleares), cursos de formação de operadores de centrais nucleares oferecidos a Eletronuclear, experimentos de arranjos críticos considerados padrões de comparação internacional junto a OECD/NEA, experimentos de interesse a validação de metodologia de cálculo (ex: Determinação da massa crítica na curva $1 / \mathrm{M})$, calibração dos canais de potência do reator através do mapeamento do fluxo de nêutrons por folhas de ativação de ouro hiper-puras, através da técnica de análise de ruído, calibração das barras de controle, coeficientes de reatividade isotérmico e de vazio, determinação do Buckling do reator, estudos da reatividade de configurações utilizando veneno queimável e este trabalho que vem se somar a tantos outros e que objetivou a determinação experimental da distribuição energética de nêutrons na região central do núcleo do reator IPEN/MB-01. 


\section{ANEXO B - Propagação de erros}

Diversos parâmetros nucleares são obtidos através da adição, subtração, multiplicação ou divisão de grandezas físicas. Quando estas grandezas associadas apresentam desvios padrões é necessária à propagação de erros para obter uma estimativa da incerteza final. Portanto para determinar à estimativa da incerteza é utilizada a lei geral de propagação de $\operatorname{erros}^{19,30}$, sendo esta utilizada para o tratamento de variáveis independentes e não correlacionadas, assim como variáveis dependentes e correlacionadas entre si.

\section{B.1 Variáveis independentes (não-correlacionadas)}

Para variáveis independentes e não correlacionadas, a lei geral de propagação de erro é dado por

$$
\sigma_{u}^{2}=\sum_{i=1}^{n}\left(\frac{\partial u}{\partial x_{i}}\right)^{2} \sigma_{i}^{2}
$$

Portanto, torna-se relevante analisar alguns casos aplicados neste trabalho. O primeiro caso é a adição ou subtração de grandezas, isto é, $u=x_{1} \pm$ $x_{2}$, resultando em

$$
\sigma_{u}=\sqrt{\sigma_{1}^{2}+\sigma_{2}^{2}}
$$

sendo $\sigma_{1}$ o desvio padrão da grandeza $x_{1}$ e $\sigma_{2}$ o desvio padrão de $x_{2}$.

O segundo caso é a multiplicação de uma variável $x$ por uma constante $A, u=A x$, e o seu desvio padrão é dado por

$$
\sigma_{u}=A \sigma_{x}
$$


sendo $\sigma_{x}$ o desvio padrão da grandeza $x$.

A multiplicação ou divisão entre variáveis, ou seja, $u=x_{1} x_{2}$ ou $u=\frac{x_{1}}{x_{2}}$ tem-se como desvio padrão,

$$
\frac{\sigma_{u}}{u}=\sqrt{\left(\frac{\sigma_{1}}{x_{1}}\right)^{2}+\left(\frac{\sigma_{2}}{x_{2}}\right)^{2}} .
$$

\section{B.2 Variáveis correlacionadas}

Para variáveis correlacionadas, a lei de propagação é dada por

$$
\sigma_{u}^{2}=\sum_{i, j}^{n}\left(\frac{\partial u}{\partial x_{i}}\right)\left(\frac{\partial u}{\partial x_{j}}\right) \operatorname{cov}\left(x_{i}, x_{j}\right)
$$

sendo $\operatorname{cov}\left(x_{i}, x_{j}\right)$ a covariância entre as variáveis $x_{i}$ e $x_{j}$.

A covariância entre mesma grandeza é a variância desta grandeza em questão, por exemplo, $\operatorname{cov}\left(x_{i}, x_{i}\right)$ é $\sigma_{x_{i}}^{2}$.

Procedendo da mesma maneira que no caso das variáveis independentes, alguns casos serão analisados. Inicia-se pela adição entre variáveis correlacionadas, $u=x_{1}+x_{2}$, e aplicando a expressão (C.5) tem-se que a expressão para o desvio padrão dada por

$$
\sigma_{u}=\sqrt{\sigma_{1}^{2}+\sigma_{2}^{2}+2 \operatorname{cov}\left(x_{1}, x_{2}\right)},
$$

e o desvio padrão para a subtração de variáveis é

$$
\sigma_{u}=\sqrt{\sigma_{1}^{2}+\sigma_{2}^{2}-2 \operatorname{cov}\left(x_{1}, x_{2}\right)}
$$


No caso da multiplicação de variáveis correlacionadas, $u=x_{1} x_{2}$, 0 resultado obtido para o desvio padrão é

$$
\frac{\sigma_{u}}{u}=\sqrt{\left(\frac{\sigma_{1}}{x_{1}}\right)^{2}+\left(\frac{\sigma_{2}}{x_{2}}\right)^{2}+2 \frac{\operatorname{cov}\left(x_{1}, x_{2}\right)}{x_{1} x_{2}}}
$$

e para a divisão entre variáveis, $u=\frac{x_{1}}{x_{2}}$, o desvio padrão é dado por

$$
\frac{\sigma_{u}}{u}=\sqrt{\left(\frac{\sigma_{1}}{x_{1}}\right)^{2}+\left(\frac{\sigma_{2}}{x_{2}}\right)^{2}-2 \frac{\operatorname{cov}\left(x_{1}, x_{2}\right)}{x_{1} x_{2}}}
$$

\section{B.2 Média Ponderada}

Em um conjunto de dados experimentais, pode-se obter o valor médio dos dados levando-se em conta as incertezas associadas aos mesmos. A equação (B.10) a seguir demonstra como calcular a média ponderada ${ }^{19}$ :

$$
\bar{x}=\frac{\sum_{i=1}^{n} w_{i} x_{i}}{\sum_{i=1}^{n} w_{i}}
$$

Onde:

$\mathrm{N}$ é o numero de valores a serem considerados no calculo;

$\mathrm{w}_{\mathrm{i}}$ é a incerteza do valor a ser usado no calculo;

$x_{i}$ é o valor a ser usado no calculo.

A incerteza associada ao calculo da média ponderada é dada pela equação (B.11).

$$
s^{2}(x)=\frac{\sum_{i=1}^{n} w_{i}\left(x_{i}-\bar{x}\right) /(n-1)}{\sum_{i=1}^{n} w_{i} / n}
$$




\section{ANEXO C - Buckling para diversas configurações de núcleo}

A tabela C.1 apresenta as equações para Buckling geométricos e o perfil de fluxo para diferentes geometrias e configurações do núcleo de um reator ${ }^{13,14}$.

Tabela C.1. Geometrias típicas de núcleos e seus respectivos Buckling geométricos e perfis de fluxo.

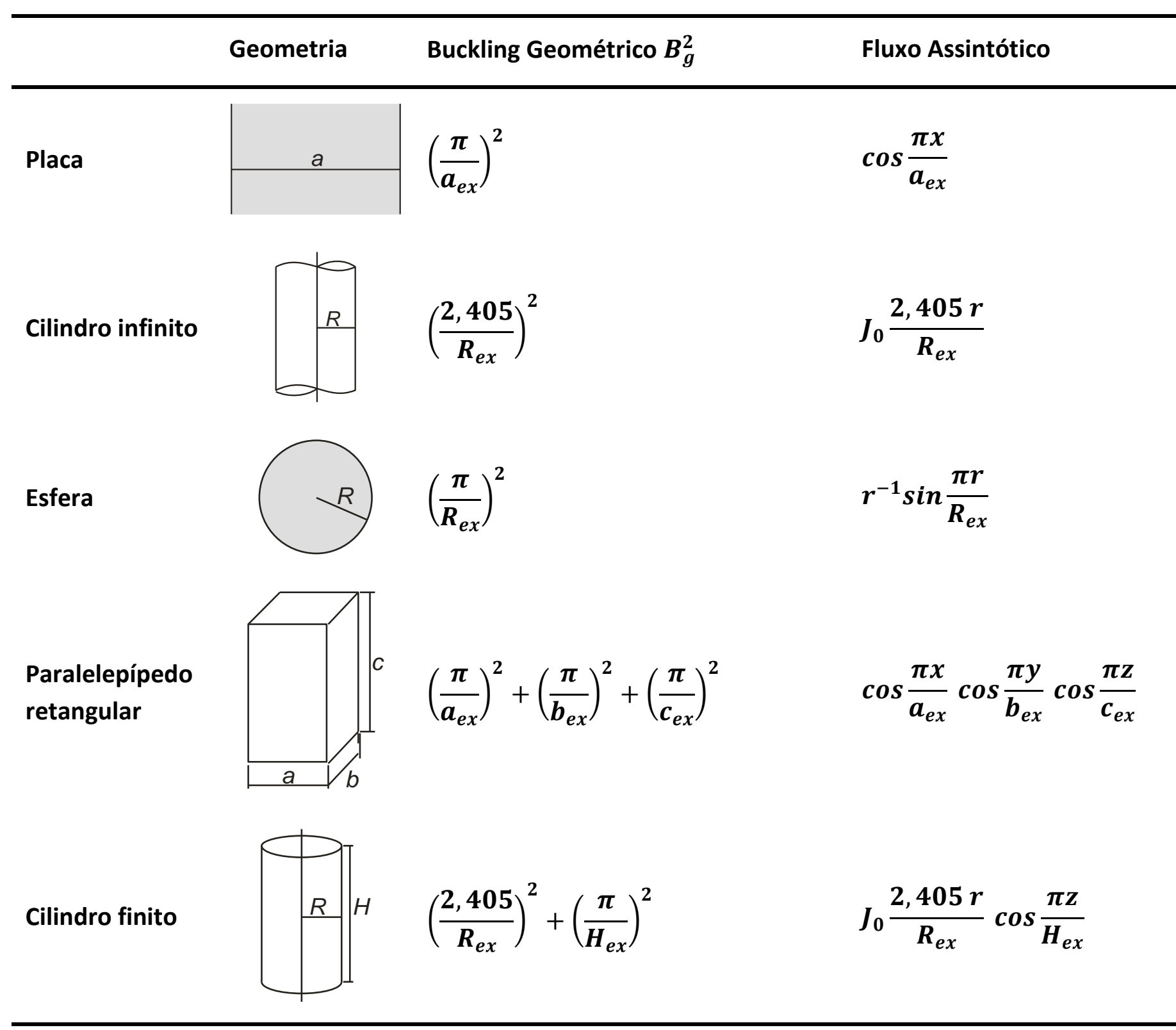




\section{REFERÊNCIAS BIBLIOGRÁFICAS}

[1] Eletrobrás - Panorama da Energia Nuclear No Mundo, Nov 2011.

[2] http://www.eletronuclear.gov.br/Home.aspx, acessado em 20/11/2014

[3] Fonte Nuclear -ano 2012, número 3, 25 de junho de 2012.

[4] Profio, A.E. Experimental Reactor Physics. New York, Wiley, 1976.

[5] Nunes, B. G. Determinação experimental de razões espectrais e do espectro de energia dos nêutrons no combustível do reator nuclear IPEN/MB-01 Dissertação de Mestrado, São Paulo 2012.

[6] LUX, I. Calculation of Foil-Activation-Correction by Monte Carlo Method Perturbations in Fuel-Cells with White Boundary Conditions. Central Research Institute for Physics H-1525 Budapest, Hungary, 1981.

[7] GONÇALVES, L. B. Calibração dos Canais Nucleares do Reator IPEN/MB01, Obtida a partir da Medida da Distribuição Espacial do Fluxo de Nêutrons Térmicos no Núcleo do Reator através da Irradiação de Folhas de Ouro Infinitamente Diluídas. Dissertação (Mestrado) - Instituto de Pesquisas Energéticas e Nucleares. São Paulo, 2008.

[8] MURA, L. E. C. Caracterização dos Campos Neutrônicos obtidos por meio de Armadilhas de Nêutrons no Interior do Núcleo do Reator Nuclear IPEN/MB-01. Dissertação (Mestrado) - Instituto de Pesquisas Energéticas e Nucleares. São Paulo, 2011.

[9] ZSOLNAY, E. M. Neutron Flux and Spectrum Measurement by Activation Method. Lectures Notes for the Training Course and Measurements of 
Neutron Flux Spectrum for Research Reactor. International Atomic Energy Agency, Serpong, Hacarta, Indonesia, 1993.

[10] MURA, L. E. C. Caracterização Dos Campos Neutronicos Obtidos Por Meio De Armadilhas De Nêutrons No Interior Do Núcleo Do Reator Nuclear IPEN/MB-01. São Paulo: 2011. Dissertação (Mestrado)- Instituto de Pesquisas Energéticas e Nucleares.

[11] SILVA, A. F. P. Calibração da Potência do Reator IPEN/MB-01 na Configuração Cilíndrica de Menor Excesso de Reatividade obtida a partir da Medida Absoluta do Fluxo Médio de Nêutrons, IPEN, Dissertação de Mestrado, 2014

[12] PROFIO, A.E. Experimental reactor physics. John Wiley \& Sons, 1976.

[13] LAMARSH, J. R. "Introduction to Nuclear Reactor Theory" Massachusetts, New York University, 1966.

[14] LAMARSH, J. R. and BARATA, A. J. - Introducion to Nuclear Engineering, Prentice Hall, third edition, 2001.

[15] BITELLI, U. D’U. “CIORP - Curso Introdutório de Operação de Reatores de Pesquisa" São Paulo, IPEN, 2011.

[16] Aulas Ministradas de Experimentos no Reator IPEN/MB-01 no IPEN.

[17] ZAMBONI, C. B. "Física de Nêutrons" São Paulo, Ed. Livraria da Física, 2007.

[18] Aredes, V. O. G. Caracterização do núcleo cilíndrico de menor excesso de reatividade do reator ipen/mb-01, pela medida da distribuição espacial e energética do fluxo de neutrons - Dissertação, Ipen, São Paulo 2014. 
[19] Zijp, W. L., Treatment of Measurement Uncertainties, ECN-194, January (1987).

[20] DUDERSTADT e HAMILTON - Nuclear Reactor Analisys. John Whiley e Sons Inc.1976.

[21] BRASIL. PCN+ Ensino Médio: Orientações Educacionais Complementares aos Parâmetros Curriculares Nacionais - Ciências da Natureza, Matemática e suas Tecnologias. Ministério da Educação/SEMTEC, Brasília, 2002.

[22] Pereira, Grazielle Rodrigues. Filho, Marcus Valerio Bouzada. Nexes, Marcelo Azevedo Um estudo sobre a inserção do tema "Energia Nuclear" no ensino médio de municípios da baixada Fluminense - RJ.

[23] WATT, B.E. Energy Spectrum of neutrons from thermal fission of U235. Phys. Rev. 87 (1952). 1037.

[24] Veneziani, C.L\& Peres, A.D. Reator Nuclear IPEN/MB-01 - Curso Preparatório de Operadores de Reator, IPEN-CNEN/SP, Centro de Engenharia Nuclear, Reator IPEN/MB-01, Março de 1994.

[25] Bitelli, U. d'U.et all. Medida do Buckling na Unidade Crítica IPEN/MB-01. X Encontro de Física de Reatores e Termohidraulica. Agosto 7-11, 1995, Aguas de Lindóia, São Paulo, Brasil.

[26] Fowlwe,T.B Vondy,D,R. Cunningham, G.W. Nuclear Reactor Core Analysis Code: CITATION , Oak Ridge National laboratory, ORNL-TM-2496,Revision 2, July, 1971.

[27] Bahren, J. Rhotenstein,W. and Taviv E. The Hammer Code System Technion , Israel, Institute of Technology, Haifa, Israel, NP-565, 1978. 
[28] Breimeister, J.F. MCNP-A General Monte Carlo N-Particle Transport Code, version 5, Los Alamos National laboratory, USA, 2003.

[29] Bitelli, U. U. Medida dos Parâmetros Integrais no Reator IPEN/MB-01, Tese de doutorado, IPEN, 2001.

[30] Vuolo, J. H. Fundamentos da Teoria de Erros - Ed. Edgard Blucher Ltda, $2^{a}$ edição, 1996.

[31] Bitelli, U. U. and Santos, A. and Jerez, R. Medida do Buckling na Unidade Crítica IPEN/MB-01. Anais do X ENFIR 7-11 de Agosto de 1995, Àguas de Lindóia, SP, Brasil.

[32] Mendes Junior, D.R; Cajacuri,R.A; Junior, O.C; Campos, P.H.O.V; Fajardo, E; Mura, L.F.L; Jerez, R; Bitelli, U. U. Medida da Curvatura do Fluxo de Nêutrons ("Buckling") através do Mapeamento do Fluxo de Nêutrons Rápidos e/ou Térmicos no Núcleo do Reator Nuclear IPEN/MB-01, 2001.

[33] Fanaro, L.C.B. Determinação Experimental de Índices Espectrais por Varredura Gama de Vareta Combustível no Reator IPEN/MB-01, Tese de Doutorado, IPEN, 2009.

[34] Marques, L.F; Ting, D.K.S; Bitelli, U. U. Medida do Fluxo de Nêutrons Térmicos do Reator IPEN/MB-01 com Detetores de Ativação de fios de ${ }^{197} \mathrm{Au}$. X ENFIR - 1995, Águas de Lindoia/SP, Brasil.

[35] http://www.nucleonica.net/wiki/images/8/89/MCNPvoll.pdf, acessado em 02/11/2014. 